\title{
Controlled Diffusion of Photoswitchable Receptors by Binding Antielectrostatic Phosphate Oligomers
}

Thomas MacDonald, Ben L. Feringa, William S. Price, Sander J. Wezenberg, Jonathon Beves Submitted date: 14/05/2020 Posted date: 15/05/2020

Licence: CC BY-NC-ND 4.0

Citation information: MacDonald, Thomas; Feringa, Ben L.; Price, William S.; Wezenberg, Sander J.; Beves, Jonathon (2020): Controlled Diffusion of Photoswitchable Receptors by Binding Antielectrostatic Phosphate Oligomers. ChemRxiv. Preprint. https://doi.org/10.26434/chemrxiv.12298919.v1

Dihydrogen phosphate anions are found to spontaneously associate into anti-electrostatic oligomers via hydrogen bonding interactions at millimolar concentrations in DMSO. Diffusion NMR measurements supported formation of these oligomers, which can be bound by photoswitchable anion receptors to form large bridged assemblies of approximately three times the volume of the unbound receptor. Photoisomerization of the oligomer-bound receptor causes a decrease in diffusion coefficient of up to $16 \%$, corresponding to a $70 \%$ increase in effective volume. This new approach to external control of diffusion opens prospects in controlling molecular transport.

File list (7)

Supporting Information.pdf (7.09 MiB)

view on ChemRxiv • download file

Manuscript_deWileyed.pdf (505.83 KiB)

view on ChemRxiv • download file

NMR_purehost-H2PO4_titrations.zip (630.22 MiB)

view on ChemRxiv • download file

Viscometry.zip (6.10 KiB)

view on ChemRxiv • download file

Diffusion data.zip (430.82 KiB)

view on ChemRxiv - download file

NMR_aniondilutionstudies.zip (285.32 MiB)

view on ChemRxiv - download file

NMR_photodiffusion.zip (1.15 GiB)

view on ChemRxiv • download file 


\section{Table of Contents}

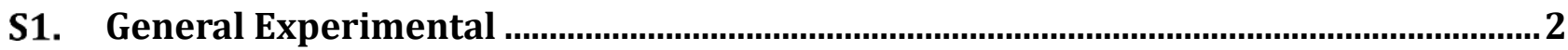

S2. Speciation of acetate and dihydrogen phosphate: literature data................................. 3

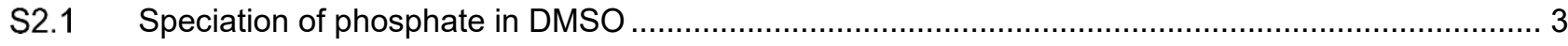

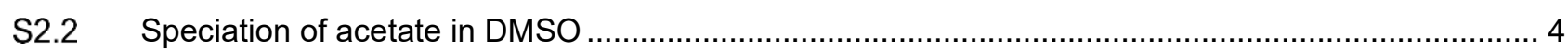

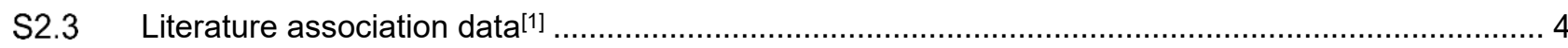

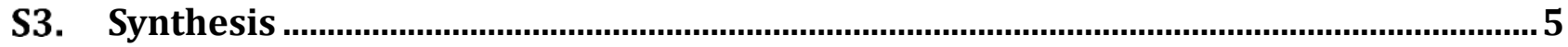

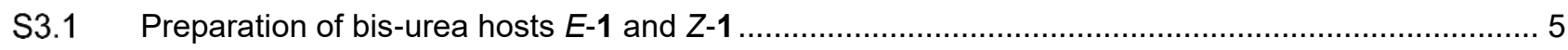

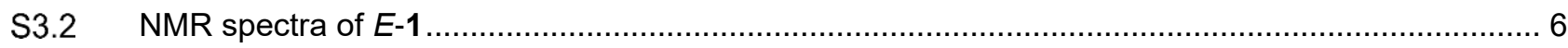

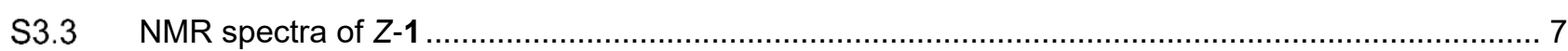

S4. Viscosity measurements of tetrabutylammonium dihydrogen phosphate solutions 8

S5. Mathematical modelling of isodesmic self-association............................................. 10

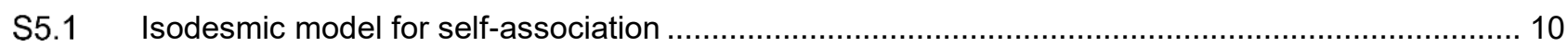

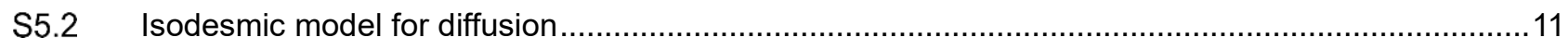

S5.3 Estimated diffusion of host-guest complexes........................................................................... 12

S6. Experimental determination of the thermodynamics of $\mathrm{H}_{2} \mathrm{PO}_{4}$ - self-association.. 13

S6.1 Control experiments with tetrabutylammonium acetate ......................................................... 16

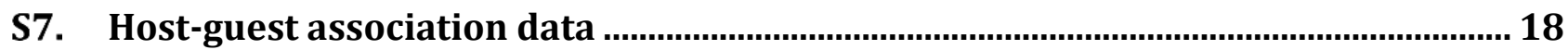

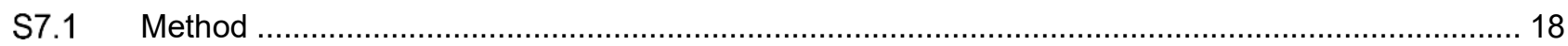

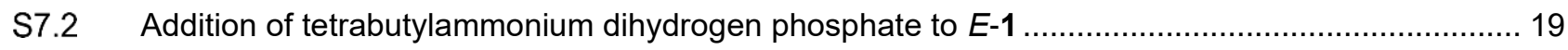

S7.3 Addition of tetrabutylammonium dihydrogen phosphate to Z-1 (up to 3 equiv.) ............................ 21

S7.4 Z-1 dihydrogen phosphate binding fitted to a 1:1 model........................................................ 23

S7.5 Addition of tetrabutylammonium dihydrogen phosphate to Z-1 (beyond 3 equiv.)........................ 24

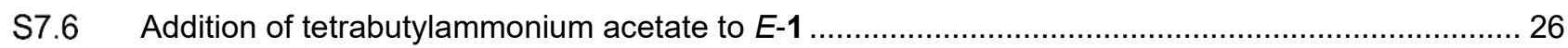

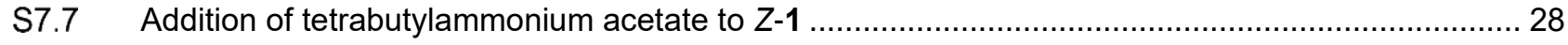

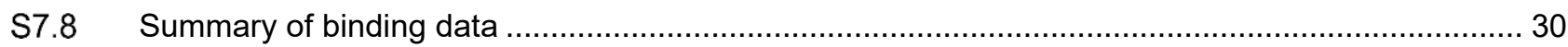

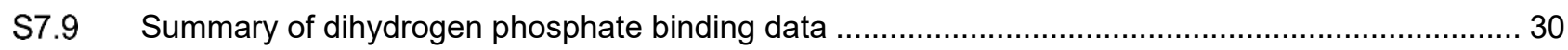

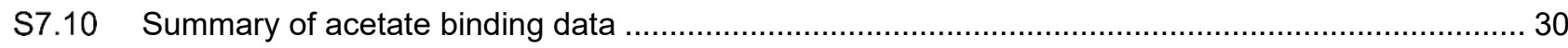

S7.11 Host-guest binding models with an aggregating guest .............................................................. 31

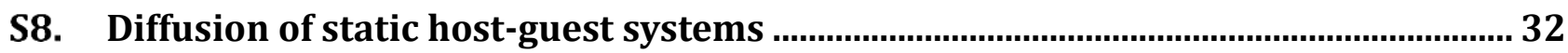

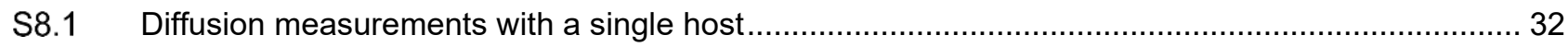

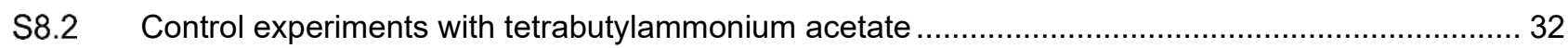

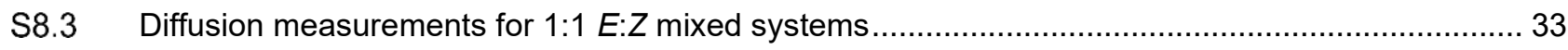

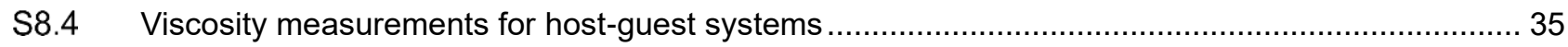

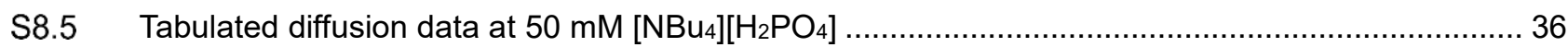

S9. Comparison of modelled and measured guest-dependent diffusion coefficients for

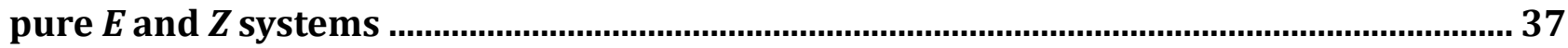

S9.1 Estimated diffusion coefficients of potential supramolecular host-guest complexes ....................... 38

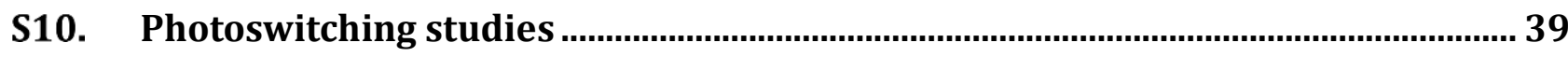

S10.1 Time-dependent diffusion with in situ irradiation .......................................................................... 39 
S10.2 Monitoring temperatures and suppressing convection

S10.3 Demonstration of reversible photoswitching by UV-vis

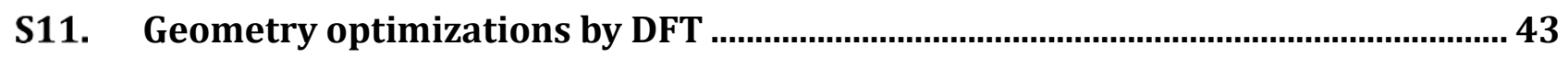

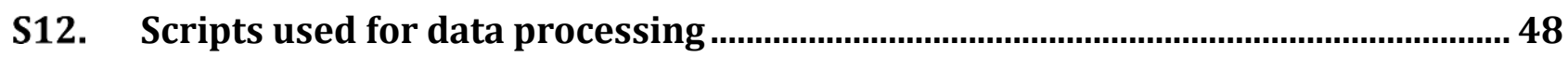

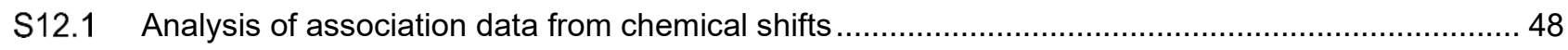

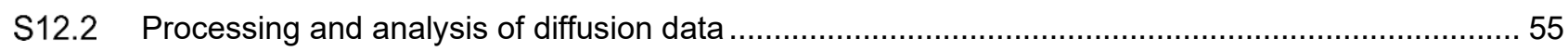

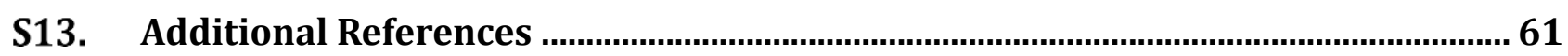

\section{S1. General Experimental}

Reagents were purchased from Combi-Blocks or Sigma-Aldrich and used as received. Deuterated NMR solvents were purchased from Cambridge Isotope Laboratories and used as received unless otherwise noted.

NMR experiments were conducted using a Bruker Avance III $500 \mathrm{MHz}$ spectrometer equipped with a TBI $\left({ }^{31} \mathrm{P}\right)$ probe fitted with standard high-resolution gradient coils capable of generating gradient pulses up to $53.45 \mathrm{G}$ $\mathrm{cm}^{-1}$. Diffusion experiments were prepared and executed through the Bruker diff5 utility and used the diffSte stimulated-echo pulse sequence. Typical parameters for ${ }^{1} \mathrm{H}$ diffusion experiments were $\Delta=50 \mathrm{~ms}$ and $\delta=4$ $\mathrm{ms}$. Typical parameters for ${ }^{31} \mathrm{P}$ diffusion experiments were $\Delta=100 \mathrm{~ms}$ and $\delta=7 \mathrm{~ms}$. Gradient pulses were sine-shaped, and gradient lists typically consisted of 12 gradient strengths linearly increasing from $0-53.45 \mathrm{~g}$ $\mathrm{cm}^{-1}$.

Spectra were automatically phased and baseline-corrected with MestReNova software 12.0, with peak integrals obtained using the built-in data analysis routines and exported as csv data for further processing.

High resolution mass spectra were collected on a Thermo Scientific LTQ-FT-ICR Mass Spectrometer equipped with a nanoESI source and Thermo Xcalibur software used for analysis. 


\section{S2. Speciation of acetate and dihydrogen phosphate: literature data}

Given the focus placed upon the dihydrogen phosphate anion, it is important to consider potential protonation-deprotonation that may occur under the conditions of wet DMSO. Acid-base properties in non-aqueous solutions are notoriously uncharacterised, but in this case we have access to a carefully-conducted recent study of the acid-base properties of $\mathrm{H}_{2} \mathrm{PO}_{4}^{-}$and $\mathrm{CH}_{3} \mathrm{CO}_{2}-$ in DMSO.[1] That study also measured an association constant for antielectrostatic $\mathrm{H}_{2} \mathrm{PO}_{4}^{-}$dimerization of $180 \mathrm{M}^{-1}$ in DMSO, but did not consider indefinite association to form higher oligomers as is presented here.

It has previously been shown that the deprotonaton of $\mathrm{H}_{2} \mathrm{PO}_{4}^{-}$in DMSO is highly unfavorable. ${ }^{[1]}$ As such, we limit our consideration to the possibility of forming of phosphoric acid, $\mathrm{H}_{3} \mathrm{PO}_{4}$, by protonation of $\mathrm{H}_{2} \mathrm{PO}_{4}{ }^{-}$with water. Literature data for $K^{H}$, the acid association constant of a species, are given in Table S1.

Table S1. Literature acid-base association constants for phosphate, ${ }^{[1]}$ acetate ${ }^{[1]}$ and water ${ }^{[2]}$ in DMSO.

\begin{tabular}{cc}
$K^{\mathrm{H}}=\frac{[\mathrm{AH}]}{[\mathrm{H}][\mathrm{A}]}$ \\
\hline Species & $\log \mathrm{K}^{\mathrm{H}}$ (DMSO) \\
\hline $\mathrm{H}_{3} \mathrm{PO}_{4}{ }^{[1]}$ & 10.8 \\
$\mathrm{H}_{3} \mathrm{CO}_{2} \mathrm{H}^{[1]}$ & 12.8 \\
$\mathrm{H}_{2} \mathrm{O}^{[2]}$ & 28 \\
\hline
\end{tabular}

\section{S2.1 Speciation of phosphate in DMSO}

Proton transfer from water to dihydrogen phosphate would occur as:

$$
\mathrm{H}_{2} \mathrm{PO}_{4}^{-}+\mathrm{H}_{2} \mathrm{O} \leftrightarrow \mathrm{H}_{3} \mathrm{PO}_{4}+\mathrm{OH}^{-}
$$

With the acid-base relationship and using the values in Table S1:

$$
\frac{\left[\mathrm{OH}^{-}\right]\left[\mathrm{H}_{3} \mathrm{PO}_{4}\right]}{\left[\mathrm{H}_{2} \mathrm{PO}_{4}^{-}\right]\left[\mathrm{H}_{2} \mathrm{O}\right]}=\frac{10^{-28}}{10^{-10.8}}=10^{-17.2}
$$

At $0.5 \% \mathrm{v} / \mathrm{v} \mathrm{H}_{2} \mathrm{O},\left[\mathrm{H}_{2} \mathrm{O}\right]_{0}=280 \mathrm{mM}$. Considering the case for $50 \mathrm{mM}\left[\mathrm{H}_{2} \mathrm{PO}_{4}{ }^{-}\right]$and setting $x$ as the concentration $\left[\mathrm{OH}^{-}\right]$and $\left[\mathrm{H}_{3} \mathrm{PO}_{4}\right]$, we can restate this as:

$$
\frac{\left[\mathrm{OH}^{-}\right]\left[\mathrm{H}_{3} \mathrm{PO}_{4}\right]}{\left[\mathrm{H}_{2} \mathrm{PO}_{4}^{-}\right]\left[\mathrm{H}_{2} \mathrm{O}\right]}=\frac{x^{2}}{\left(\left[\mathrm{H}_{2} \mathrm{PO}_{4}^{-}\right]_{0}-x\right)\left(\left[\mathrm{H}_{2} \mathrm{O}\right]_{0}-x\right)}=10^{-17.2}
$$

And then:

$$
\begin{aligned}
\frac{x^{2}}{\left(50 \times 10^{-3}-x\right)\left(280 \times 10^{-3}-x\right)} & =10^{-17.2} \\
x^{2} & =\left(\left(50 \times 10^{-3}\right)\left(280 \times 10^{-3}\right)-x\left(280 \times 10^{-3}+50 \times 10^{-3}\right)+x^{2}\right) 10^{-17.2} \\
x & =9.4 \times 10^{-9} \mathrm{M}^{-1}
\end{aligned}
$$

$\left[\mathrm{H}_{3} \mathrm{PO}_{4}\right]$ is thus expected to be vanishingly small, and is not expected to play any part in supramolecular assembly. 


\section{S2.2 Speciation of acetate in DMSO}

Following the same steps as above:

$$
\frac{\left[\mathrm{OH}^{-}\right][\mathrm{AcOH}]}{\left[\mathrm{AcO}^{-}\right]\left[\mathrm{H}_{2} \mathrm{O}\right]}=\frac{10^{-28}}{10^{-12.8}}=10^{-15.2}
$$

And solving for the extent of proton transfer:

$$
\begin{aligned}
\frac{x^{2}}{\left(50 \times 10^{-3}-x\right)\left(280 \times 10^{-3}-x\right)} & =10^{-15.2} \\
x^{2} & =\left(\left(50 \times 10^{-3}\right)\left(280 \times 10^{-3}\right)-x\left(280 \times 10^{-3}+50 \times 10^{-3}\right)+x^{2}\right) 10^{-17.2} \\
x & =9.4 \times 10^{-8} \mathrm{M}^{-1}
\end{aligned}
$$

While the formation of $\mathrm{CH}_{3} \mathrm{CO}_{2} \mathrm{H}$ is slightly more favorable than that of $\mathrm{H}_{3} \mathrm{PO}_{4}$, it is still expected to only be present at insignificant $(\sim \mathrm{nM})$ concentration.

\section{S2.3 Literature association data ${ }^{[1]}$}

In a previous study, acetate was proposed to be incapable of forming an antielectrostatic dimer, while a dimerization constant of $K=180 \mathrm{M}^{-1}$ was reported for dihydrogen phosphate. ${ }^{[1]}$ No indefinite association models were considered in that work.

These anions are able to associate with their respective conjugate acid $\left(K_{1,1}\right)$, with a high $\left(\sim 10^{4} \mathrm{M}^{-1}\right)$ association constant found for phosphate.

Table S2. Literature association values for dimerization of phosphate and acetate species, with method of determination noted in parentheses. ${ }^{[1]} \mathrm{H}_{2} \mathrm{PO}_{4}$ was found to form antielectrostatic dimers with $K=180 \mathrm{M}^{-1}$, similar to the $120 \mathrm{M}^{-1}$ isodesmic $K_{\mathrm{i}}$ found here using an indefinite self-association model.

\begin{tabular}{ccccccc}
\hline Species & $\begin{array}{c}\log K_{0,2} \\
{\left[\mathrm{~B}^{-}+\mathrm{B}^{-}\right] \rightarrow\left[\mathrm{B}_{2}\right]^{2-}}\end{array}$ & $\begin{array}{c}K_{0,2} \\
/ \mathbf{M}^{-1}\end{array}$ & $\begin{array}{c}\log K_{1,1} \\
{\left[\mathrm{HB}+\mathrm{B}^{-}\right] \rightarrow\left[\mathrm{HB}_{2}\right]^{-}}\end{array}$ & $\begin{array}{c}K_{1,1} \\
/ \mathbf{M}^{-1}\end{array}$ & $\begin{array}{c}\log K_{1,2} \\
{[\mathrm{HB}-\mathrm{B}]^{-}+\mathrm{B}^{-} \rightarrow\left[\mathrm{HB}_{2}\right]^{2-}}\end{array}$ & $\begin{array}{c}K_{1,2} \\
/ \mathbf{M}^{-1}\end{array}$ \\
\hline $\mathrm{H}_{2} \mathrm{PO}_{4}{ }^{-[1]}$ & $2.26(6)(\mathrm{ITC})$ & $1.8 \times 10^{2}$ & $4.23(3)(\mathrm{NMR})$ & $1.7 \times 10^{4}$ & $2.92(\mathrm{ITC})$ & $8.3 \times 10^{2}$ \\
$\mathrm{OAc}^{[1]}$ & - & - & $2.45(1)(\mathrm{ITC})$ & $2.8 \times 10^{2}$ & - & \\
\hline
\end{tabular}




\section{S3. Synthesis}

The $E$ and Z-stiff-stilbene diamine $\mathbf{S 1}$ was prepared as previously reported.[3]

\section{S3.1 Preparation of bis-urea hosts $E-1$ and $Z-1$}<smiles>Nc1ccc2c(c1)C(=C1CCc3ccc(N)cc31)CC2</smiles>

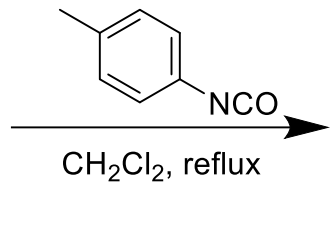<smiles>Cc1ccc(NC(=O)c2ccccc2)cc1</smiles><smiles>O=C(Nc1ccc(I)cc1)Nc1ccc2c(c1)/C(=C1\CCc3ccc(I)cc31)CC2</smiles>

Compound $E$-S1 (100 mg, $0.38 \mathrm{mmol}$ ) was suspended in $50 \mathrm{~mL}$ dry $\mathrm{CH}_{2} \mathrm{Cl}_{2}$, and $p$-tolylisocyanate (101 $\mathrm{mg}$, $95 \mu \mathrm{L}, 0.76 \mathrm{mmol}$ ) was added by syringe. The reaction mixture was stirred at reflux overnight, cooled to $\mathrm{rt}$, and the precipitate was filtered off to obtain crude $E-1$. The crude was washed with $\mathrm{CH}_{2} \mathrm{Cl}_{2}$ and aq. $\mathrm{HCl}(1 \mathrm{M}$ ), suspended in water and sonicated, and the precipitate was collected by filtration to give $E-1$ as a fine beige solid (167 mg, 83\%).

${ }^{1} \mathrm{H}$ NMR (600 MHz, DMSO-d 6$) \delta 8.70\left(\mathrm{~s}, 2 \mathrm{H}, \mathrm{H}^{\mathrm{f}}\right), 8.57\left(\mathrm{~s}, 2 \mathrm{H}, \mathrm{H}^{\mathrm{g}}\right), 7.89\left(\mathrm{~d}, \mathrm{~J}=1.9 \mathrm{~Hz}, 2 \mathrm{H}, \mathrm{H}^{\mathrm{e}}\right), 7.35(\mathrm{~d}, \mathrm{~J}=8.1$ $\left.\mathrm{Hz}, 4 \mathrm{H}, \mathrm{H}^{\mathrm{h}}\right), 7.26-7.20\left(\mathrm{~m}, 4 \mathrm{H}, \mathrm{H}^{\mathrm{c}, \mathrm{d}}\right), 7.09\left(\mathrm{~d}, \mathrm{~J}=8.1 \mathrm{~Hz}, 4 \mathrm{H}, \mathrm{H}^{\mathrm{i}}\right), 3.11\left(\mathrm{~m}, 4 \mathrm{H}, \mathrm{H}^{\mathrm{a}}\right), 3.04\left(\mathrm{~m}, 4 \mathrm{H}, \mathrm{H}^{\mathrm{b}}\right), 2.25(\mathrm{~s}$, $6 \mathrm{H}, \mathrm{H}^{\mathrm{j})} .{ }^{13} \mathrm{C}$ NMR $\left(151 \mathrm{MHz}\right.$, DMSO-d $\left.\mathrm{d}_{6}\right) \delta 152.80,140.12,138.37,137.24,135.08,130.49,129.15,128.48$, 124.82, 118.31, 117.58, 114.27, 31.66, 29.82, 20.35. HR-MS found: 529.25972; $\left[\mathrm{C}_{34} \mathrm{H}_{32} \mathrm{~N}_{4} \mathrm{O}_{2}+\mathrm{H}\right]^{+}$requires $529.25980 \mathrm{~m} / \mathrm{z}$.

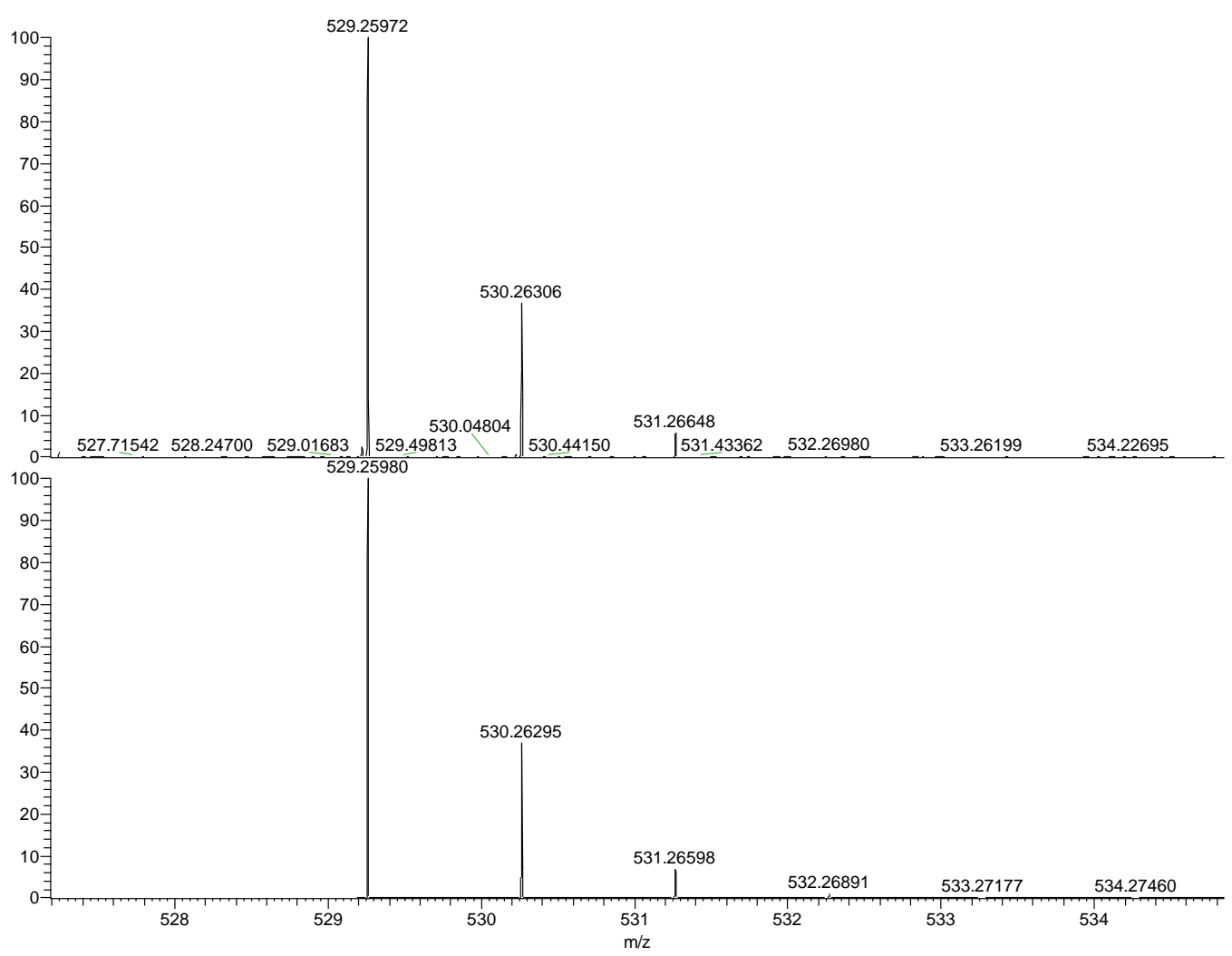

Figure S1. High resolution mass spectrum of $[E-1+H]^{+}$ 

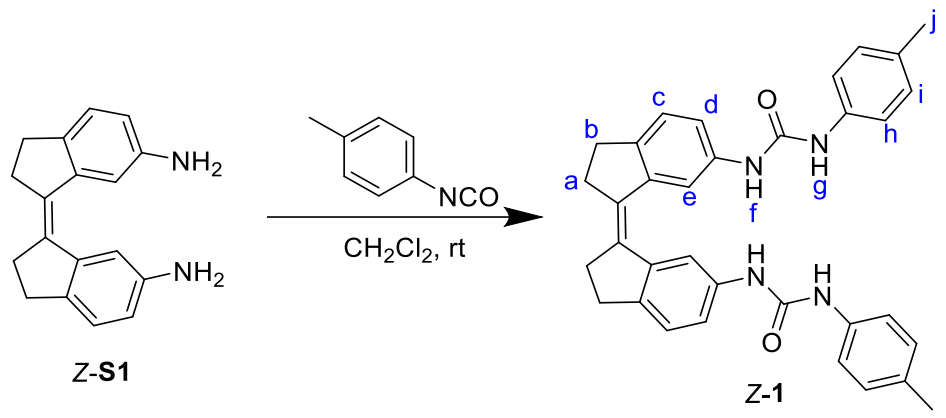

Compound Z-S1 (100 mg, $0.38 \mathrm{mmol}$ ) was dissolved in $5 \mathrm{~mL}$ of dry $\mathrm{CH}_{2} \mathrm{Cl}_{2}$, and $p$-tolylisocyanate (101 $\mathrm{mg}$, 95 $\mu \mathrm{L}, 0.76 \mathrm{mmol}$ ) was added by syringe. The reaction mixture was stirred at $\mathrm{rt}$ overnight and the precipitate was filtered off to obtain crude $Z-1$. The crude was washed with $\mathrm{CH}_{2} \mathrm{Cl}_{2}$ and aq. $\mathrm{HCl}(1 \mathrm{M})$, suspended in water and sonicated, and the precipitate was collected by filtration to give $Z-1$ as a fine beige solid (152 $\mathrm{mg}, 75 \%$ ).

${ }^{1} \mathrm{H}$ NMR $(600 \mathrm{MHz}$, DMSO-d $) \delta 8.59\left(\mathrm{~s}, 2 \mathrm{H}, \mathrm{H}^{\mathrm{g}}\right), 8.43\left(\mathrm{~s}, 2 \mathrm{H}, \mathrm{H}^{\mathrm{f}}\right), 8.11\left(\mathrm{~s}, 2 \mathrm{H}, \mathrm{H}^{\mathrm{e}}\right), 7.42(\mathrm{dd}, \mathrm{J}=8.2,1.9 \mathrm{~Hz}$, $\left.2 \mathrm{H}, \mathrm{H}^{\mathrm{d}}\right), 7.29\left(\mathrm{~d}, \mathrm{~J}=8.0 \mathrm{~Hz}, 4 \mathrm{H}, \mathrm{H}^{\mathrm{h}}\right), 7.22\left(\mathrm{~d}, \mathrm{~J}=8.2 \mathrm{~Hz}, 2 \mathrm{H}, \mathrm{H}^{\mathrm{c}}\right), 6.88\left(\mathrm{~d}, \mathrm{~J}=8.0 \mathrm{~Hz}, 4 \mathrm{H}, \mathrm{H}^{\mathrm{l}}\right), 2.89\left(\mathrm{~m}, 4 \mathrm{H}, \mathrm{H}^{\mathrm{b}}\right)$, $2.77\left(\mathrm{~m}, 4 \mathrm{H}, \mathrm{H}^{\mathrm{a}}\right), 2.11\left(\mathrm{~s}, 6 \mathrm{H}, \mathrm{H}^{\mathrm{j}}\right) .{ }^{13} \mathrm{C}$ NMR $\left(151 \mathrm{MHz}, \mathrm{DMSO}-\mathrm{d}_{6}\right) \delta 152.71,141.27,140.05,137.59,137.28$, $134.86,130.20,129.04,125.10,118.14,117.71,113.62,34.45,29.39,20.22$.

\section{S3.2 NMR spectra of $E-1$}

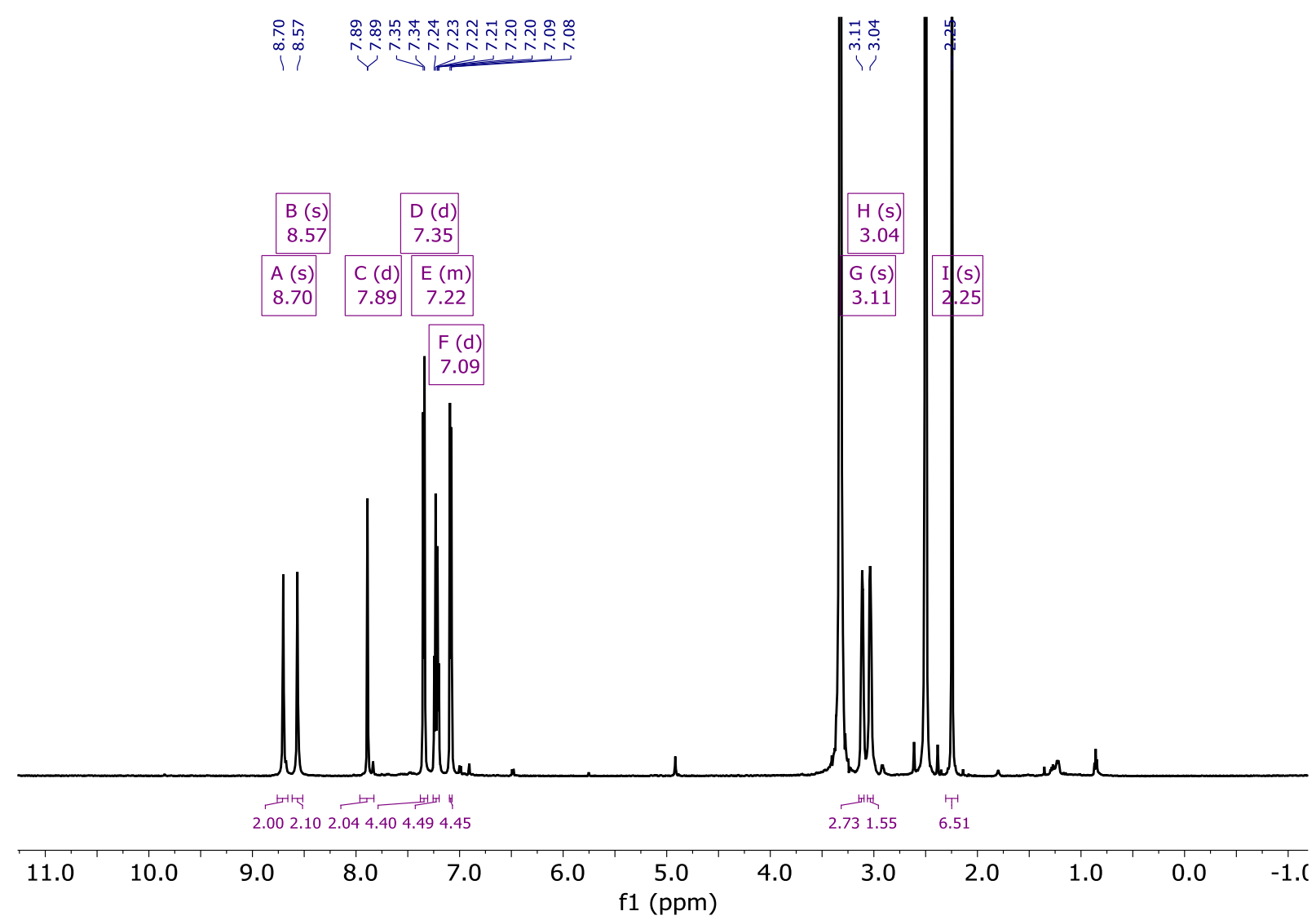

Figure S2. ${ }^{1} \mathrm{H}$ NMR spectrum of $E-1\left(600 \mathrm{MHz}, \mathrm{DMSO}-d_{6}\right)$. 


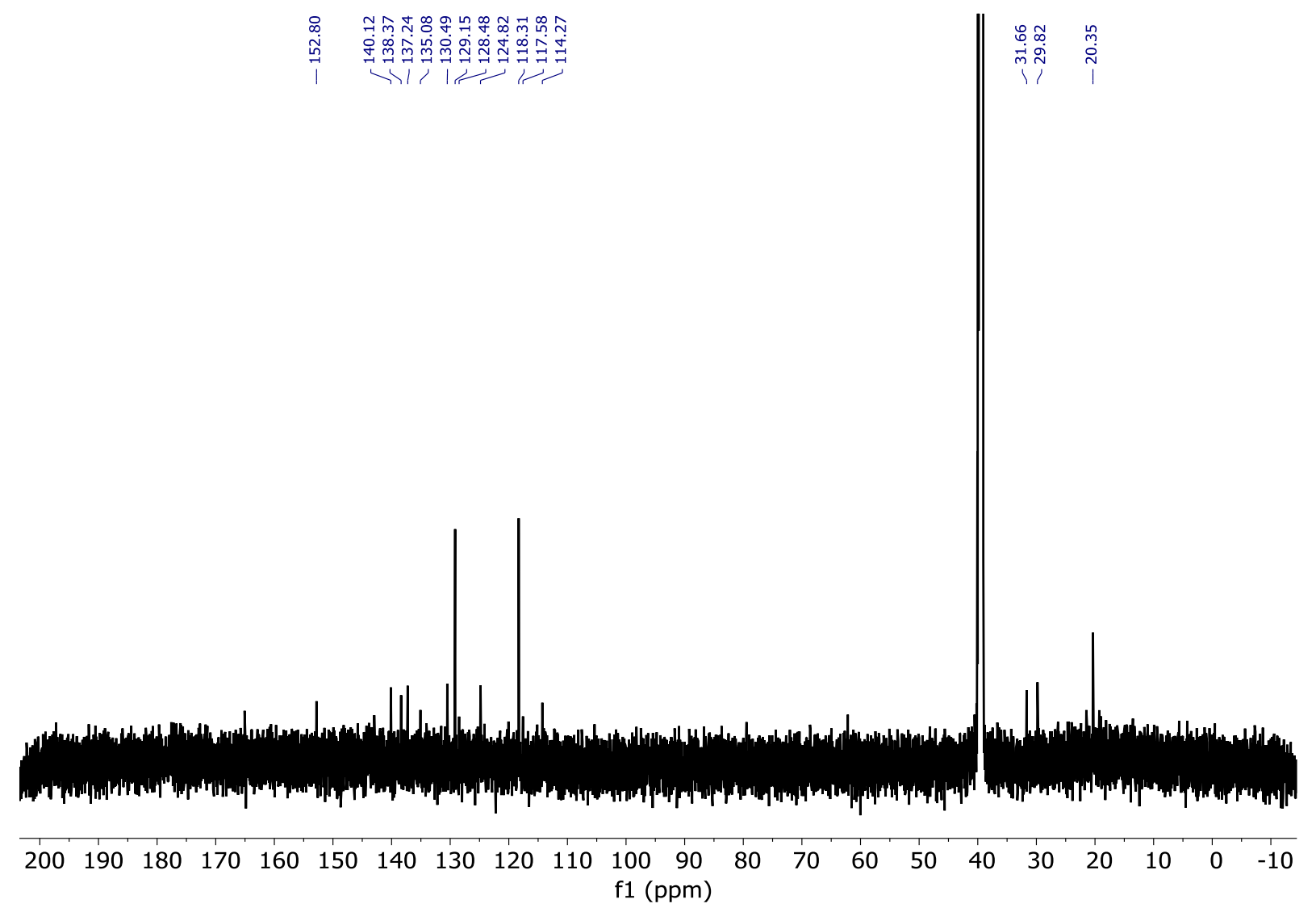

Figure S3. ${ }^{13} \mathrm{C}\left\{{ }^{1} \mathrm{H}\right\}$ NMR spectrum of $E-1$ (125 MHz, DMSO- $\left.d_{6}\right)$. Low signal-to-noise due to poor solubility.

\section{S3.3 NMR spectra of Z-1}

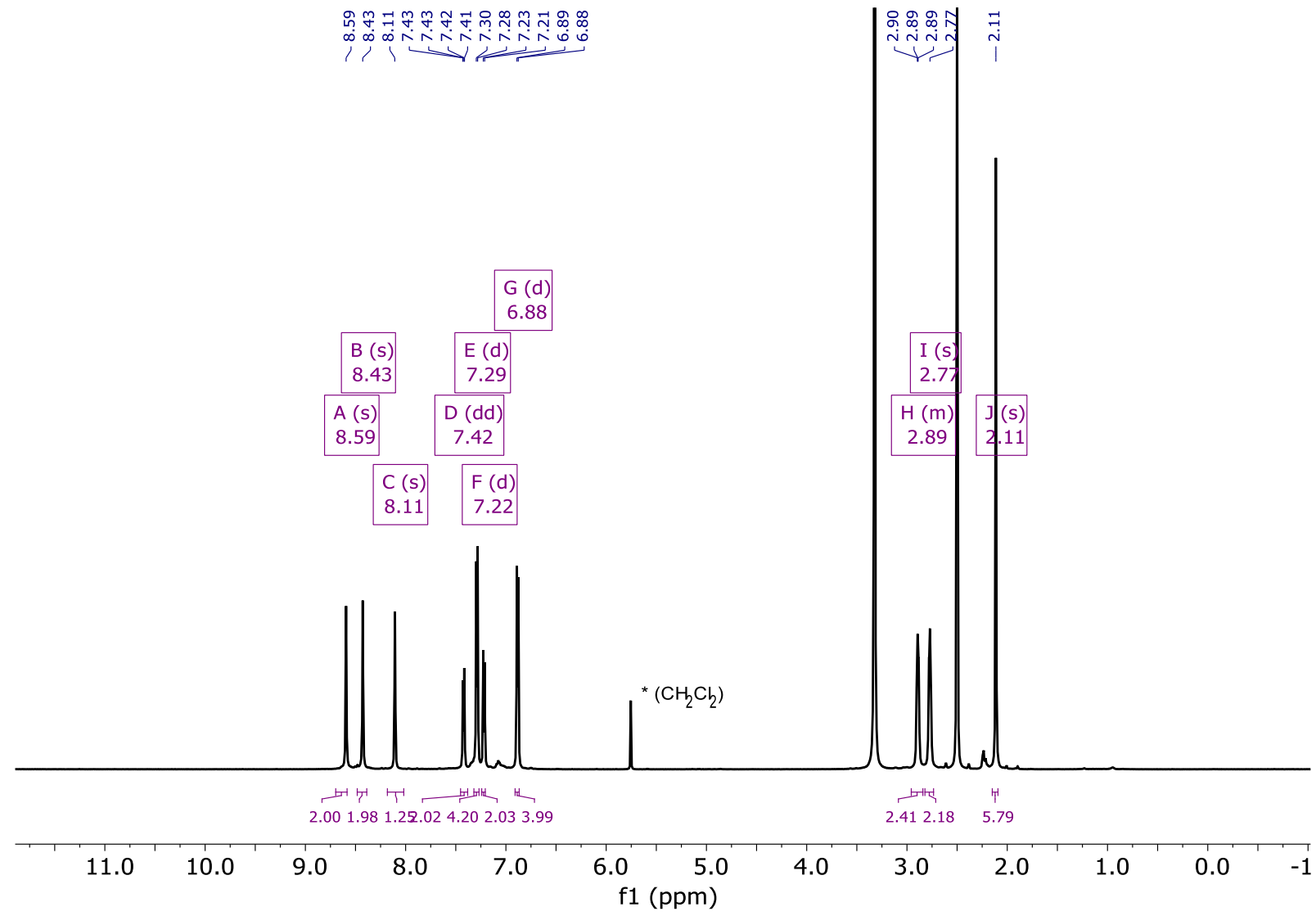

Figure S4. ${ }^{1} \mathrm{H}$ NMR spectrum of $Z-1\left(600 \mathrm{MHz}\right.$, DMSO- $\left.d_{6}\right)$. 


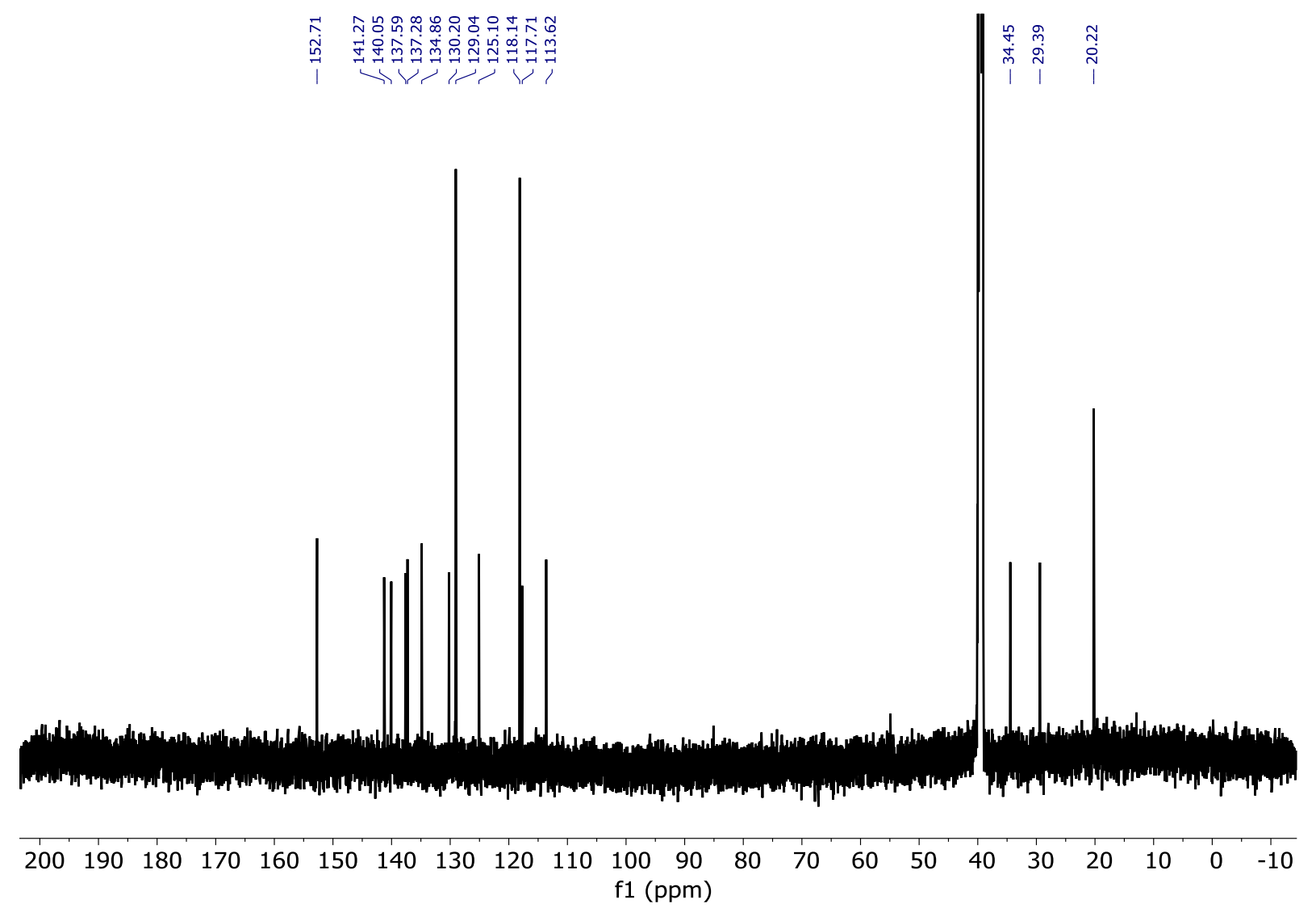

Figure S5. ${ }^{13} \mathrm{C}\left\{{ }^{1} \mathrm{H}\right\}$ NMR spectrum of $Z-1\left(125 \mathrm{MHz}\right.$, DMSO- $\left.d_{6}\right)$.

\section{S4. Viscosity measurements of tetrabutylammonium dihydrogen phosphate solutions}

Viscosities and densities were measured at $25{ }^{\circ} \mathrm{C}$ using a Lovis $2000 \mathrm{M}$ rolling ball viscometer $(\varnothing 1.59 \mathrm{~mm}$ capillary; $1 \mathrm{~mm}$ stainless steel ball), with results shown in Table S3.

Table S3. Viscosity measurements of solutions of $\left[\mathrm{NBu}_{4}\right]\left[\mathrm{H}_{2} \mathrm{PO}_{4}\right]$ in DMSO- $d_{6}$ with $0.5 \% \mathrm{v} / \mathrm{v}$ added water.

\begin{tabular}{ccccccc}
\hline $\begin{array}{c}{\left[\mathrm{NBu}_{4}\right]\left[\mathrm{H}_{2} \mathrm{PO}_{4}\right]} \\
/ \mathbf{~ m M}\end{array}$ & $\begin{array}{c}\text { Density } \\
/ \mathbf{g} \cdot \mathbf{c m}^{-3}\end{array}$ & $\begin{array}{c}\text { Temperature } \\
/{ }^{\circ} \mathbf{C} /\end{array}$ & $\begin{array}{c}\text { Dyn. Viscosity } \\
/ \mathrm{mPa} \cdot \mathbf{s}\end{array}$ & $\begin{array}{c}\text { Kin. Viscosity } \\
/ \mathbf{m m}^{2} \cdot \mathbf{s}^{-1}\end{array}$ & $\begin{array}{c}\text { Temperature } \\
/{ }^{\circ} \mathbf{C}\end{array}$ & $\begin{array}{c}\text { Error } \\
/ \%\end{array}$ \\
\hline 0 & 1.1833 & 25.04 & 2.149 & 1.816 & 25.00 & 0.02 \\
5 & 1.1833 & 25.00 & 2.210 & 1.868 & 25.00 & 0.08 \\
20 & 1.1828 & 25.08 & 2.259 & 1.910 & 25.00 & 0.04 \\
50 & 1.1820 & 25.04 & 2.334 & 1.974 & 24.99 & 0.03 \\
100 & 1.1805 & 25.06 & 2.499 & 2.117 & 25.00 & 0.01 \\
300 & 1.1752 & 25.04 & 3.251 & 2.767 & 25.00 & 0.02 \\
\hline
\end{tabular}




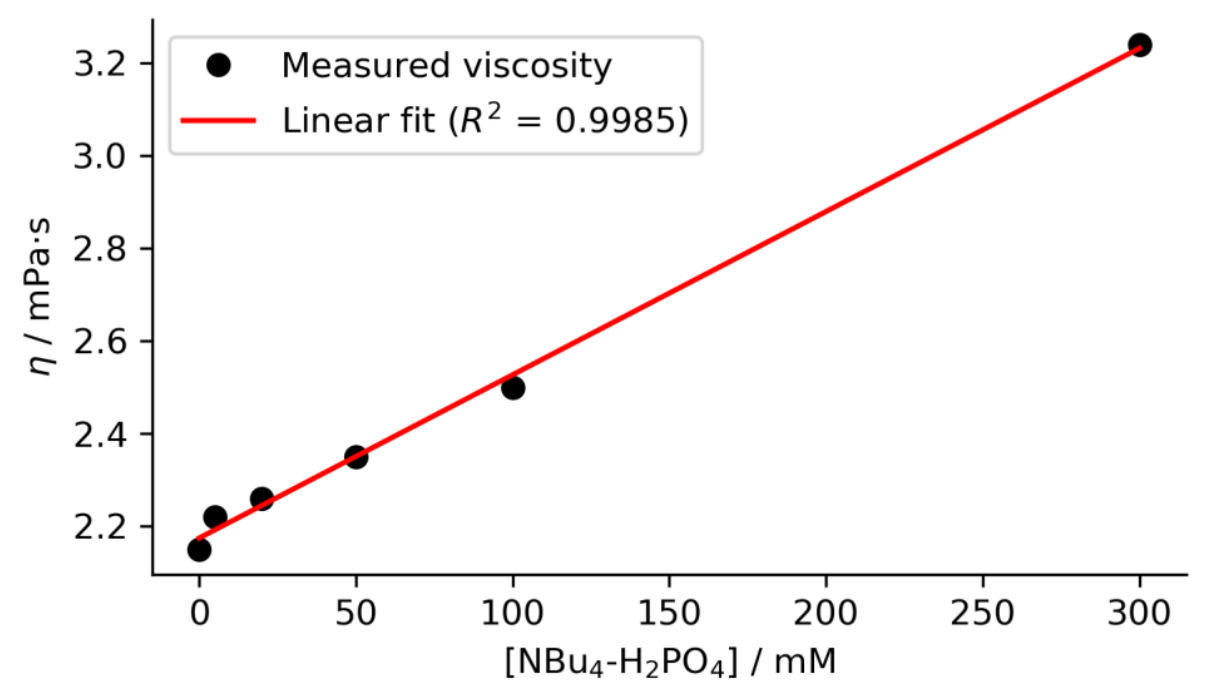

Figure S6. Concentration dependence of the measured viscosity of tetrabutylammonium dihydrogen phosphate solutions in DMSO- $d_{6}$ with $0.5 \%$ added water. Linear fit: $\eta=2.17+\left(3.53 \times 10^{-3}\right)\left(\left[\mathrm{NBu}_{4}\right]\left[\mathrm{H}_{2} \mathrm{PO}_{4}\right]\right)$. For calibrating diffusion measurements, it is convenient to express this in relative form: $\left.\eta / \eta_{0}=1+1.63 \times\left[\mathrm{NBu}_{4}\right]\left[\mathrm{H}_{2} \mathrm{PO}_{4}\right] / \mathrm{mM}\right]$ 


\section{S5. Mathematical modelling of isodesmic self-association}

The association of dihydrogen phosphate was fitted to an isodesmic model, ${ }^{[4]}$ constructed as follows.

\section{S5.1 Isodesmic model for self-association}

Consider a monomer $\mathrm{A}$ capable of forming an oligomer of arbitrary length, where each association step $\mathrm{A}_{n-1}+\mathrm{A} \rightarrow \mathrm{A}_{\mathrm{n}}$ occurs with the same (isodesmic) association constant $K_{i}$ :

$$
K_{i}=\frac{\left[\mathrm{A}_{\mathrm{n}}\right]}{[\mathrm{A}]\left[\mathrm{A}_{\mathrm{n}-1}\right]}
$$

And the total concentration of $A$ is given as:

$$
[\mathrm{A}]_{0}=\sum_{n=1}^{\infty} n\left[\mathrm{~A}_{\mathrm{n}}\right]
$$

It is convenient to define $z=[\mathrm{A}] K_{i}$. Then:

$$
\begin{aligned}
{\left[\mathrm{A}_{\mathrm{n}}\right] } & =K_{i}[\mathrm{~A}]\left[\mathrm{A}_{\mathrm{n}-1}\right] \\
& =z\left[\mathrm{~A}_{\mathrm{n}-1}\right]
\end{aligned}
$$

As $\left[\mathrm{A}_{1}\right]=[\mathrm{A}]$, by induction:

$$
\begin{aligned}
{\left[\mathrm{A}_{n}\right] } & =[\mathrm{A}] z^{n-1} \\
& =\frac{z^{n}}{K_{i}}
\end{aligned}
$$

We can combine (2) and (3) to build a mass balance equation for $[\mathrm{A}]_{0}$ :

$$
\begin{aligned}
{[\mathrm{A}]_{0} } & =\sum_{n=1}^{\infty} n\left[\mathrm{~A}_{\mathrm{n}}\right] \\
& =\frac{1}{K_{i}} \sum_{n=1}^{\infty} n z^{n} \\
& =\frac{z}{K_{i}(z-1)^{2}}
\end{aligned}
$$

Allowing us to express $z$ as the root of a quadratic:

$$
\begin{gathered}
{[\mathrm{A}]_{0} K_{i}(z-1)^{2}=z} \\
{[\mathrm{~A}]_{0} K_{i} z^{2}-\left(2[\mathrm{~A}]_{0} K_{i}+1\right) z+[\mathrm{A}]_{0} K_{i}=0}
\end{gathered}
$$

Defining $L=[\mathrm{A}]_{0} K_{i}$ and assuming that $z$ is the smallest solution to the quadratic:

$$
z=\frac{2 L+1-\sqrt{4 L+1}}{2 L}
$$

From $z$ we can obtain the concentration of monomeric (unbound) species $[\mathrm{A}]=\frac{z}{K_{i}}$, and by combining equations (4) and (3) we can calculate the size distribution of oligomers from the starting concentration $[\mathrm{A}]_{0}$ and association constant $K_{i}$.

One other relationship may be useful. If we assume that only the terminal sites of each oligomer are available for binding by a host (ie each monomeric or oligomeric guest species has two binding sites, regardless of size), then the guest concentration of guest binding sites in solution will be:

$$
\begin{aligned}
{\left[\mathrm{A}_{e f f}\right] } & =\sum_{n=1}^{\infty}\left[\mathrm{A}_{n}\right] \\
& =\frac{1}{K_{i}} \sum_{n=1}^{\infty} z^{n} \\
& =\frac{z}{K_{i}(1-z)}
\end{aligned}
$$




\section{S5.2 Isodesmic model for diffusion}

The Stokes-Einstein-Sutherland equation for molecular diffusion states that for hard spherical particles ${ }^{[5]}$ :

$$
D=\frac{k_{B} T}{6 \pi \eta R_{H}}
$$

For the sake of simplicity, we can approximate each monomer as a hard sphere of volume $V$ and each $n$-unit oligomer as a hard sphere of volume $n V$. This assumption of perfect packing of hard spheres to form a larger hard sphere is clearly unphysical, but the results of this approximation have previously been shown to be quite close to those obtained from more detailed treatments. ${ }^{[6]}$

The diffusion coefficient $D_{n}$ of an $n$-unit oligomer can then be expressed as

$$
D_{n}=n^{-\frac{1}{3}} D_{0}
$$

where $D_{0}$ is the diffusion coefficient of the monomeric species (i.e. at infinite dilution). For system of oligomers in fast exchange on the NMR timescale, the measured diffusion coefficient $\bar{D}$ is a concentration-weighted sum of the diffusion coefficients of all possible oligomerst:

$$
\bar{D}=\sum_{n=1}^{\infty} x_{n} D_{n}
$$

Where $x_{n}$ is the molfraction of the oligomerizing species present in an oligomer of size $n$, ie $x_{n}=\frac{n\left[\mathrm{~A}_{\mathrm{n}}\right]}{[\mathrm{A}]_{0}}$ Using the previously obtained expressions (7) and (3) for $D_{n}$ and $\left[A_{n}\right]$ respectively, we can then say:

$$
\bar{D}=\frac{D_{0}}{[\mathrm{~A}]_{0} K_{i}} \sum_{n=1}^{\infty} n^{\frac{2}{3}} Z^{n}
$$

There is no closed-form analytic solution to this infinite sum, but for numerical modelling and curve-fitting it is convenient to restate it as a polylogarithm. The polylogarithm is a special function defined as

$$
\mathrm{Li}_{s}(z)=\sum_{k=1}^{\infty} \frac{z^{k}}{k^{s}}
$$

allowing us to express $\bar{D}$ as:

$$
\bar{D}=\frac{D_{0}}{[\mathrm{~A}]_{0} K_{i}} \mathrm{Li}_{-\frac{2}{3}}\left([\mathrm{~A}] K_{i}\right)
$$

Some results of this model for the concentration-dependent diffusion of isodesmically self-associating species are plotted in Figure S7.

\footnotetext{
+ This treatment neglects potential differences in longitudinal relaxation times $T_{1}$ across oligomers of different sizes or for the different sites present within an oligomer.
} 

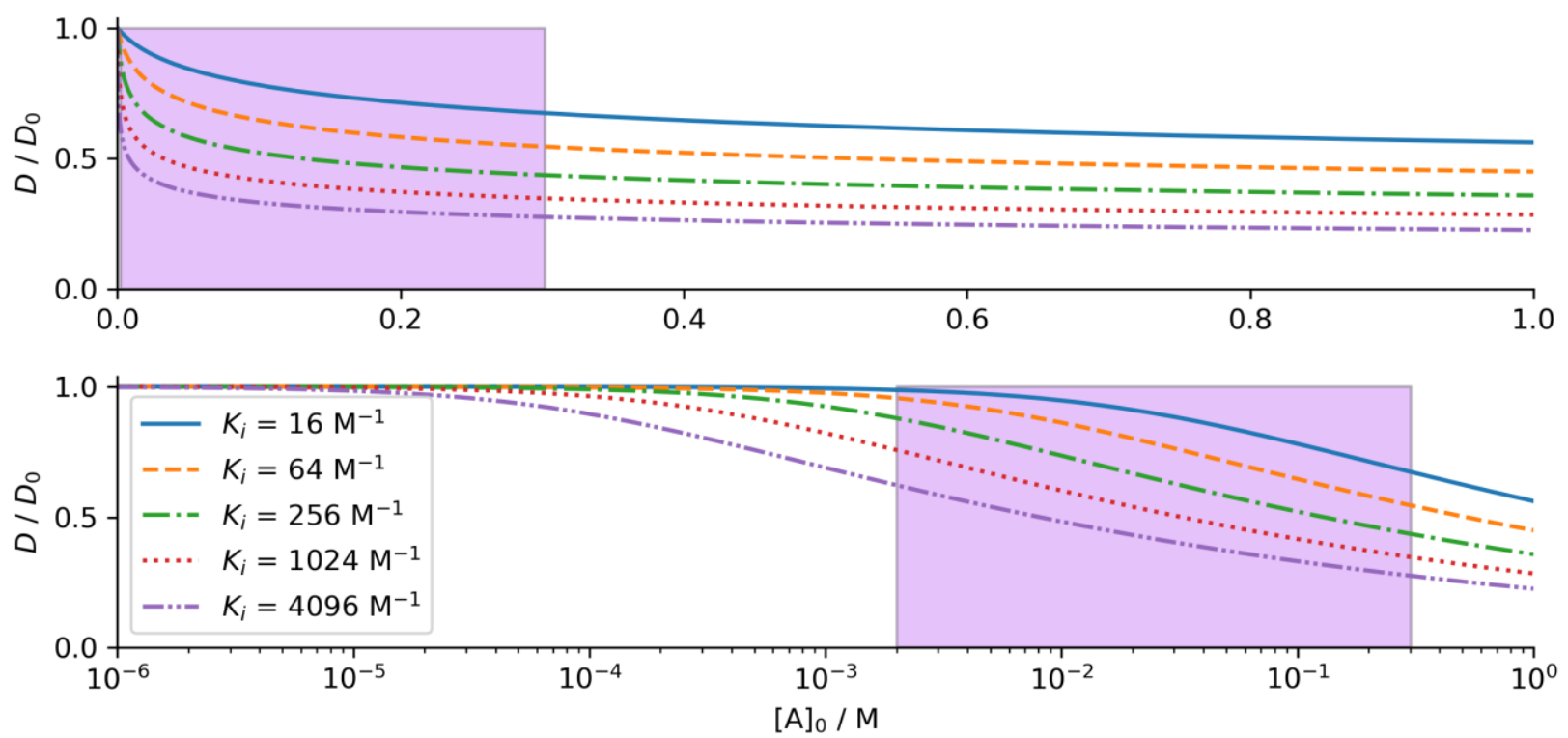

Figure S7. Modelled changes in relative diffusion coefficients $D / D_{0}$ under conditions of isodesmic self-association (Equation 10), for five different association constants $K_{\mathrm{i}}$ over the concentration range $1 \mu \mathrm{M}$ to $1 \mathrm{M}$. The $2-300 \mathrm{mM}$ concentration range studied here has been shaded in purple. Both plots show the same curves, against a linear (top) and log (bottom) concentration scale.

\section{S5.3 Estimated diffusion of host-guest complexes}

Consider a supramolecular complex made up from $m$ host molecules and $n$ guest molecules, of the form $\left[\mathrm{H}_{m} \mathrm{G}_{n}\right]$, where the diffusion coefficients of free host and free guest have been obtained as $D_{\mathrm{H}}$ and $D_{\mathrm{G}}$. Under the same approximation of perfectly packing hard spheres used previously, we can then approximate the diffusion coefficient of the complex as:

$$
D(m, n)=\left(m D_{h}^{-3}+n D_{G}^{-3}\right)^{-\frac{1}{3}}
$$

As the hosts and guests will not pack perfectly into hard spherical complexes, the diffusion coefficients of complexes estimated by this method can be considered upper bounds for the actual diffusion coefficients.

Assuming fast exchange of species on the NMR timescale, the diffusion coefficient measured for a host species is a population-weighted average of all $\mathrm{H}_{m} \mathrm{G}_{n}$ species present:

$$
\overline{D_{H}}=\frac{1}{[H]_{0}} \sum_{m=1}^{\infty} \sum_{n=0}^{\infty} m \cdot D(m, n)\left[\mathrm{H}_{m} \mathrm{G}_{\mathrm{n}}\right]
$$

For the case of discrete complexes involving a single host and up to two guests, this can be expanded to

$$
\overline{D_{H}}=\frac{1}{[H]_{0}}\left([H] D_{H}+[H G]\left(D_{H}^{-3}+D_{G}^{-3}\right)^{-\frac{1}{3}}+\left[H G_{2}\right]\left(D_{H}^{-3}+2 D_{G}^{-3}\right)^{-\frac{1}{3}}\right)
$$

where $[H],[H G]$, and $\left[\mathrm{HG}_{2}\right]$ can be calculated using the total concentrations of host and guest and the association constants $K_{1}$ and $K_{2} \cdot{ }^{[7]}$ If the guest self-associates using isodesmic kinetics (such as $\mathrm{H}_{2} \mathrm{PO}_{4}^{-}$), then $D_{G}$ can be replaced with the concentration-dependent diffusion model given in Equation 10. 


\section{S6. Experimental determination of the thermodynamics of $\mathrm{H}_{2} \mathrm{PO}_{4}^{-}$self-association}

Solutions of tetrabutylammonium dihydrogen phosphate $\left(\left[\mathrm{NBu}_{4}\right]\left[\mathrm{H}_{2} \mathrm{PO}_{4}\right]\right)$ were prepared in DMSO- $d_{6}$ with $0.5 \% \mathrm{v} / \mathrm{v} \mathrm{H}_{2} \mathrm{O}$ added (Millipore). $500 \mu \mathrm{L}$ aliquots were transferred to standard $5 \mathrm{~mm} \mathrm{NMR}$ tubes (Wilmad) and ${ }^{1} \mathrm{H}$ and ${ }^{31} \mathrm{P}$ diffusion experiments were obtained and processed as previously described (S1 General Experimental). Diffusion coefficients were then obtained by nonlinear regression of $I=I_{0} \exp [-b D]$, where $b$ is the effective attenuation strength of the experiment as calculated by the Bruker diff5 utility ( $b=$ $g^{2} \delta^{2} \gamma^{2}\left(\Delta-\frac{\delta}{3}\right)$ for square gradient pulses).

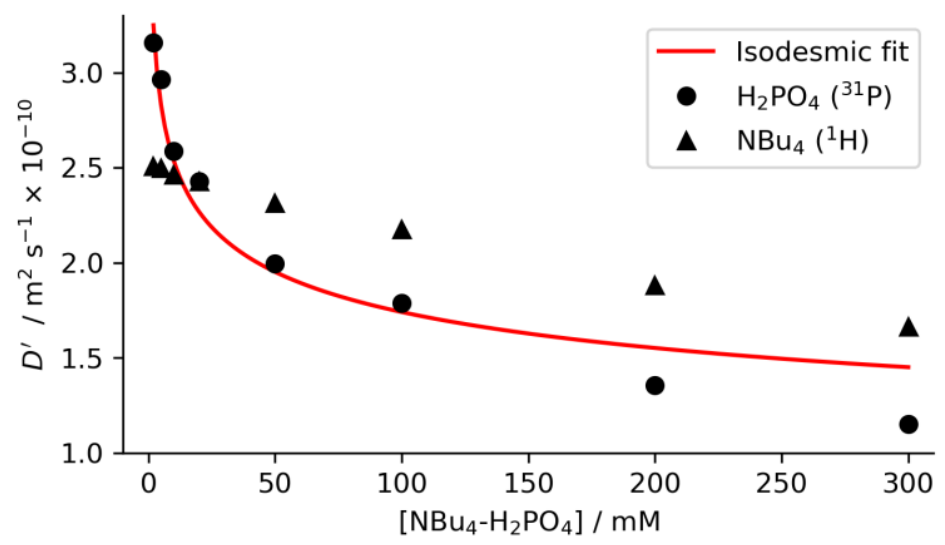

Figure S8. Measured diffusion coefficients of tetrabutylammonium and dihydrogen phosphate uncorrected for changes in viscosity. The model for isodesmic diffusion shown in $\mathrm{Eq}(10)$ has been regressed unsuccessfully onto measured $D\left(\mathrm{H}_{2} \mathrm{PO}_{4}\right)$, with obtained parameters $K_{\mathrm{i}}=(2.5 \pm 9) \times 10^{3} \mathrm{M}^{-1}$ and $D_{0}=(4.9 \pm 2.7) \times 10^{-10} \mathrm{~m}^{2} \mathrm{~s}^{-1}$.

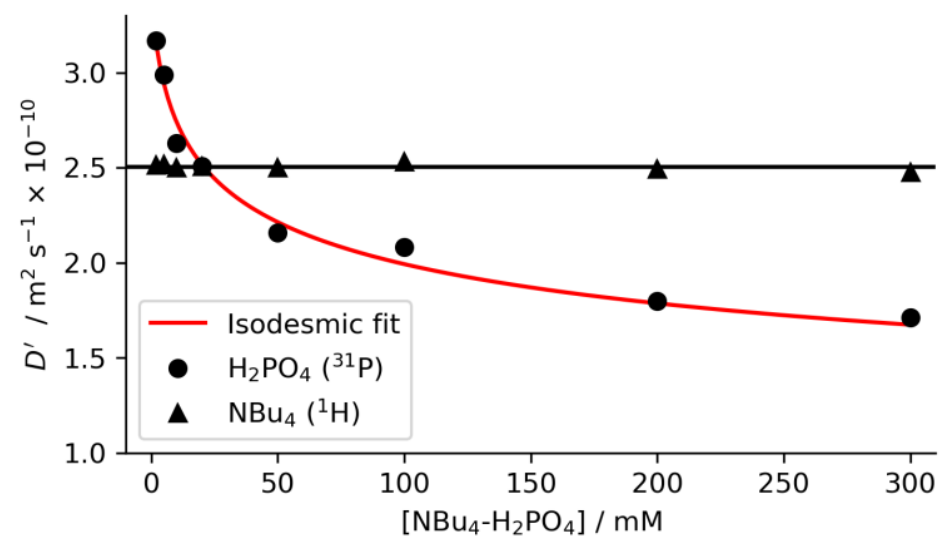

Figure S9. Measured diffusion coefficients of tetrabutylammonium and dihydrogen phosphate corrected for changes in viscosity using the measured viscosities of these solutions (see Table S3; Figure 1 in manuscript). The model for isodesmic diffusion shown in Eq (10) has been regressed onto measured $D\left(\mathrm{H}_{2} \mathrm{PO}_{4}\right)$, with obtained parameters $K_{\mathrm{i}}=(120 \pm 32) \mathrm{M}^{-1}$ and $D_{0}=(3.39 \pm 0.11) \times 10^{-10} \mathrm{~m}^{2} \mathrm{~s}^{-1}$. After correction, no change in $D\left(\mathrm{NBu}_{4}\right)$ is observed (horizontal black line). 


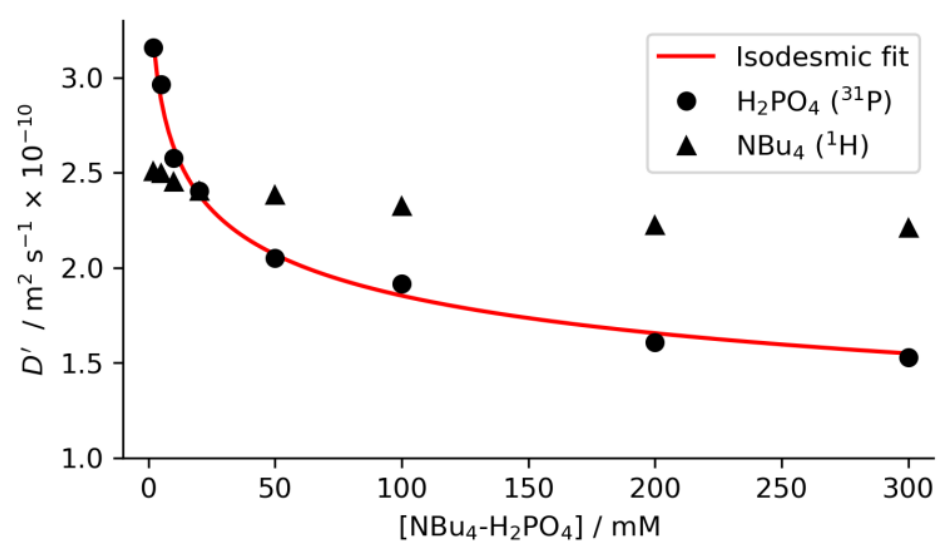

Figure S10. Measured diffusion coefficients of tetrabutylammonium and dihydrogen phosphate corrected for changes in viscosity using the change in the measured diffusion coefficient of the DMSO- $d_{6}$ solvent residual. The model for isodesmic diffusion shown in Eq (10) has been regressed onto measured $D\left(\mathrm{H}_{2} \mathrm{PO}_{4}\right)$, with obtained parameters $K_{\mathrm{i}}=(333 \pm 110) \mathrm{M}^{-1}$ and $D_{0}=(3.71 \pm 0.16) \times 10^{-10} \mathrm{~m}^{2} \mathrm{~s}^{-1}$.

Table S4. Tabulated data for dihydrogen phosphate isodesmic self-association data.

\begin{tabular}{ccccc}
\hline Correction & $\boldsymbol{K}_{\mathrm{i}} / \mathbf{M}^{-1}$ & Relative error $\left(\boldsymbol{K}_{\mathrm{i}}\right)$ & $\boldsymbol{D}_{0} / \mathbf{m}^{2} \mathbf{s}^{-1}$ & Relative error $\left(\boldsymbol{D}_{0}\right)$ \\
\hline Uncorrected $^{[\mathrm{ab}}$ & $(2.5 \pm 9) \times 10^{3}$ & $360 \%$ & $(4.9 \pm 2.7) \times 10^{-10}$ & $55 \%$ \\
Indirect correction $^{[\mathrm{b}]}$ & $(3.33 \pm 1.10) \times 10^{2}$ & $33 \%$ & $(3.71 \pm 0.16) \times 10^{-10}$ & $4.3 \%$ \\
Direct correction $^{[\mathrm{c}]}$ & $(1.20 \pm 0.32) \times 10^{2}$ & $27 \%$ & $(3.39 \pm 0.11) \times 10^{-10}$ & $3.2 \%$ \\
\hline
\end{tabular}

[a] Isodesmic fit to diffusion data as-measured; [b] Isodesmic fit to diffusion data corrected for viscosity changes by normalising $D$ for the DMSO solvent residual; [c] Isodesmic fit to diffusion data corrected for viscosity changes using independently measured viscosity data.

Viscosity changes must be corrected for to allow successful fitting of the isodesmic diffusion model with errors smaller than the fitted value themselves (Table S4). Direct corrections using the change in viscosity measured independently by falling-ball viscometry (SI-S4) gave slightly smaller relative errors than an indirect correction approach using the change in measured $D$ for the DMSO- $d_{5}$ solvent residual peak. These parameters can be used to calculate the size distribution of oligomeric $\mathrm{H}_{2} \mathrm{PO}_{4}{ }^{-}$at arbitrary concentrations, as shown in Figure S11. 

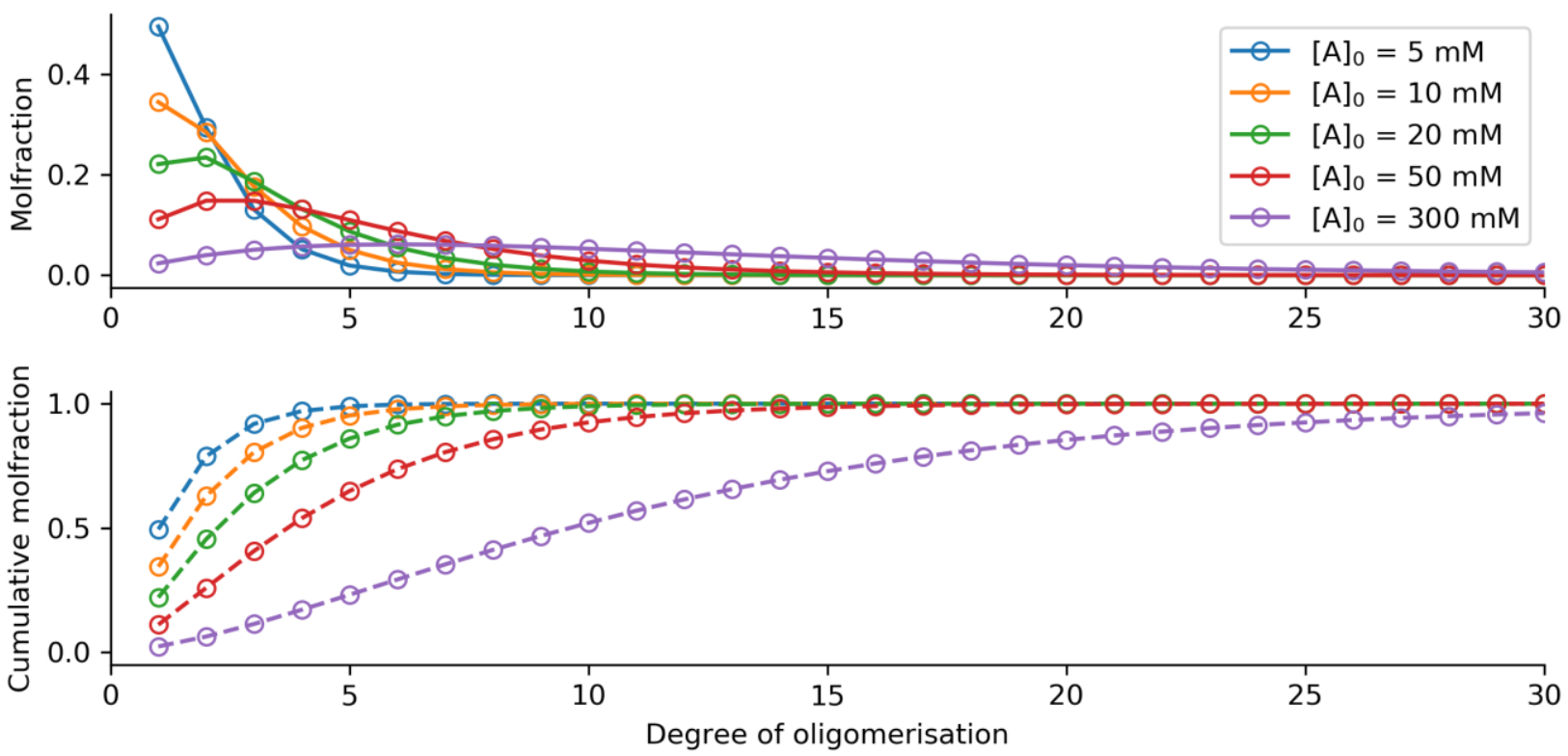

Figure S11. Visualization of the size distribution of phosphate oligomers using experimentally obtained parameters. Top: distribution of oligomers $\left(n=1\right.$ to 30 ) for solutions of $[\mathrm{A}]_{0}=5,10,20,50$, and $300 \mathrm{mM}$ with isodesmic $K_{\mathrm{i}}=120 \mathrm{M}^{-1}$ (as experimentally obtained for $\left[\mathrm{NBu}_{4}\right]\left[\mathrm{H}_{2} \mathrm{PO}_{4}\right]$ in DMSO- $\left.d_{6}\right)$. Bottom: cumulative distribution functions under the same conditions. For the $50 \mathrm{mM}$ solutions of $\left[\mathrm{NBu}_{4}\right]\left[\mathrm{H}_{2} \mathrm{PO}_{4}\right]$ used repeatedly in this work (red) the median phosphate oligomer contains $n=4$ units, the $90^{\text {th }}$ percentile contains $n=10$ units, and the $99^{\text {th }}$ percentile oligomer contains 16 units. 


\section{S6.1 Control experiments with tetrabutylammonium acetate}

Due to the large quantities of DMSO- $d_{6}$ required for falling-ball viscometry, no direct viscosities were measured for solutions of tetrabutylammonium acetate ([NBu 4$][\mathrm{OAc}])$. Instead, an indirect viscosity calibration was performed from the measured diffusion coefficient of the DMSO-d6 solvent residual, under the assumption that changes in measured $D$ for the solvent residual would be primarily a result of changing viscosity.

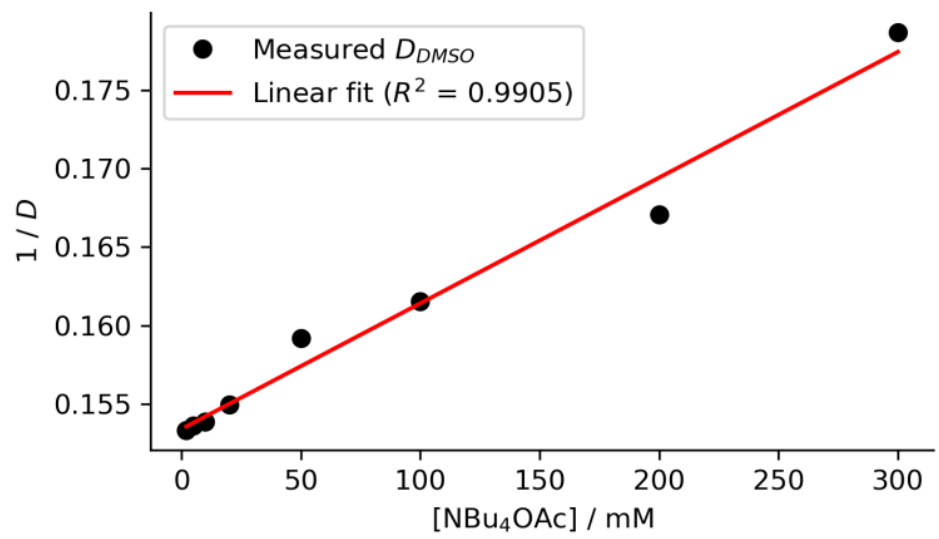

Figure S12. Indirect viscosity calibration for tetrabutylammonium acetate, using the diffusion coefficient of the DMSO solvent residual peak. Linear fit for implied relative change in dynamic viscosity: $\frac{\eta}{\eta_{0}}=1+\left(0.521 \times 10^{-3}\right)\left[\mathrm{NBu}_{4} \mathrm{OAc}\right]$.
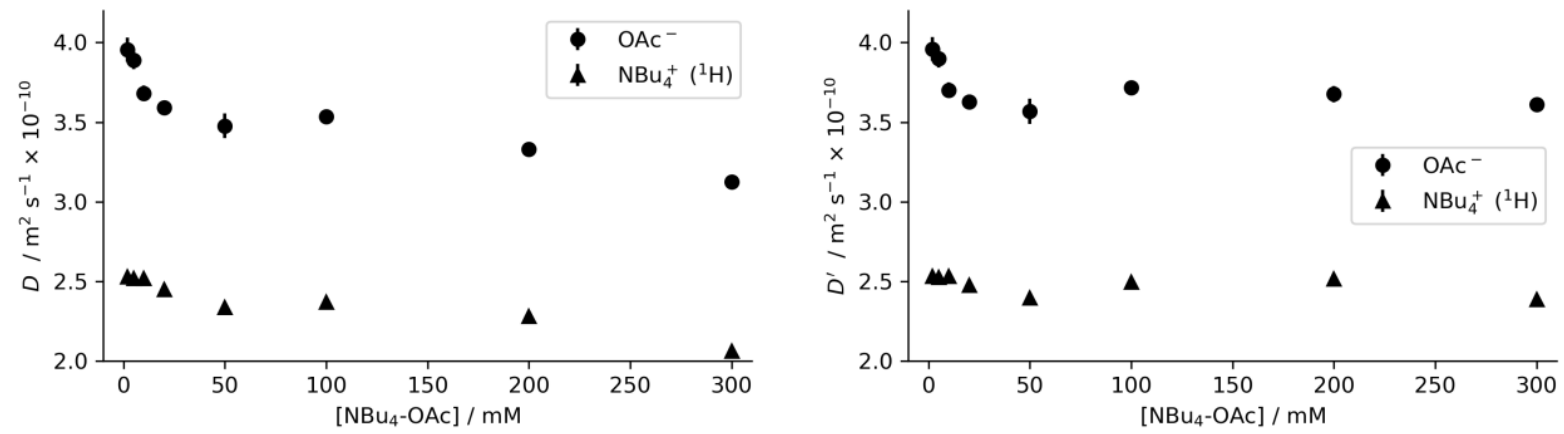

Figure S13. Measured diffusion coefficients of tetrabutylammonium acetate over the concentration range $0-300 \mathrm{mM}$ without (left) and with (right) correction for changes in viscosity (see Figure S12). While some acetate self-association appears to occur, the $<10 \%$ decrease in the measured diffusion coefficient is much smaller than that seen for dihydrogen phosphate. 
Table S5. Measured diffusion coefficients for DMSO, tetrabutylammonium, and acetate over a range of tetrabutylammonium acetate concentrations. No correction for viscosity has been applied to these data. ${ }^{1} \mathrm{H}, 500 \mathrm{MHz}$, DMSO- $d_{6}$ with $0.5 \%$ added $\mathrm{H}_{2} \mathrm{O}$.

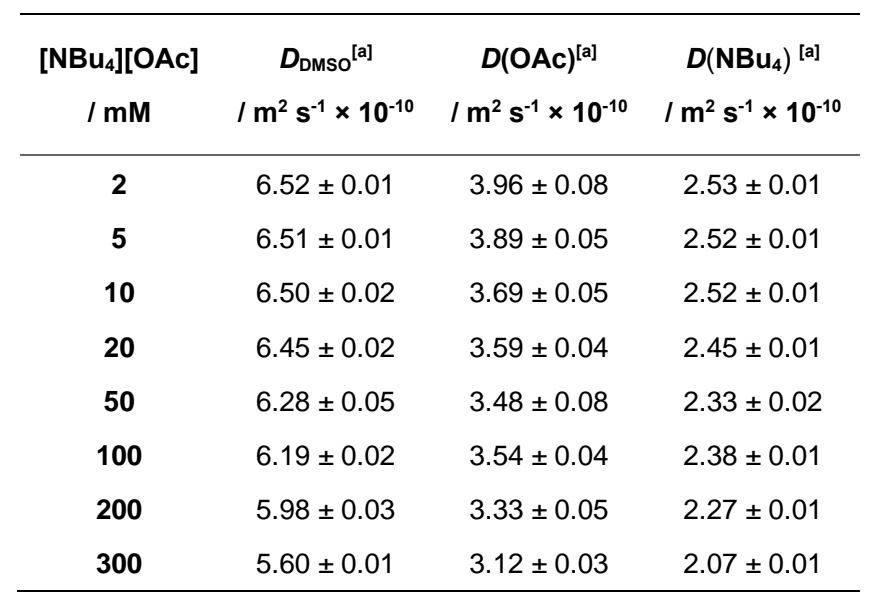

[a] $500 \mathrm{MHz}{ }^{1} \mathrm{H}$ PGSTE, $\delta=4 \mathrm{~ms}, \Delta=50 \mathrm{~ms}, g=0-53.45 \mathrm{G} \mathrm{cm}^{-1}$

Table S6. Changes in diffusion coefficients for solutions of 2-300 mM tetrabutylammonium dihydrogen phosphate $\left(\left[\mathrm{NBu}_{4}\right]\left[\mathrm{H}_{2} \mathrm{PO}_{4}\right]\right.$; $D\left(\mathrm{H}_{2} \mathrm{PO}_{4}\right)$ and tetrabutylammonium acetate $\left(\mathrm{OAc} ; D_{\mathrm{OAc}}\right)$, corrected for change in viscosity.

\begin{tabular}{|c|c|c|c|c|}
\hline $\begin{array}{c}{\left[\mathrm{NBu}_{4}\right][\text { Anion }]} \\
/ \mathrm{mM}\end{array}$ & $\begin{array}{c}D\left(\mathrm{H}_{2} \mathrm{PO}_{4}\right)^{[\mathrm{b}]} \\
/ \mathrm{m}^{2} \mathrm{~s}^{-1} \times 10^{-10}\end{array}$ & $\begin{array}{c}D\left(\mathrm{NBu}_{4}\right)^{[\mathrm{c}]}\left(\mathrm{H}_{2} \mathrm{PO}_{4}\right) \\
/ \mathrm{m}^{2} \mathrm{~s}^{-1} \times 10^{-10}\end{array}$ & $\begin{array}{c}D(\mathrm{OAc})^{[\mathrm{b}]} \\
/ \mathrm{m}^{2} \mathrm{~s}^{-1} \times 10^{-10}\end{array}$ & $\begin{array}{c}\mathrm{D}\left(\mathrm{NBu}_{4}\right)^{[\mathrm{b}]}(\mathrm{OAc}) \\
/ \mathrm{m}^{2} \mathrm{~s}^{-1} \times 10^{-10}\end{array}$ \\
\hline 2 & $3.17 \pm 0.28$ & $2.52 \pm 0.01$ & $3.96 \pm 0.1$ & $2.53 \pm 0.01$ \\
\hline 5 & $2.99 \pm 0.17$ & $2.52 \pm 0.01$ & $3.90 \pm 0.08$ & $2.53 \pm 0.01$ \\
\hline 10 & $2.63 \pm 0.08$ & $2.50 \pm 0.01$ & $3.70 \pm 0.07$ & $2.53 \pm 0.01$ \\
\hline 20 & $2.51 \pm 0.10$ & $2.51 \pm 0.02$ & $3.63 \pm 0.06$ & $2.48 \pm 0.01$ \\
\hline 50 & $2.16 \pm 0.03$ & $2.50 \pm 0.02$ & $3.57 \pm 0.1$ & $2.40 \pm 0.03$ \\
\hline 100 & $2.08 \pm 0.02$ & $2.53 \pm 0.02$ & $3.72 \pm 0.05$ & $2.49 \pm 0.01$ \\
\hline 200 & $1.80 \pm 0.01$ & $2.49 \pm 0.01$ & $3.68 \pm 0.07$ & $2.52 \pm 0.01$ \\
\hline 300 & $1.71 \pm 0.02$ & $2.48 \pm 0.03$ & $3.61 \pm 0.05$ & $2.39 \pm 0.01$ \\
\hline
\end{tabular}

[a] At concentrations below $20 \mathrm{mM}$ the $\mathrm{H}_{2} \mathrm{PO}_{4}{ }^{-}$anion ( $\mathrm{MW}=97$ ) diffuses more rapidly than the $\left[\mathrm{NBu}_{4}\right]^{+}$cation $(\mathrm{MW}=242)$, but at concentrations higher than $20 \mathrm{mM}$ the diffusion coefficient of $\mathrm{H}_{2} \mathrm{PO}_{4}{ }^{-}$is lower than that of $\left[\mathrm{NBu}_{4}\right]^{+}$. In contrast, the diffusion coefficient of the acetate anion drops slightly until $50 \mathrm{mM}$ concentration, after which it does not lower any further. Measurements compensated for changes in viscosity using the measured viscosity $\left(\left[\mathrm{NBu}_{4}\right]\left[\mathrm{H}_{2} \mathrm{PO}_{4}\right]\right)$, or the measured diffusion of residual DMSO $\left(\left[\mathrm{NBu}_{4}\right][\mathrm{OAc}]\right)$ as an internal standard. DMSO- $d_{6}$ with $0.5 \%$ added $\mathrm{H}_{2} \mathrm{O}, 500 \mathrm{MHz}{ }^{1} \mathrm{H}$. [b] ${ }^{31} \mathrm{P}$ PGSTE, $\delta=7 \mathrm{~ms}, \Delta=100 \mathrm{~ms}, g=0-53.45 \mathrm{G} \mathrm{cm}^{-1}$. [c] ${ }^{1} \mathrm{H}$ PGSTE, $\delta=4 \mathrm{~ms}, \Delta=50 \mathrm{~ms}, g=0-53.45 \mathrm{G} \mathrm{cm}^{-1}$. 


\section{S7. Host-guest association data}

\section{S7.1 Method}

Dilution-corrected NMR titrations were performed by adding aliquots of a solution of guest containing $5 \mathrm{mM}$ host to $5 \mathrm{mM}$ solutions of host (in DMSO- $d_{6} / 0.5 \% \mathrm{H}_{2} \mathrm{O}$. The spectra obtained were processed and analysed using MestReNova software to obtain chemical shift data, which were used to obtain association constants using the processing routines given in Script S1 (see section S11). In all cases, the data was fitted to 1:2 H:G binding models ${ }^{[7]}$ giving $K_{1}$ and $K_{2}$, which are defined as:

$$
K_{1}=\frac{[\mathrm{HG}]}{[\mathrm{H}][\mathrm{G}]}
$$

and

$$
K_{2}=\frac{\left[\mathrm{HG}_{2}\right]}{[\mathrm{HG}][\mathrm{G}]}
$$

with cooperativity a defined as

$$
\alpha=\frac{K_{1}}{4 K_{2}}
$$

For the $E$-host, the urea binding sites were treated as equal, i.e. a non-cooperative $(\alpha=1)$ model was used. For the Z-host, a cooperative model with a floating a was used as two urea groups may be involved in binding one anion. 


\section{S7.2 Addition of tetrabutylammonium dihydrogen phosphate to $E-1$}

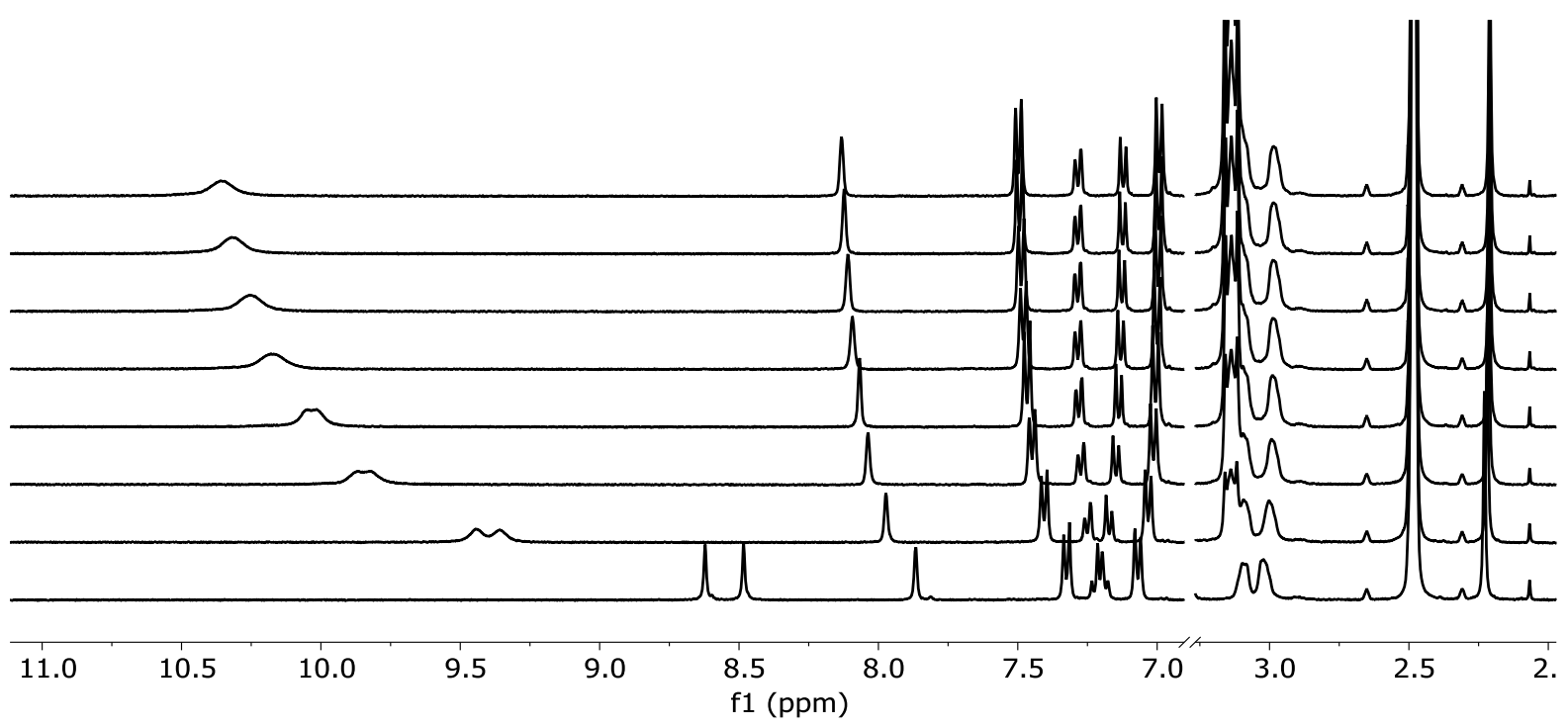

Figure S14. Titration of $50 \mathrm{mM}\left[\mathrm{NBu}_{4}\right]\left[\mathrm{H}_{2} \mathrm{PO}_{4}\right]$ into $5 \mathrm{mM}$ of $E-1.400 \mathrm{MHz}$, DMSO-d $d_{6}+0.5 \% \mathrm{H}_{2} \mathrm{O}$.

$\mathrm{K} 1: 361+/-322$

K2: 90 , alpha: $1.00+/-0.00$
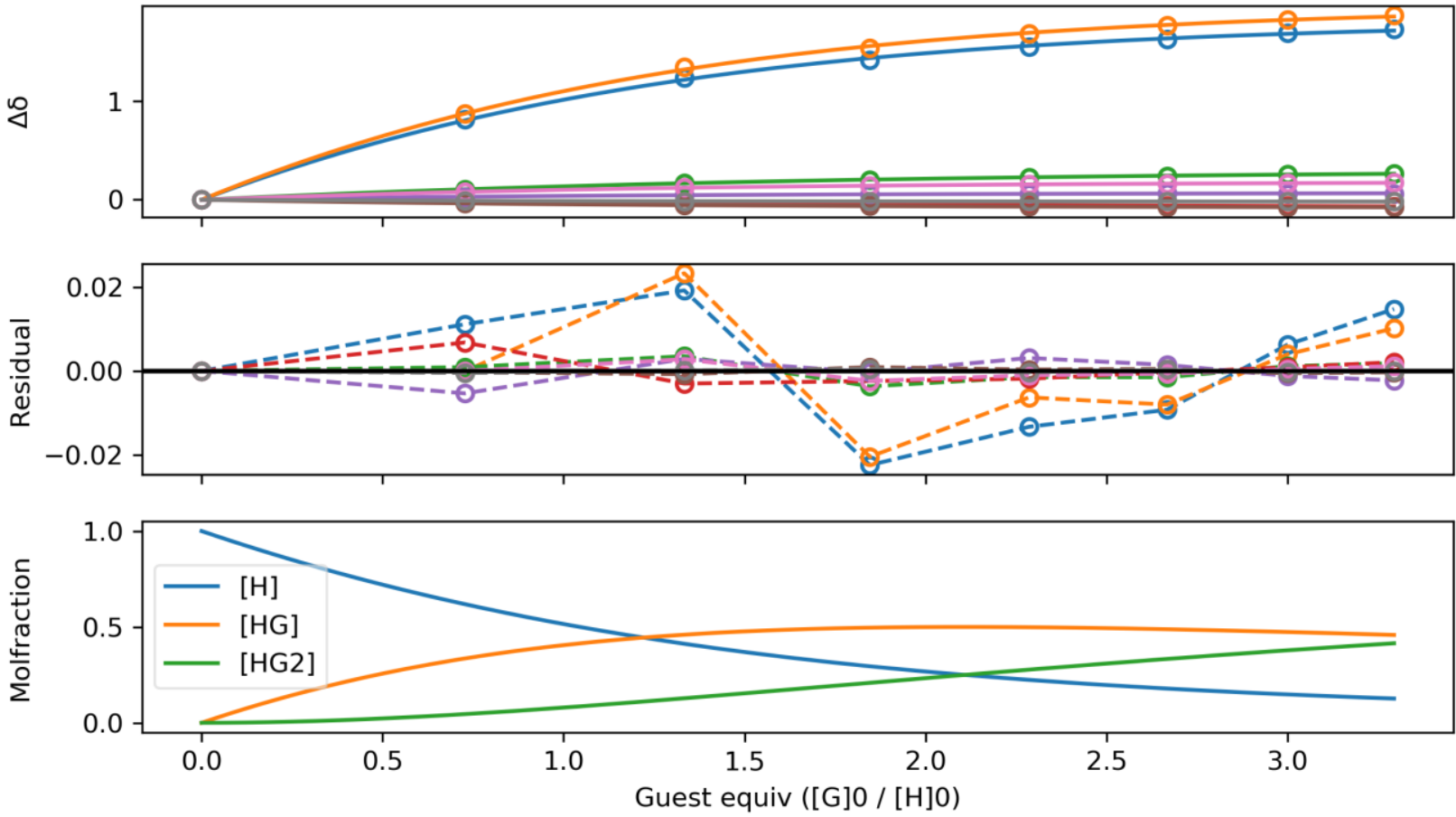

Figure S15. Data from Figure S14 fitted to a non-cooperative 1:2 host:guest association model. $K_{1}=3.6 \times 10^{2} \mathrm{M}^{-1}, K_{2}=9.0 \times 10^{1} \mathrm{M}^{-1}$. 


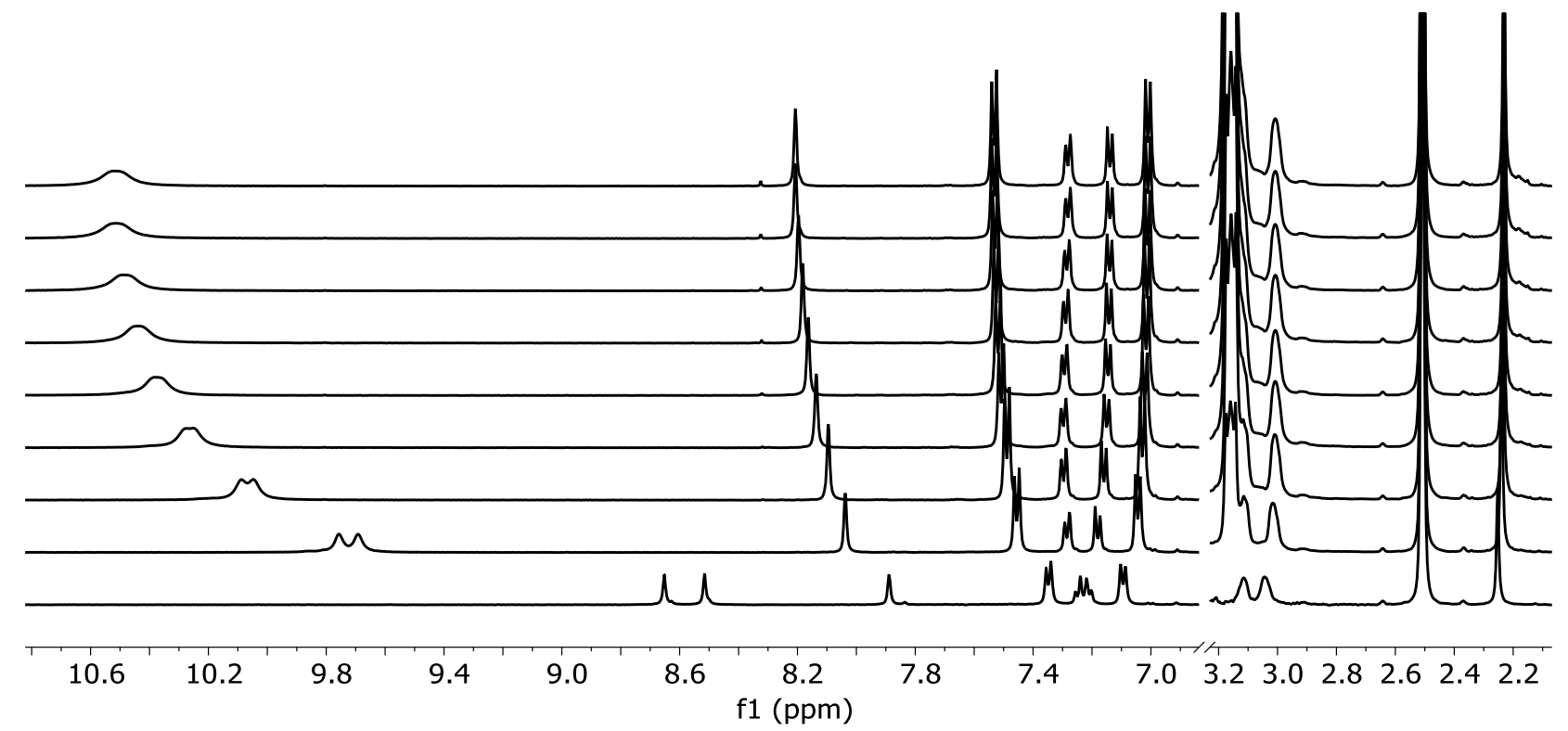

Figure S16. Titration of $50 \mathrm{mM}\left[\mathrm{NBu}_{4}\right]\left[\mathrm{H}_{2} \mathrm{PO}_{4}\right]$ into $5 \mathrm{mM}$ of $E-1.500 \mathrm{MHz}$, DMSO- $d_{6}+0.5 \% \mathrm{H}_{2} \mathrm{O}$.

$\mathrm{K} 1: 226+/-139$
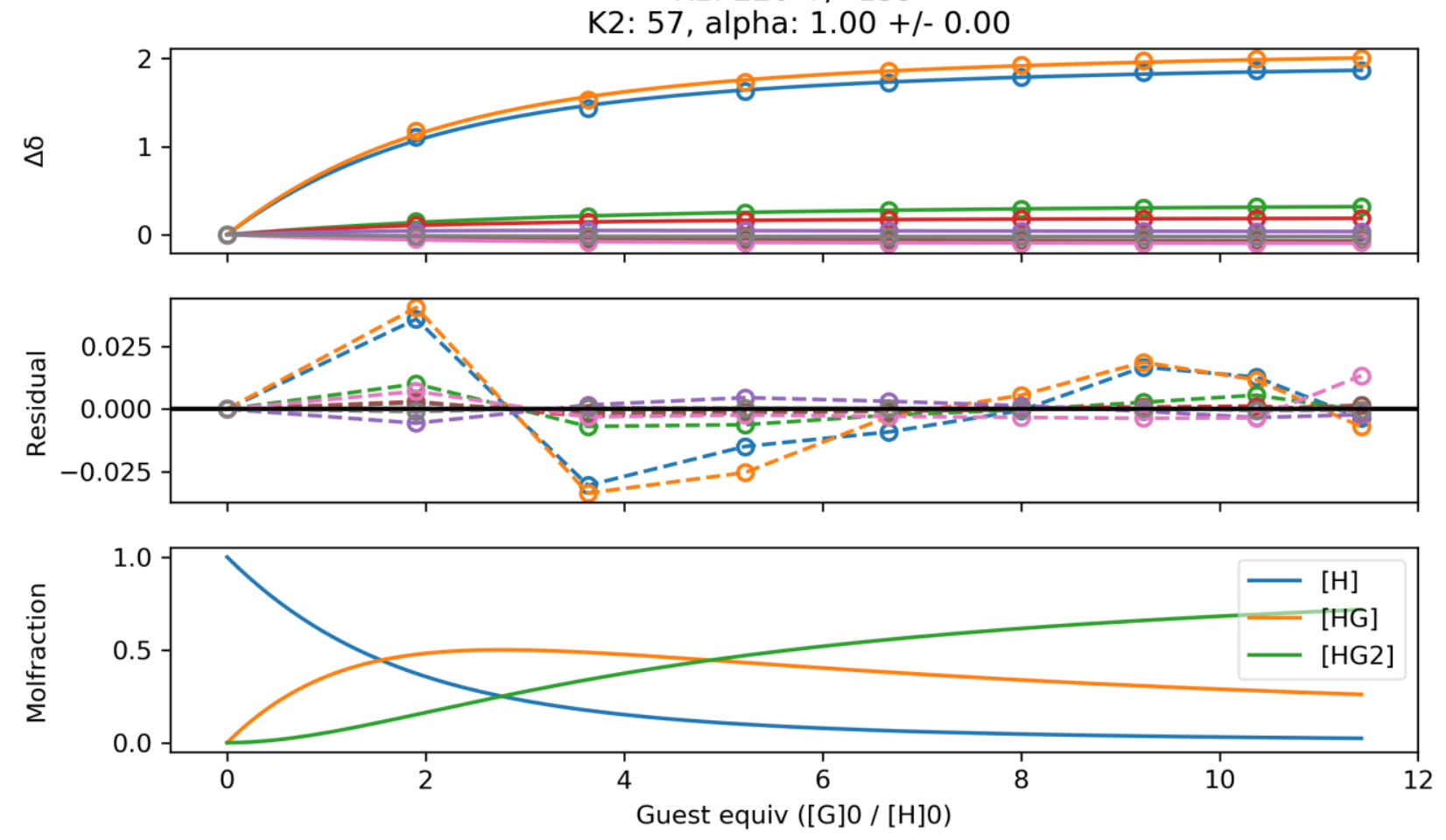

Figure S17. Data from Figure S16 fitted to a non-cooperative 1:2 host:guest association model. $K_{1}=2.3 \times 10^{2}, \mathrm{M}^{-1}, K_{2}=6.0 \times 10^{1} \mathrm{M}^{-1}$. 
S7.3 Addition of tetrabutylammonium dihydrogen phosphate to Z-1 (up to 3 equiv.)

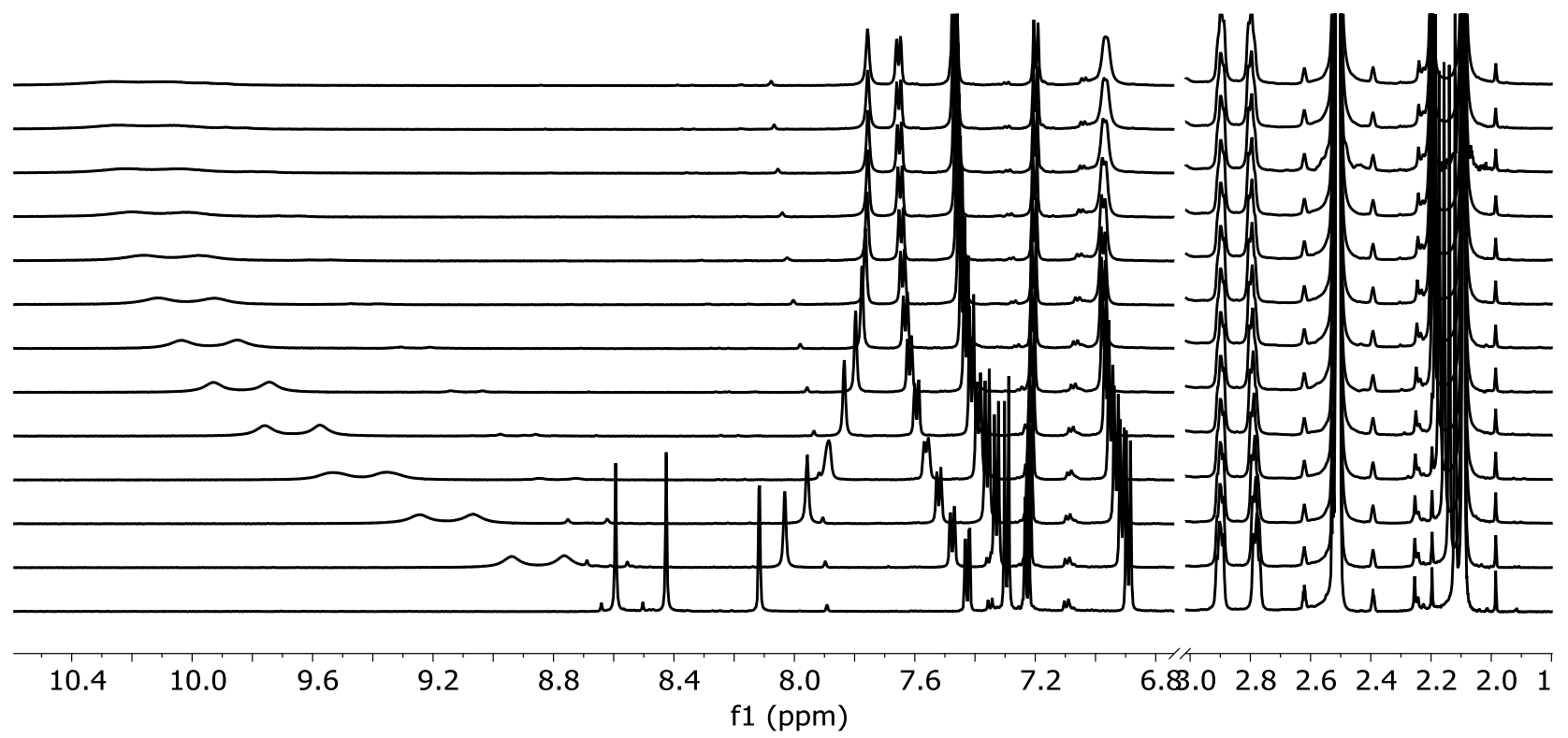

Figure S18. Titration of $50 \mathrm{mM}\left[\mathrm{NBu}_{4}\right]\left[\mathrm{H}_{2} \mathrm{PO}_{4}\right]$ into $5 \mathrm{mM}$ of Z-1, to $9.7 \mathrm{mM}$ guest concentration. $600 \mathrm{MHz}$, DMSO- $d_{6}+0.5 \% \mathrm{H}_{2} \mathrm{O}$.

$\mathrm{K} 1: 2126+/-2120$

K2: 72 , alpha: $0.14+/-0.33$
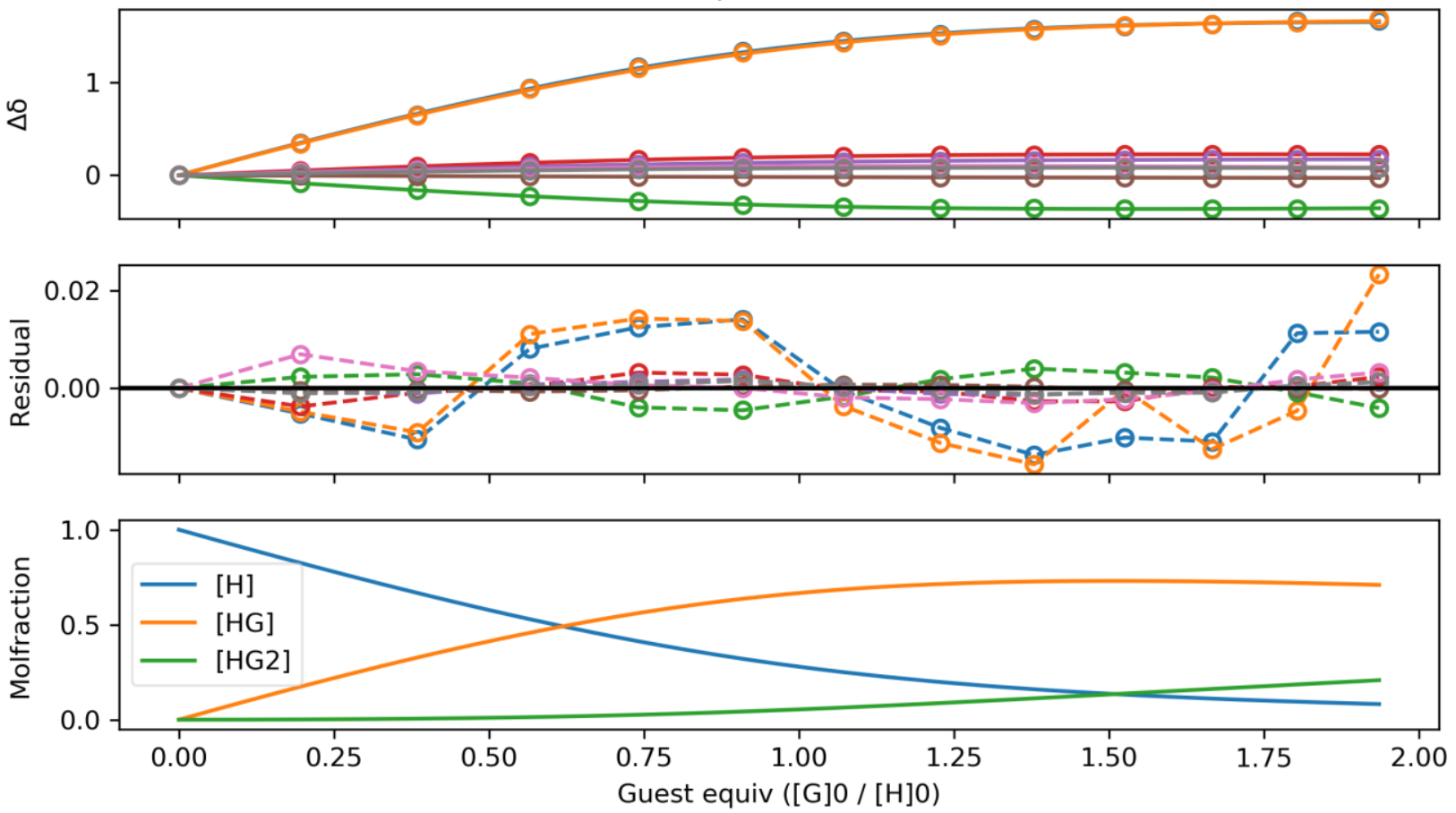

Figure S19.Data from Figure S18 fitted to a 1:2 host:guest association model. $K_{1}=2.1 \times 10^{3} \mathrm{M}^{-1}, K_{2}=7.0 \times 10^{1} \mathrm{M}^{-1}$. 


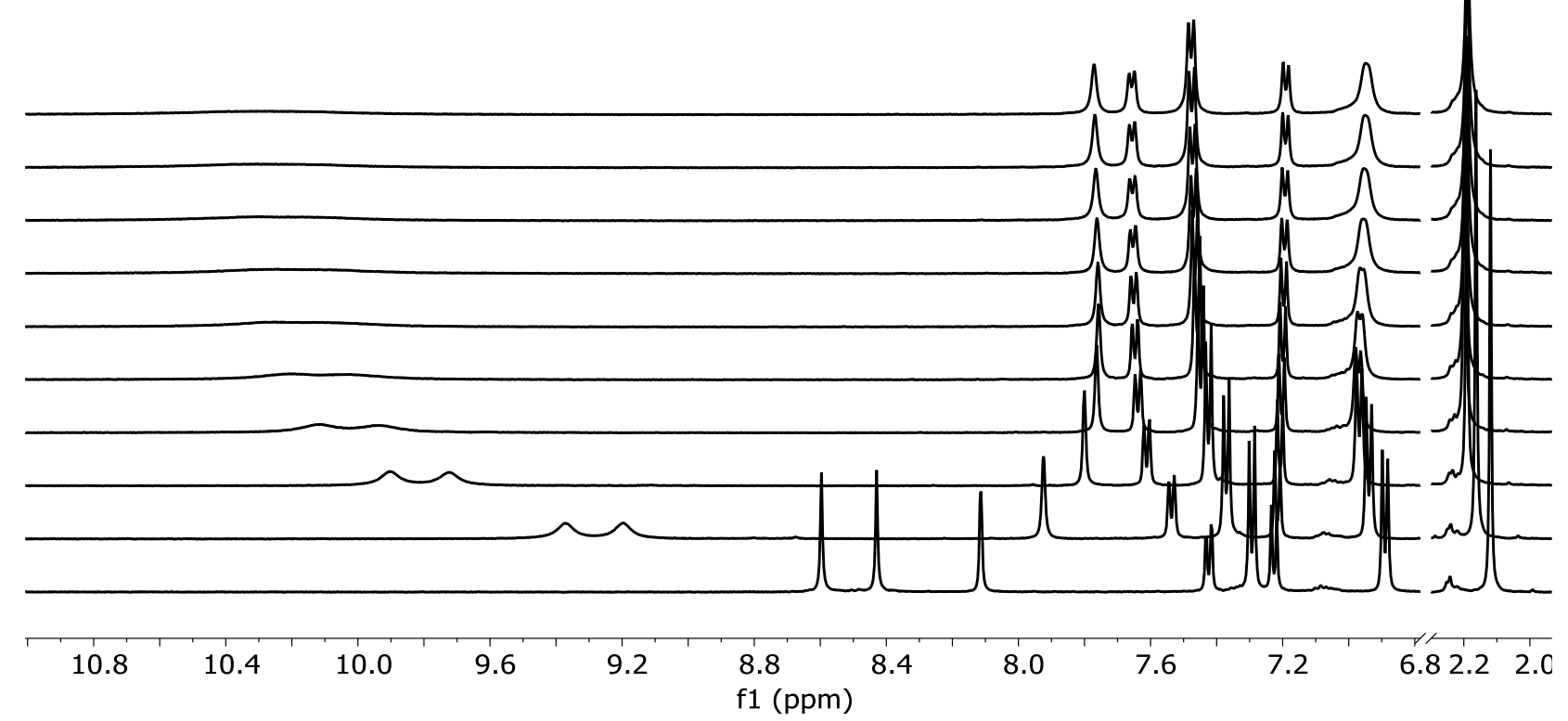

Figure S20. Titration of $50 \mathrm{mM}\left[\mathrm{NBu}_{4}\right]\left[\mathrm{H}_{2} \mathrm{PO}_{4}\right]$ into $5 \mathrm{mM}$ of $Z-1$ to $15.5 \mathrm{mM}$ guest concentration. $500 \mathrm{MHz}$, DMSO- $d_{6}+0.5 \% \mathrm{H}_{2} \mathrm{O}$.

K1: $3491+/-1141$
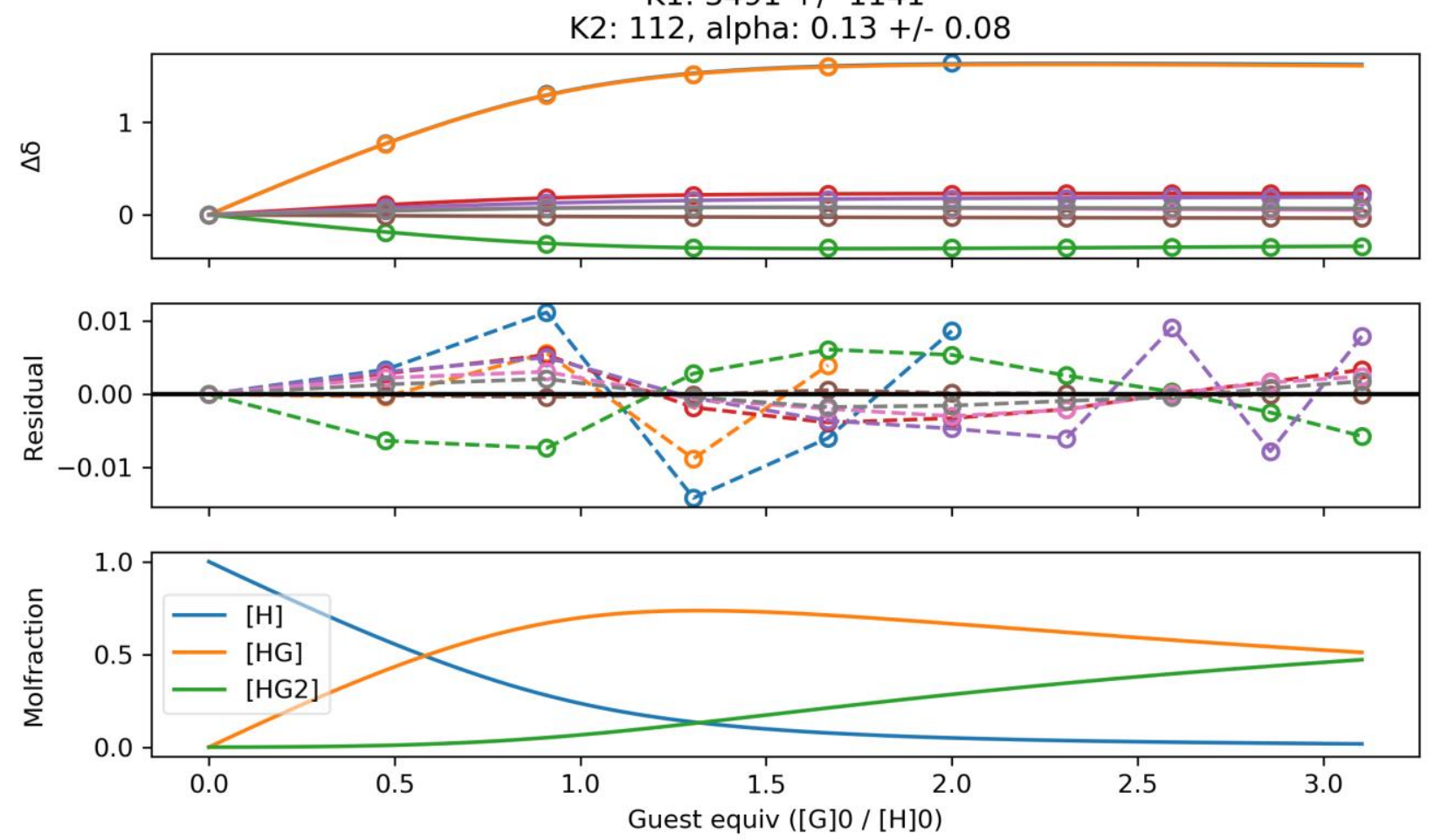

Figure S21. Data from Figure S20 fitted to a 1:2 host:guest association model. $\mathrm{K}_{1}=3.5 \times 10^{3} \mathrm{M}^{-1}, \mathrm{~K}_{2}=1.1 \times 10^{2} \mathrm{M}^{-1}$. 


\section{S7.4 Z-1 dihydrogen phosphate binding fitted to a 1:1 model}
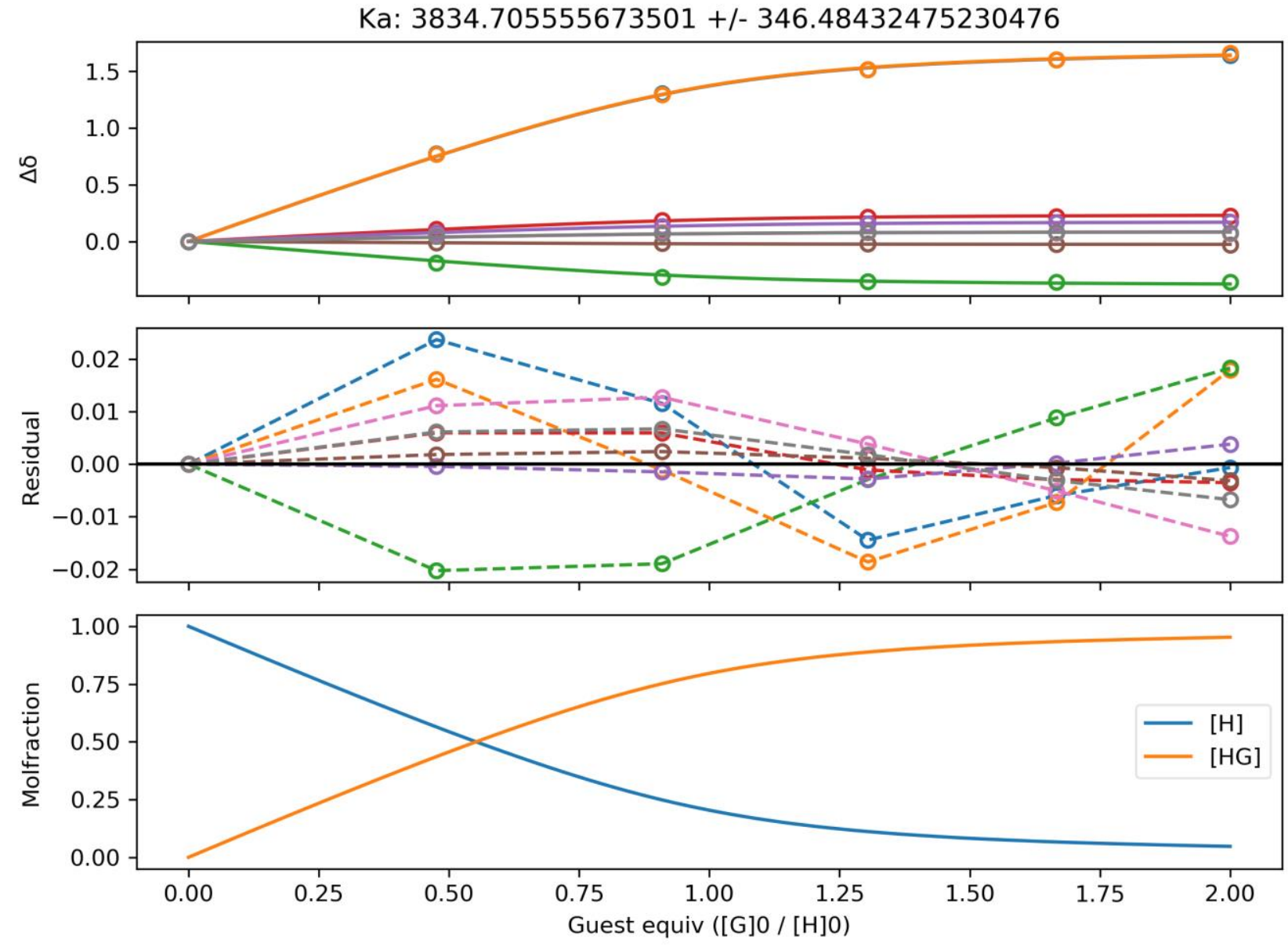

Figure S22. Data from Figure S20 over a low concentration range $\left(5 \mathrm{mM} \mathrm{Z-1,0}-10 \mathrm{mM} \mathrm{NBu} \mathrm{H}_{2} \mathrm{PO}_{4}\right)$ fitted to a 1:1 host:guest association model. $K_{1}=3.8 \pm 0.3 \times 10^{3} \mathrm{M}^{-1}$, within error of the value found for a 2:1 binding model in Figure S21. 


\section{S7.5 Addition of tetrabutylammonium dihydrogen phosphate to Z-1 (beyond 3 equiv.)}
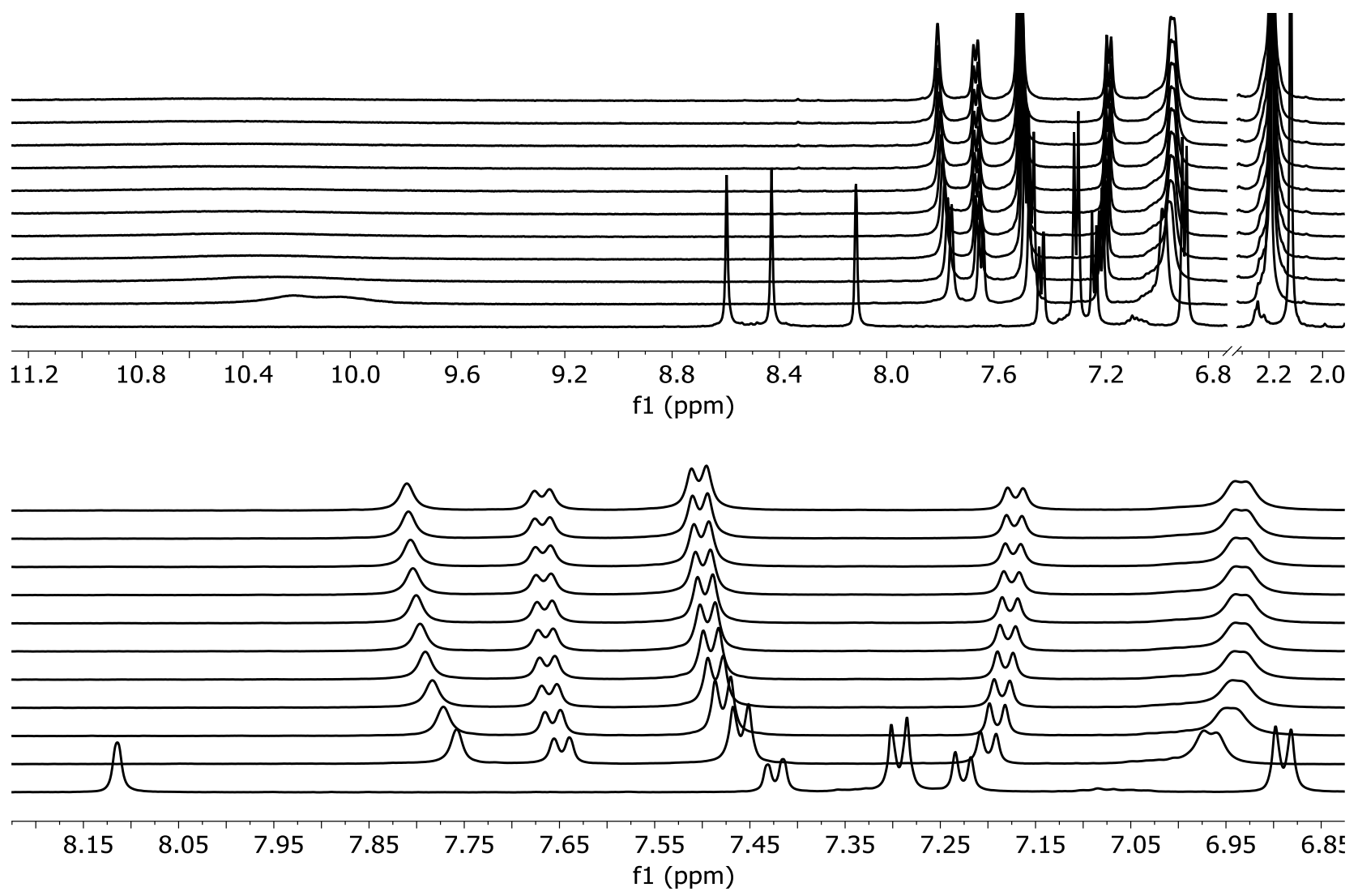

Figure S23. Titration of $200 \mathrm{mM}\left[\mathrm{NBu}_{4}\right]\left[\mathrm{H}_{2} \mathrm{PO}_{4}\right]$ into $5 \mathrm{mM}$ of $\mathrm{Z}-1$ to $66.7 \mathrm{mM}$ guest concentration. $500 \mathrm{MHz}$, DMSO-d $+0.5 \% \mathrm{H}_{2} \mathrm{O}$. Bottom: the same spectrum, zoomed to focus on the aromatic region and exclude the coalesced urea $\mathrm{NH}$ peaks.

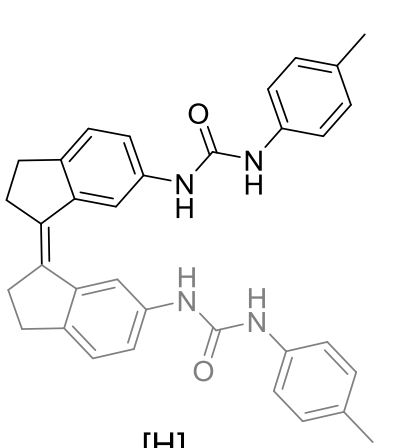

$[\mathrm{H}]$

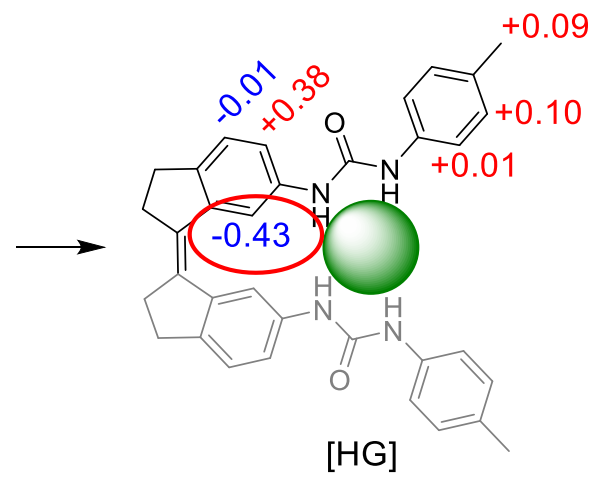

$[H G]$

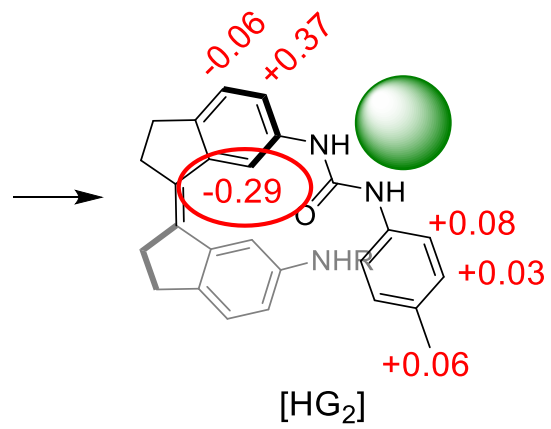

$\left[\mathrm{HG}_{2}\right]$

Figure S24. Changes in ${ }^{1} \mathrm{H}$ NMR chemical shifts of of the $[\mathrm{HG}]$ and $\left[\mathrm{HG}_{2}\right]$ complexes of $Z-1$ relative to the free host (ppm, relative to those of free $[\mathrm{H}]$ ) as obtained from the 1:2 nonlinear fit of the ${ }^{1} \mathrm{H}$ NMR titration data. The fitted chemical shift changes support the two-step binding fit proposed for the $Z$ isomer in Figure S25. Most notably, the inner aryl proton (circled) is first shielded and then deshielded by the two steps of binding. This is consistent with the expected chemical shift induced by the carbonyl group magnetic anisotropy. 
K1: $13240+/-8663$

K2: 72, alpha: $0.02+/-0.02$
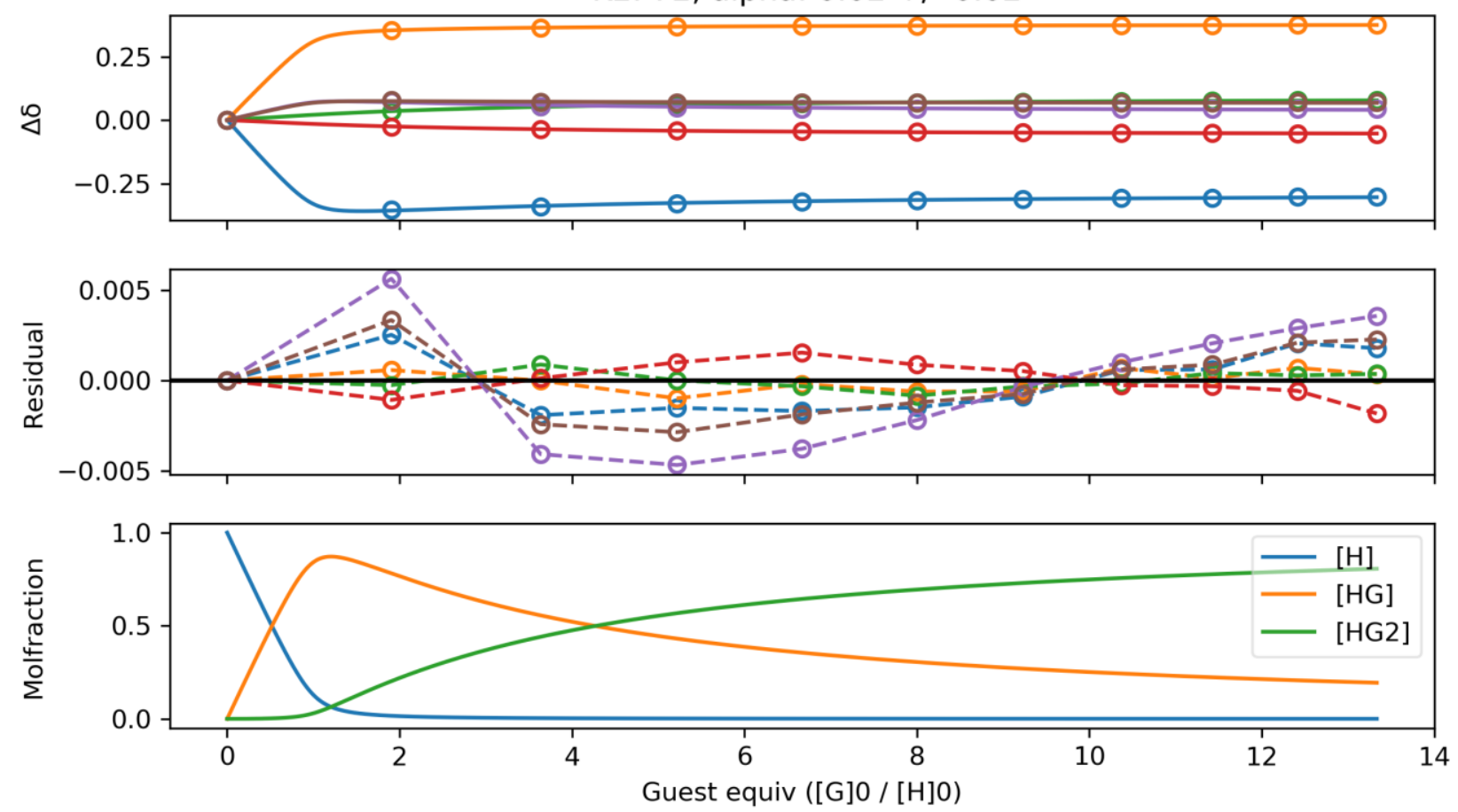

Figure S25. Data shown in Figure S23 fitted to a 1:2 host:guest association model. $K_{1}=13 \times 10^{3} \mathrm{M}^{-1}, K_{2}=7 \times 10^{1} \mathrm{M}^{-1}$. 


\section{S7.6 Addition of tetrabutylammonium acetate to $E-1$}

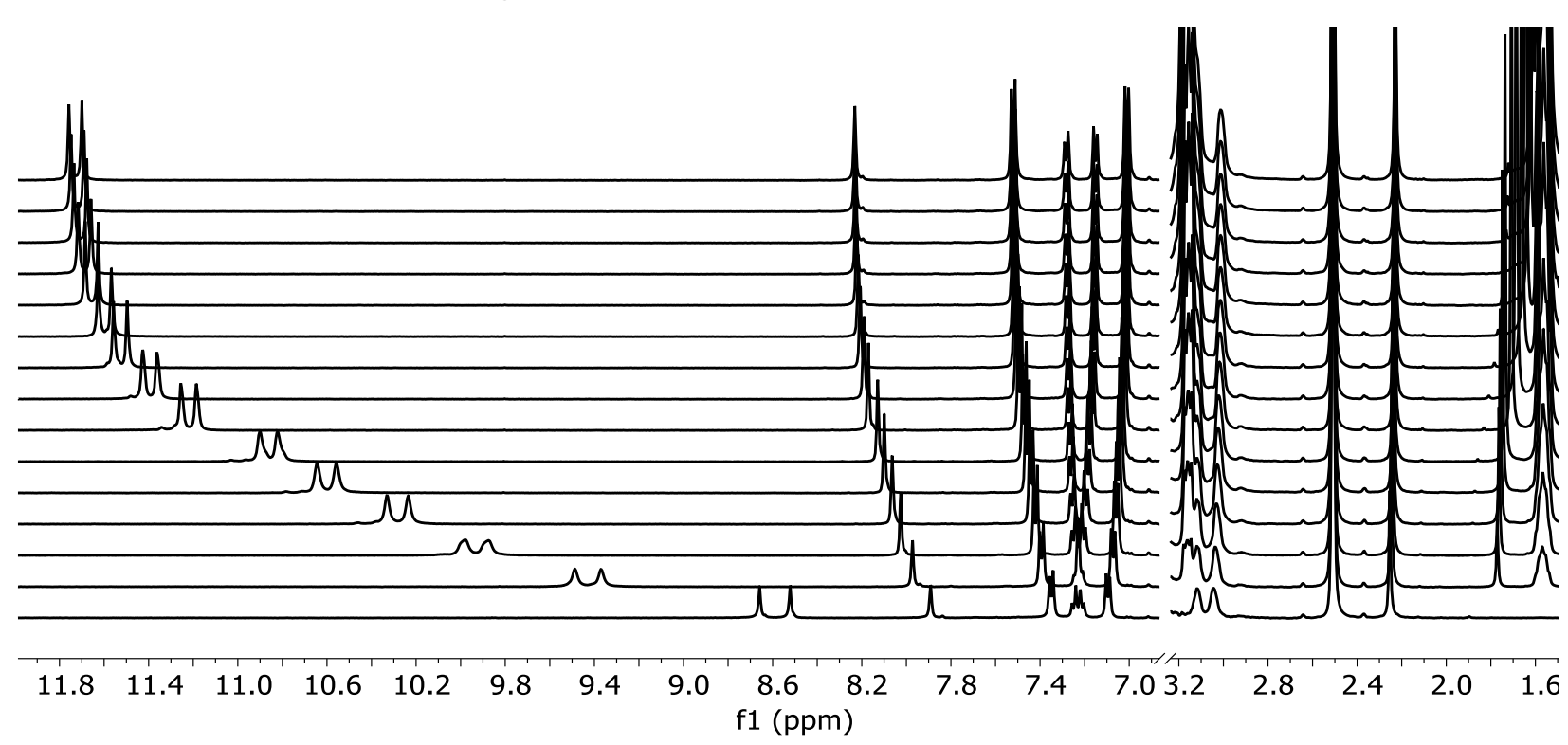

Figure S26. Titration of $200 \mathrm{mM}\left[\mathrm{NBu}_{4}\right][\mathrm{OAc}]$ into $5 \mathrm{mM}$ of $E-1.500 \mathrm{MHz}$, DMSO- $d_{6}+0.5 \% \mathrm{H}_{2} \mathrm{O}$.

$\mathrm{K} 1: 332+/-35$

K2: 83 , alpha: $1.00+/-0.00$
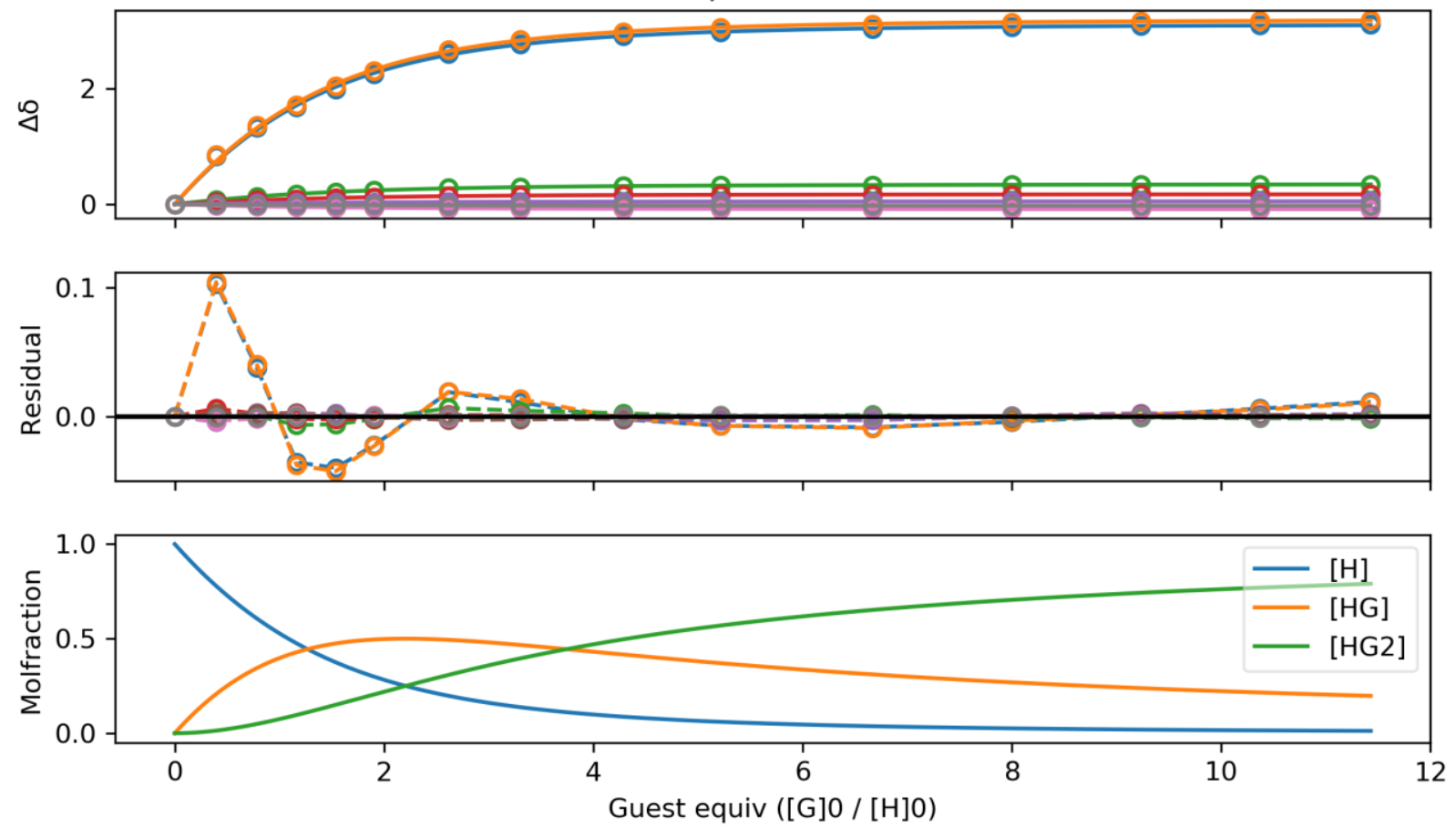

Figure S27. Data from Figure S26 fitted to a non-cooperative 1:2 host:guest association model. $K_{1}=3.3 \times 10^{2} \mathrm{M}^{-1}, K_{2}=8.3 \times 10^{1} \mathrm{M}^{-1}$. 


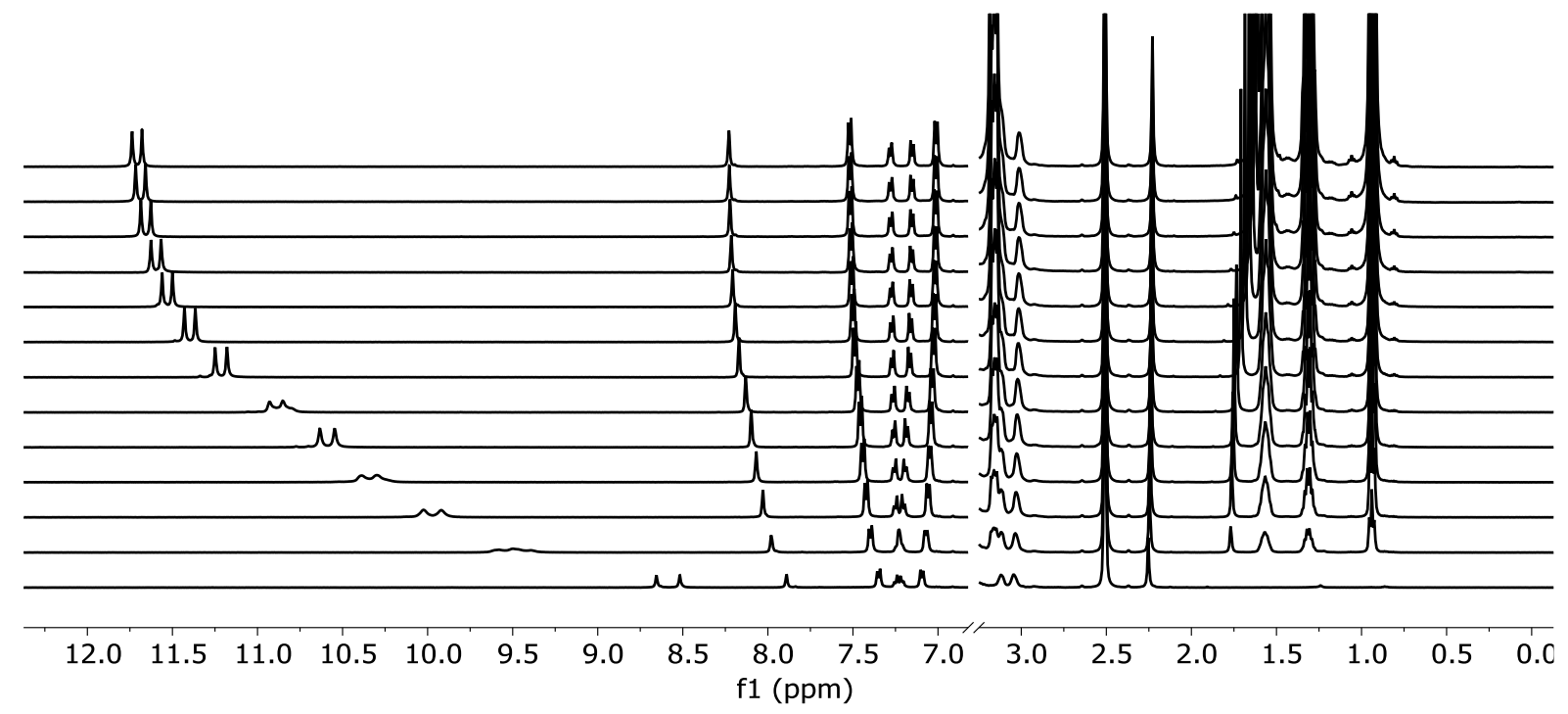

Figure S28. Titration of $200 \mathrm{mM}\left[\mathrm{NBu}_{4}\right][\mathrm{OAc}]$ into $5 \mathrm{mM}$ of $E-1.500 \mathrm{MHz}$, DMSO- $d_{6}+0.5 \% \mathrm{H}_{2} \mathrm{O}$.

$\mathrm{K} 1: 350+/-93$

K2: 87 , alpha: $1.00+/-0.00$
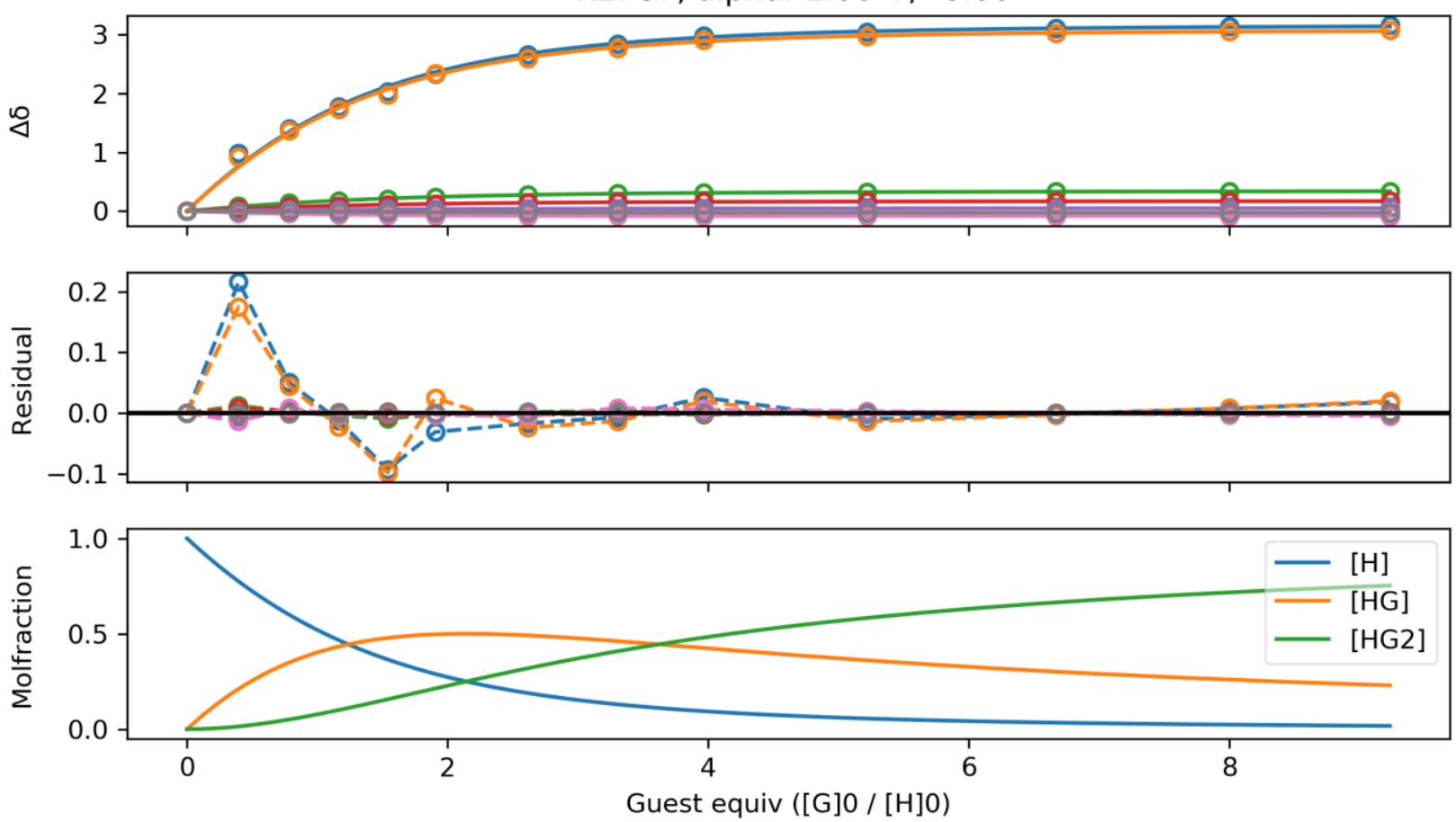

Figure S29. Data from Figure S28 fitted to a non-cooperative 1:2 host:guest association model. $K_{1}=3.5 \times 10^{2} \mathrm{M}^{-1}, K_{2}=8.7 \times 10^{1} \mathrm{M}^{-1}$. 


\section{S7.7 Addition of tetrabutylammonium acetate to Z-1}

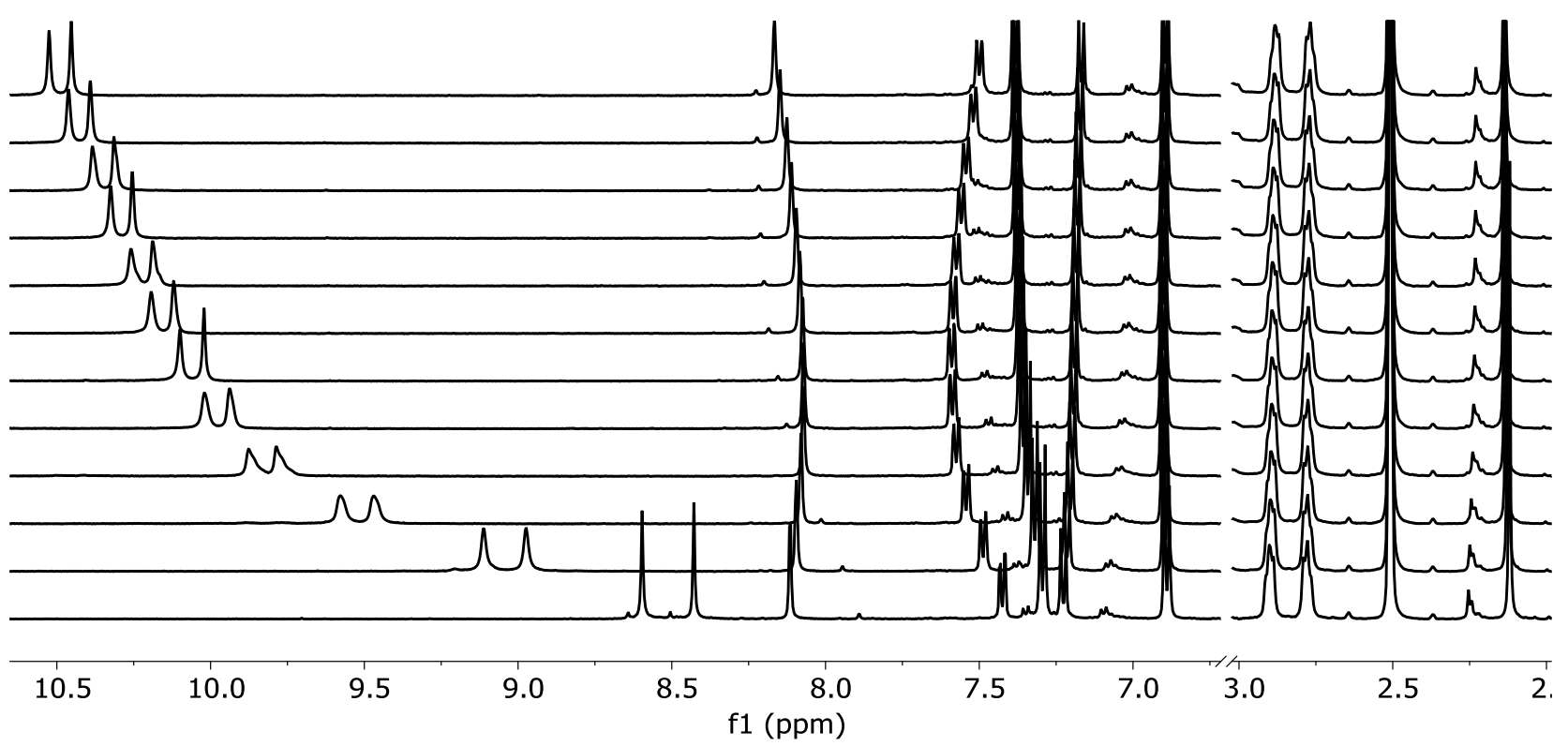

Figure S30. Titration of $200 \mathrm{mM}\left[\mathrm{NBu}_{4}\right][\mathrm{OAc}]$ into $5 \mathrm{mM}$ of $Z-1.500 \mathrm{MHz}$, DMSO- $d_{6}+0.5 \% \mathrm{H}_{2} \mathrm{O}$.

$\mathrm{K} 1: 1826+/-221$

K2: 7 , alpha: $0.01+/-0.01$
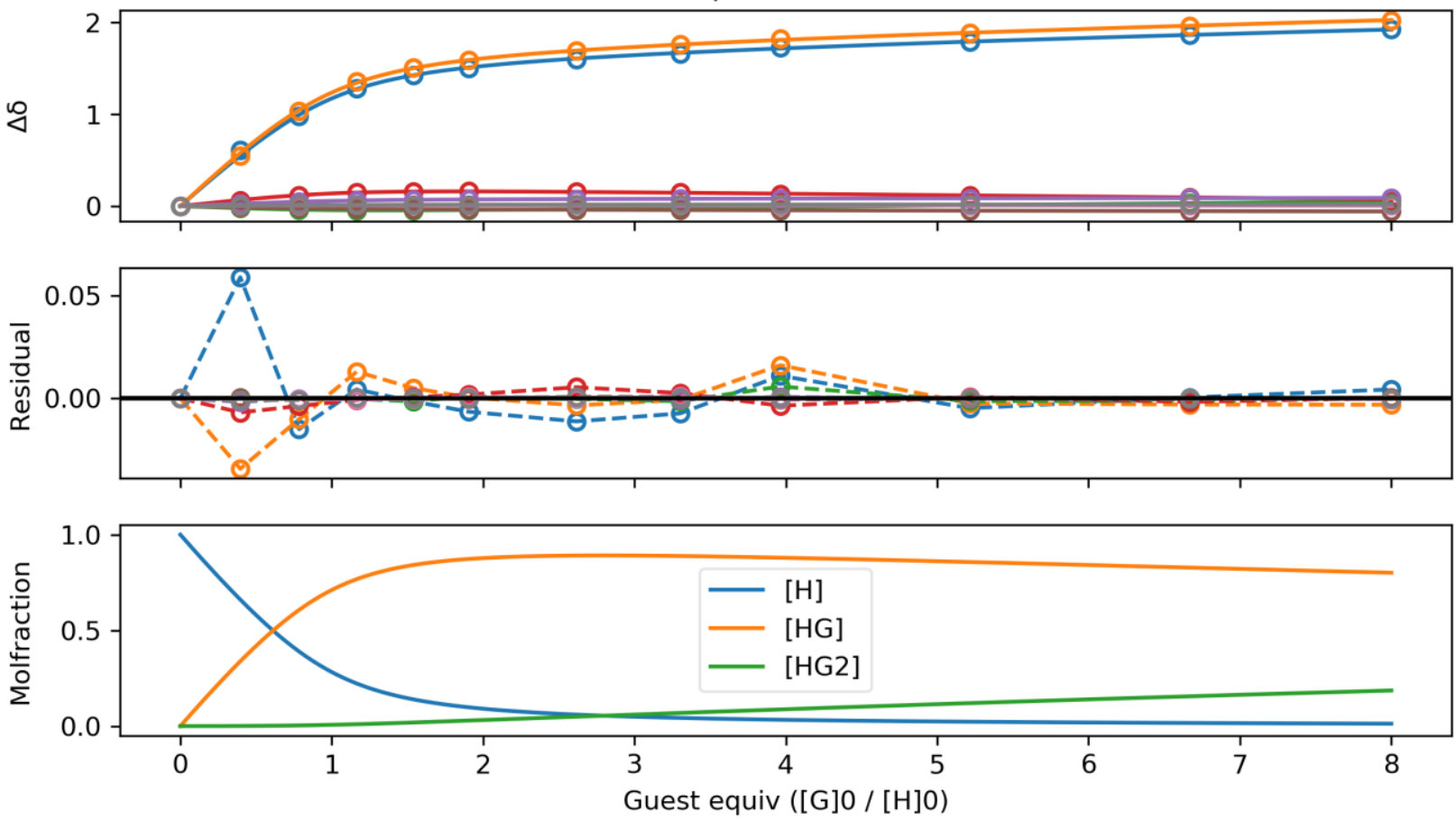

Figure S31. Data from Figure S30 fitted to a 1:2 host:guest association model. $K_{1}=1.8 \times 10^{3}, \mathrm{M}^{-1}, K_{2}=7 \mathrm{M}^{-1}$ 


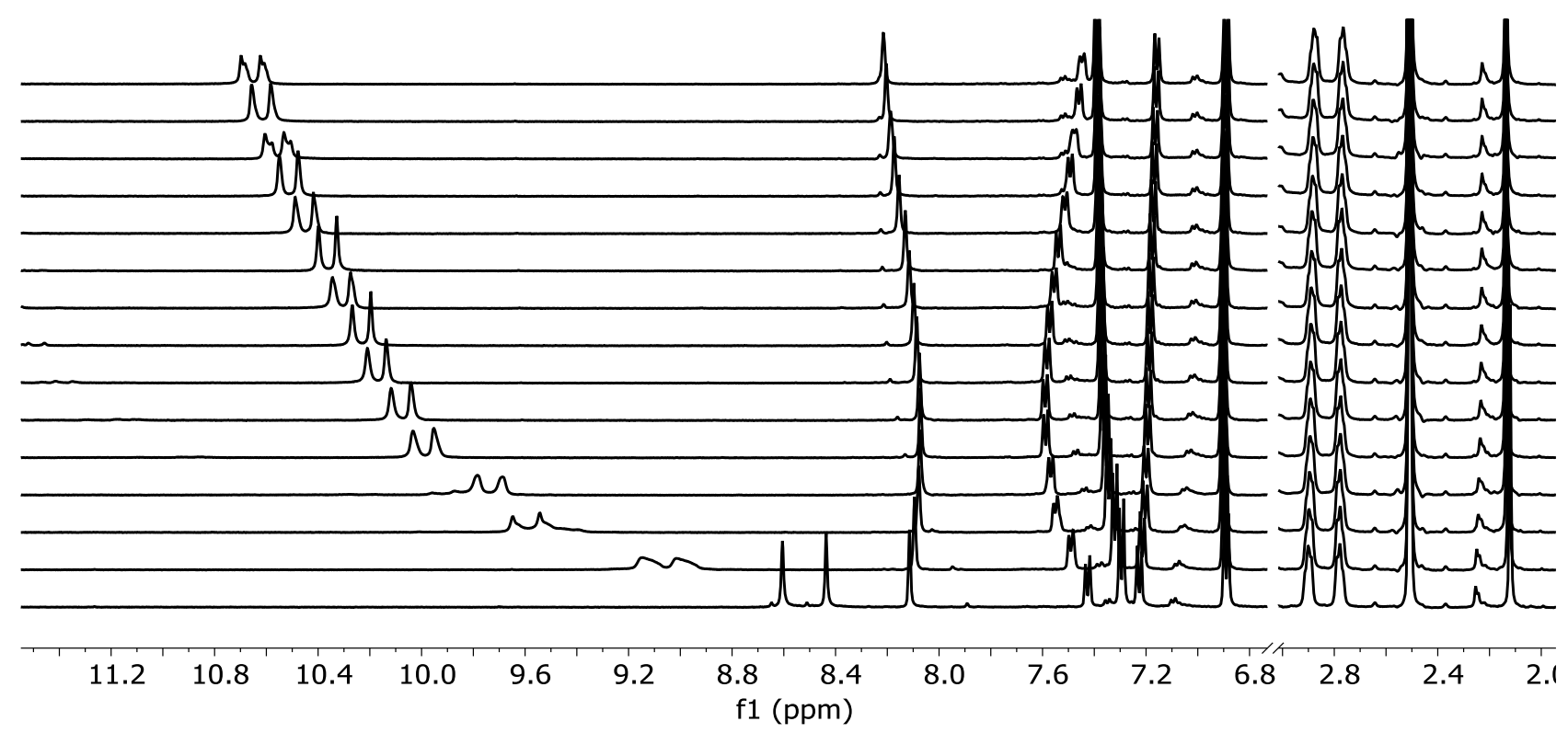

Figure S32. Titration of $200 \mathrm{mM}\left[\mathrm{NBu}_{4}\right][\mathrm{OAc}]$ into $5 \mathrm{mM}$ of $Z-1.500 \mathrm{MHz}$, DMSO- $d_{6}+0.5 \% \mathrm{H}_{2} \mathrm{O}$.

K1: $1503+/-196$

K2: 5, alpha: $0.01+/-0.01$
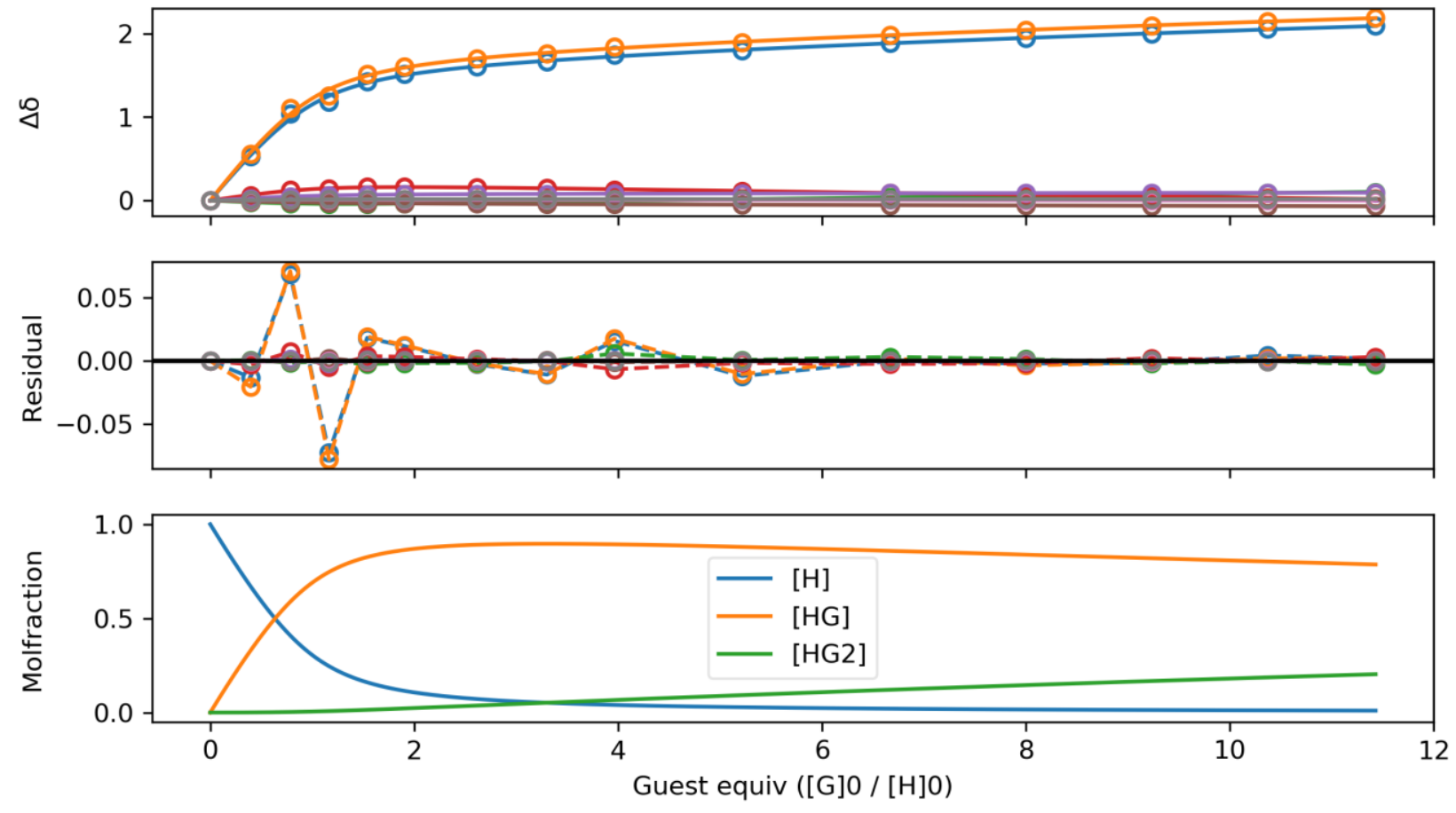

Figure S33. Data from Figure S32 fitted to a 1:2 host:guest association model. $K_{1}=1.5 \times 10^{3}, \mathrm{M}^{-1}, K_{2}=5 \mathrm{M}^{-1}$. 


\section{S7.8 Summary of binding data}

Calculated association constants for binding of acetate and dihydrogen phosphate to 1 are summarized here and compared to literature values for the previously reported phenyl-substituted stiff stilbene host S2 (Figure S34).

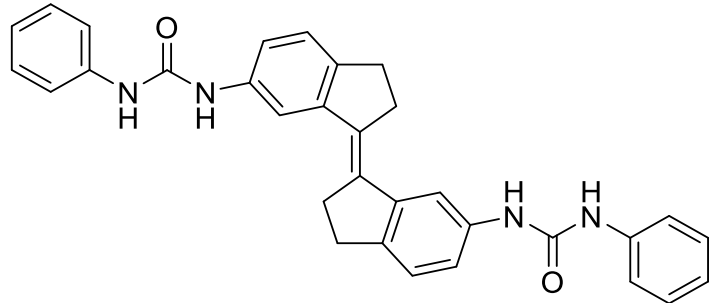

E-S2

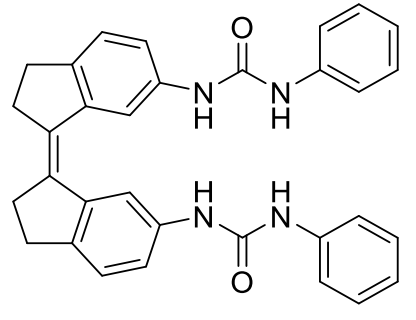

Z-S2

Figure S34. Anion-binding stiff stilbene hosts characterized in the literature. ${ }^{[3]}$ These diphenyl bisurea hosts only differ from $p$-tolylurea host 1 in the absence of a methyl group on the terminal aryl rings, and are thus expected to possess similar guest-binding properties.

\section{S7.9 Summary of dihydrogen phosphate binding data}

As discussed in detail in S7.11, the standard models of host-guest association are inapplicable here due to the self-associating nature of the $\mathrm{H}_{2} \mathrm{PO}_{4}^{-}$anion. One consequence of this is that the estimated errors obtained through nonlinear least-squares regression are nonsensical, as the experimental data is not randomly distributed about the model used. The results obtained for 1 binding $\mathrm{H}_{2} \mathrm{PO}_{4}$ are presented here for completeness and for comparison to previous studies, but we again caution that they are obtained using an approach fundamentally inadequate for this associative process.

Table S7. Summary of data for host 1 binding $\mathrm{H}_{2} \mathrm{PO}_{4}^{-}\left(\right.$as $\left[\mathrm{NBu}_{4}\right]\left[\mathrm{H}_{2} \mathrm{PO}_{4}\right]$; DMSO-d $\left.\mathrm{d}_{6}+0.5 \% \mathrm{H}_{2} \mathrm{O}\right)$.

\begin{tabular}{|c|c|c|c|c|c|c|c|}
\hline Species & $E-1^{[\mathrm{a}]}$ & $E-1^{\text {[a] }}$ & $E-S 2^{[b]}$ & $Z-1^{[\mathrm{a}]}$ & $Z_{-1}^{[\mathrm{a}]}$ & $Z-1^{[\mathrm{a}]}$ & $Z-S 2^{[b]}$ \\
\hline $\begin{array}{c}\mathrm{H}_{2} \mathrm{PO}_{4}^{-} \text {endpoint } \\
/ \mathrm{mM}\end{array}$ & 18 & 57 & & 9.8 & 15.5 & 67 & \\
\hline$K_{1} / \mathrm{M}^{-1}$ & $3.6 \pm 3.2 \times 10^{2}$ & $2.3 \pm 3.2 \times 10^{2}$ & $1.5 \times 10^{2}$ & $2.1 \pm 2.1 \times 10^{3}$ & $3.5 \pm 1.1 \times 10^{3}$ & $1.3 \pm 0.8 \times 10^{4}$ & $2.0 \times 10^{3}$ \\
\hline$K_{2} / \mathrm{M}^{-1}$ & 90 & 60 & 39 & 70 & 110 & 72 & - \\
\hline$\alpha$ & & Forced as 1 & & $0.14 \pm 0.33$ & $0.13 \pm 0.08$ & $0.02 \quad 0.02$ & - \\
\hline
\end{tabular}

[a] Measured association constants for compound 1; [b] Literature association constants for analogous compound S2. ${ }^{[3]}$

\section{S7.10 Summary of acetate binding data}

Table S8. Summary of data for host 1 binding OAc- $\left(\right.$ as $\left[\mathrm{NBu}_{4}\right][\mathrm{OAc}]$; DMSO- $\left.\mathrm{d}_{6}+0.5 \% \mathrm{H}_{2} \mathrm{O}\right)$.

\begin{tabular}{|c|c|c|c|c|c|c|}
\hline & $E-1^{[\mathrm{a}]}$ & $E-1^{[\mathrm{a}]}$ & $E-S 2^{[b]}$ & $Z-1^{[a]}$ & $Z-1^{[a]}$ & $\mathbf{Z}-\mathbf{S 2}^{[\mathrm{b}]}$ \\
\hline $\begin{array}{c}\text { OAc- Endpoint } \\
\qquad / \mathrm{mM}\end{array}$ & 57 & 8.6 & & 40 & 57 & \\
\hline$K_{1} / \mathrm{M}^{-1}$ & $3.3 \pm 0.35 \times 10^{2}$ & $3.5 \pm 0.9 \times 10^{2}$ & $2.1 \times 10^{2}$ & $1.8 \pm 0.2 \times 10^{3}$ & $1.5 \pm 0.2 \times 10^{3}$ & $1.4 \times 10^{3}$ \\
\hline$K_{2} / \mathrm{M}^{-1}$ & 83 & 87 & 52 & 7 & 5 & - \\
\hline$\alpha$ & & Forced as 1 & & $0.01 \pm 0.01$ & $0.01 \pm 0.01$ & \\
\hline
\end{tabular}

[a] Measured association constants for compound 1; [b] Literature association constants for analogous compound S2. ${ }^{[3]}$ 


\section{S7.11 Host-guest binding models with an aggregating guest}

The self-association of dihydrogen phosphate described here can make determination of binding constants challenging. Considering a minimal case of host-guest binding with a 1:1 stoichiometry and no self-association for either host or guest, the concentration of free guest [G] can be found by solving the quadratic:[7]

$$
0=[\mathrm{G}]^{2}-[\mathrm{G}]\left([\mathrm{G}]_{0}-[\mathrm{H}]_{0}-\frac{1}{K_{a}}\right)-\frac{[\mathrm{G}]_{0}}{K_{a}}
$$

where $[\mathrm{G}]_{0}$ and $[\mathrm{H}]_{0}$ are respectively the total concentration of guest and host, and $K_{a}$ is the association constant. This quadratic derives from the definition of an association constant and the mass balances for each of host and guest, as shown below:

$$
\begin{aligned}
K_{a} & =\frac{[\mathrm{HG}]}{[\mathrm{H}][\mathrm{G}]} \\
{[\mathrm{G}]_{0} } & =[\mathrm{G}]+[\mathrm{HG}] \\
{[\mathrm{H}]_{0} } & =[\mathrm{H}]+[\mathrm{HG}]
\end{aligned}
$$

If the guest is capable of indefinite self-association, constructing such a model for host-guest binding becomes more challenging. With infinite oligo-guest species present in solution, if the host binding site is capable of binding not only monomeric $G$ but also $G_{2}$ dimers, $G_{3}$ trimers, $G_{4}$ tetramers etc there is no longer a single guest but instead many different guest oligomer species that cannot be distinguished. Therefore, there is not a single host-guest association constant, $K_{\mathrm{a}}$, capable of reflecting the infinite possible host-guest interactions in solution. The mass balance equations for such a system are also complex:

$$
\begin{gathered}
{[\mathrm{G}]_{0}=\sum_{n=1}^{\infty} n\left[\mathrm{G}_{n}\right]+\sum_{n=1}^{\infty} n\left[\mathrm{HG}_{n}\right]} \\
{[\mathrm{H}]_{0}=[\mathrm{H}]+\sum_{n=1}^{\infty}\left[\mathrm{HG}_{n}\right]}
\end{gathered}
$$

Modelling the titration data to such complicated competitive systems is beyond the scope of this work. Instead, we use the standard equations of host-guest binding $\left(S 7.1^{[7]}\right)$ that assume that the guest can only exist in free or host-bound forms and that all host-guest complexes are identical.

It may be possible to measure $K_{a}$ if the speciation due to one process (i.e. host-guest binding) can be varied while the other process (i.e. the isodesmic self-association) does not change. In practice this requires the two association constants to be sufficiently different that one process can be ignored over a limited concentration range where changes due to the other process can be observed (e.g. measurement of strong association at low concentrations). 


\section{S8. Diffusion of static host-guest systems}

\section{S8.1 Diffusion measurements with a single host}

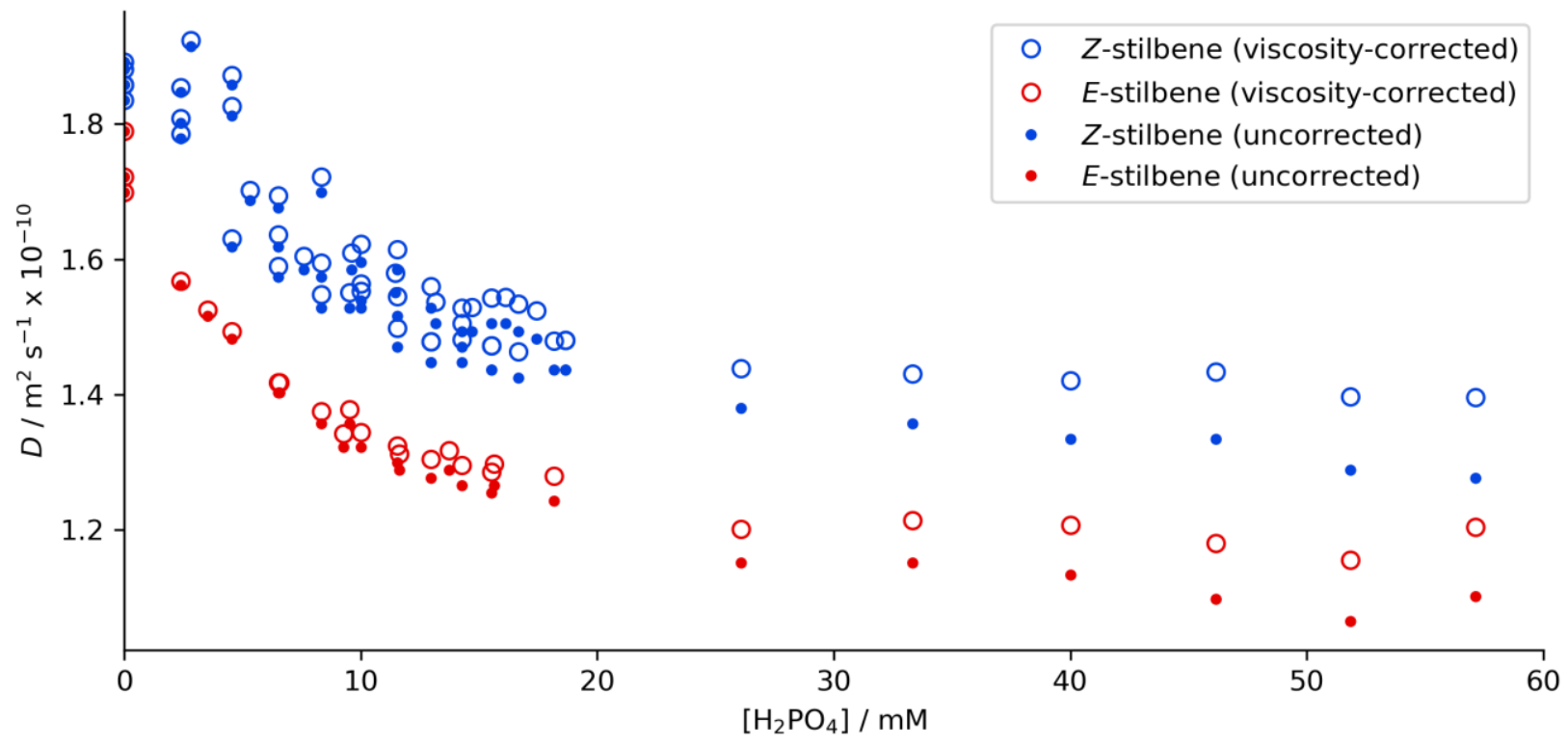

Figure S35. Measured diffusion coefficients for separate $5 \mathrm{mM}$ solutions of pure $E$ or $Z$ hosts titrated with $\left[\mathrm{H}_{2} \mathrm{PO}_{4}\right]$, presented on a single axis for clarity. Diffusion coefficients as-acquired are shown as solid points; diffusion coefficients corrected for changes in viscosity from to increasing $\left[\mathrm{H}_{2} \mathrm{PO}_{4}\right]$ are shown as empty circles (linear correction from directly measured viscosities of $\left[\mathrm{NBu}_{4}\right]\left[\mathrm{H}_{2} \mathrm{PO}_{4}\right]$ solutions; see Figure S6). Each point represents one diffusion experiment. $500 \mathrm{MHz}{ }^{1} \mathrm{H}, \Delta=50 \mathrm{~ms}, \delta=4 \mathrm{~ms}$, linear ramp of 12 gradients from $g=0-$ $53.45 \mathrm{~g} \mathrm{~cm}^{-1}$.

\section{S8.2 Control experiments with tetrabutylammonium acetate}

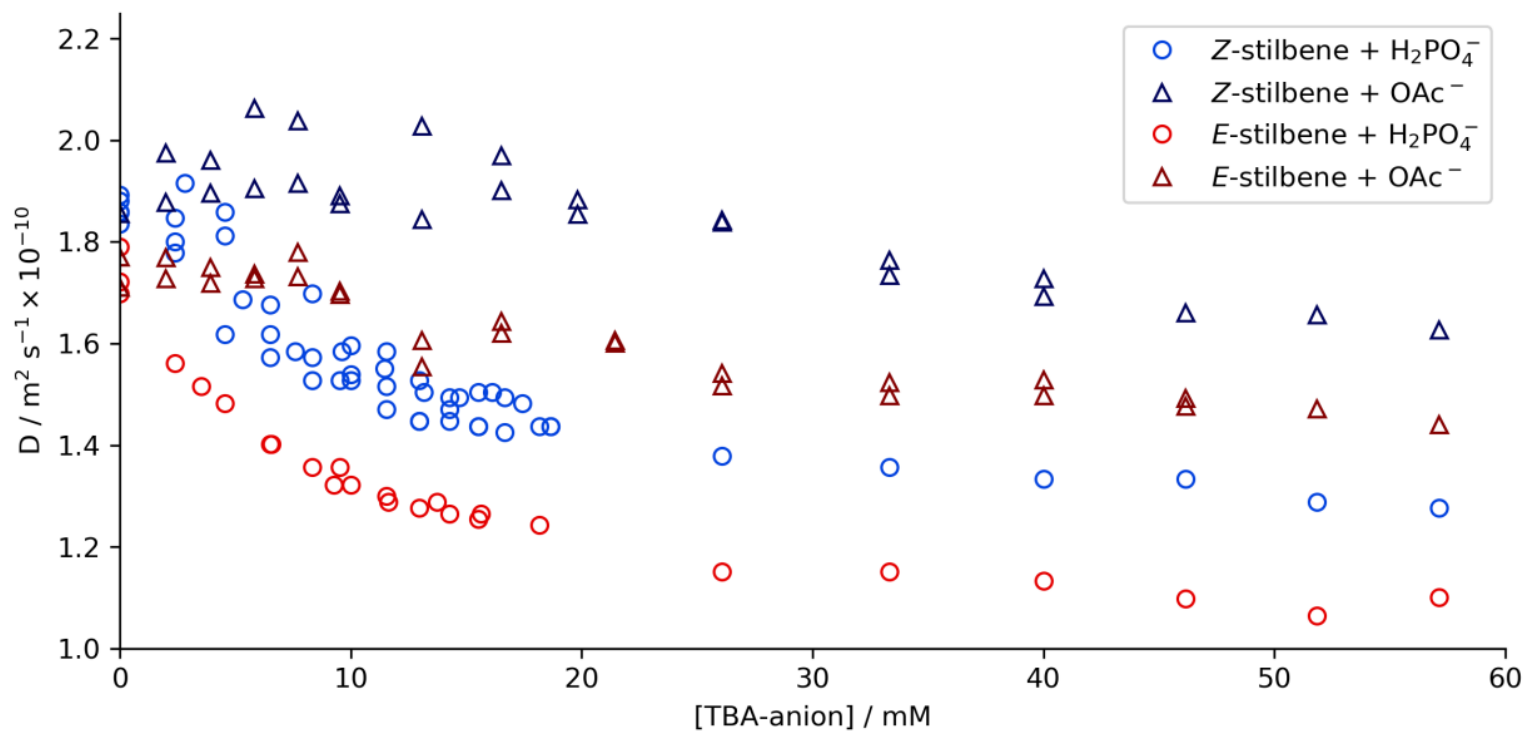

Figure S36. Comparison of guest-dependent diffusion for separate $5 \mathrm{mM}$ solutions of pure $E$ or $Z$ hosts in the presence of $\left[\mathrm{NBu}_{4}\right]\left[\mathrm{H}_{2} \mathrm{PO}_{4}\right]$ or $\left[\mathrm{NBu}_{4}\right][\mathrm{OAc}]$, presented on a single axis for clarity. No corrections have been made for changes in viscosity due to the lack of viscometry data for solutions of tetrabutylammonium acetate. Each point represents one diffusion experiment. $500 \mathrm{MHz}{ }^{1} \mathrm{H}, \Delta=50 \mathrm{~ms}, \delta$ $=4 \mathrm{~ms}$, linear ramp of 12 gradients from $\mathrm{g}=0-53.45 \mathrm{~g} \mathrm{~cm}^{-1}$. 


\section{S8.3 Diffusion measurements for 1:1 E:Z mixed systems}

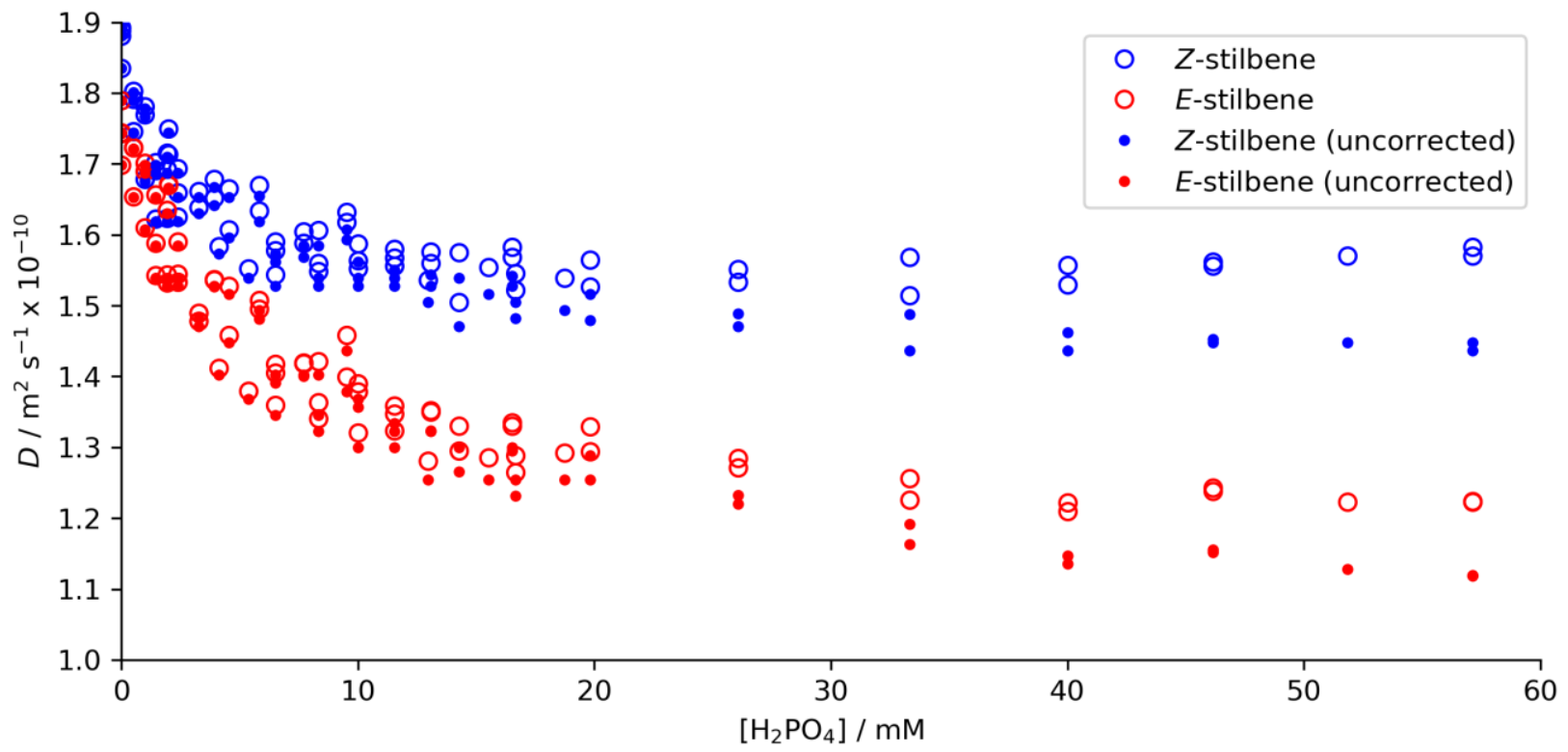

Figure S37. Diffusion of hosts 1 in $1 \mathrm{mM}$ mixed solution (1:1 E:Z), in the presence of $0-70 \mathrm{mM}\left[\mathrm{NBu}_{4}\right]\left[\mathrm{H}_{2} \mathrm{PO}_{4}\right]$. Diffusion coefficients as-acquired are shown as solid points; diffusion coefficients corrected for changes in viscosity from to increasing $\left.\left[\mathrm{NBu}_{4}\right]\left[\mathrm{H}_{2} \mathrm{PO}_{4}\right]\right]$ are shown as empty circles (linear correction from directly measured viscosities of $\left[\mathrm{NBu}_{4}\right]\left[\mathrm{H}_{2} \mathrm{PO}_{4}\right]$ solutions; see Figure S6). Each point represents one diffusion experiment. $500 \mathrm{MHz}{ }^{1} \mathrm{H}, \Delta=50 \mathrm{~ms}, \delta=4 \mathrm{~ms}$, linear ramp of 12 gradients from $g=0-53.45 \mathrm{~g} \mathrm{~cm}^{-1}$.

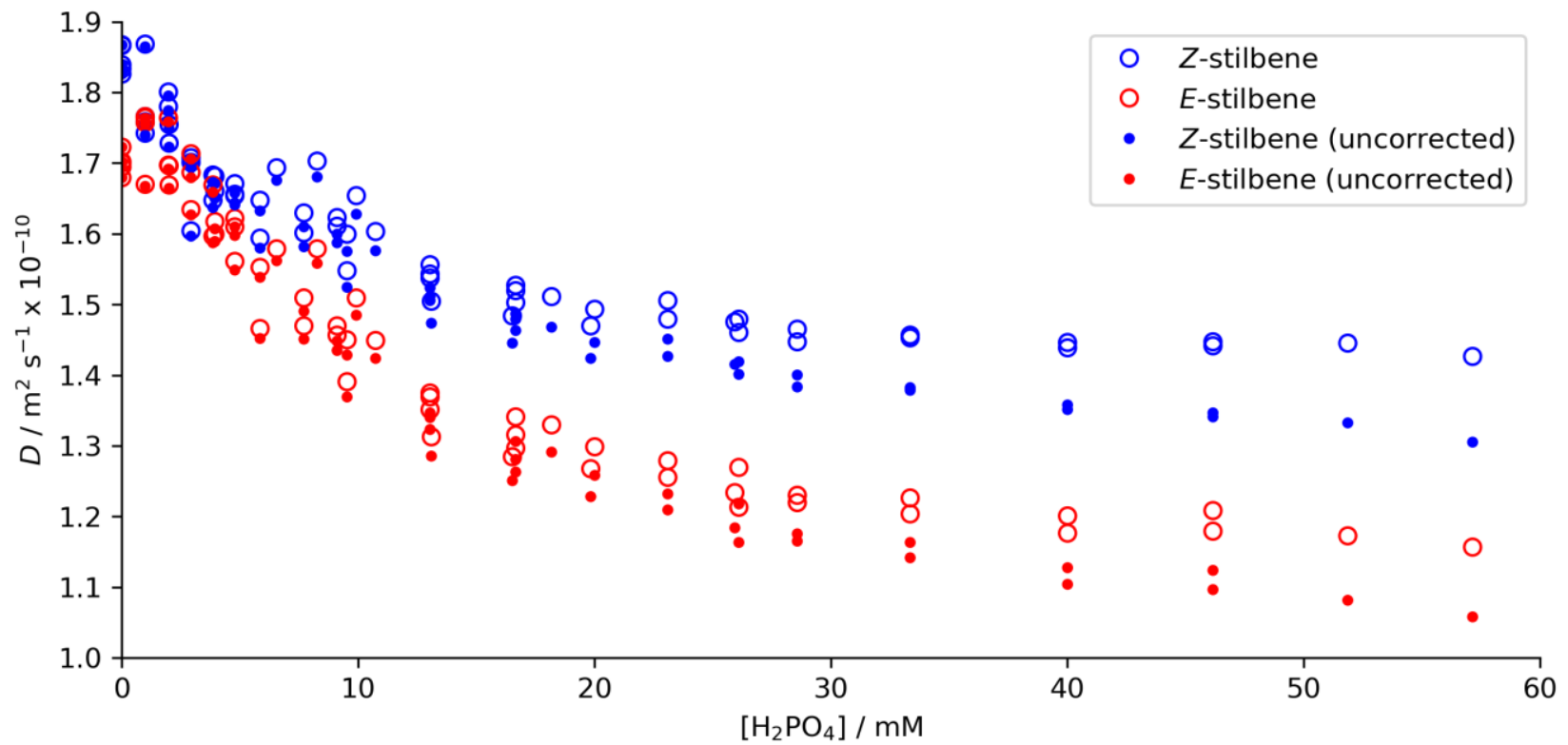

Figure S38. Diffusion of hosts 1 in $5 \mathrm{mM}$ mixed solution (1:1 E:Z), in the presence of $0-70 \mathrm{mM}\left[\mathrm{NBu}_{4}\right]\left[\mathrm{H}_{2} \mathrm{PO}_{4}\right]$. Diffusion coefficients as-acquired are shown as solid points; diffusion coefficients corrected for changes in viscosity from to increasing $\left.\left[\mathrm{NBu}_{4}\right]\left[\mathrm{H}_{2} \mathrm{PO}_{4}\right]\right]$ are shown as empty circles (linear correction from directly measured viscosities of $\left[\mathrm{NBu}_{4}\right]\left[\mathrm{H}_{2} \mathrm{PO}_{4}\right]$ solutions; see Figure S6). Each point represents one diffusion experiment. $500 \mathrm{MHz}{ }^{1} \mathrm{H}, \Delta=50 \mathrm{~ms}, \delta=4 \mathrm{~ms}$, linear ramp of 12 gradients from $g=0-53.45 \mathrm{~g} \mathrm{~cm}^{-1}$. 


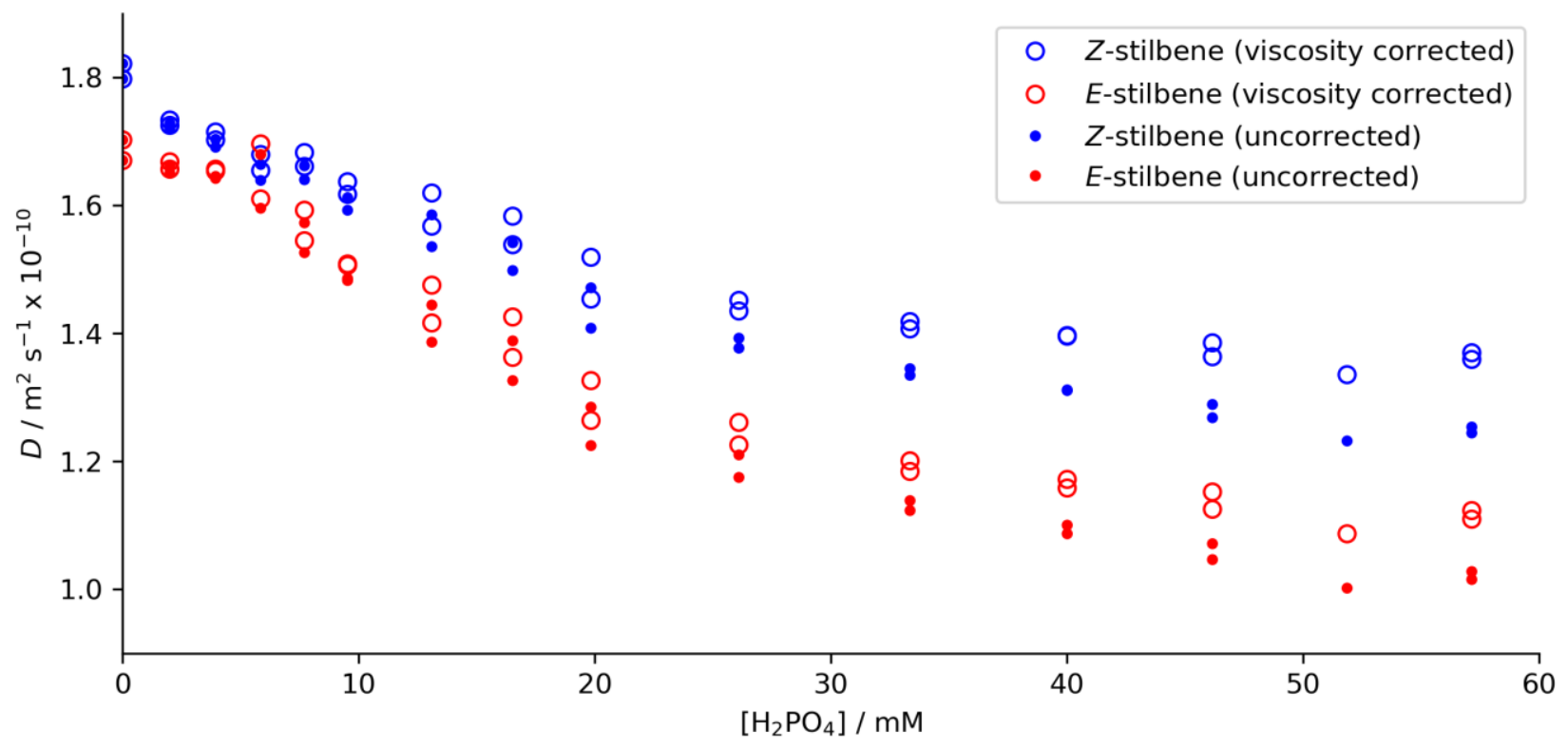

Figure S39. Diffusion of hosts 1 in $10 \mathrm{mM}$ mixed solution (1:1 E:Z), in the presence of $0-70 \mathrm{mM}\left[\mathrm{NBu}_{4}\right]\left[\mathrm{H}_{2} \mathrm{PO}_{4}\right]$. Diffusion coefficients as-acquired are shown as solid points; diffusion coefficients corrected for changes in viscosity from to increasing $\left[\mathrm{H}_{2} \mathrm{PO}_{4}\right]$ are shown as empty circles (linear correction from directly measured viscosities of $\left[\mathrm{NBu}_{4}\right]\left[\mathrm{H}_{2} \mathrm{PO}_{4}\right]$ solutions; see Figure S6). Each point represents one diffusion experiment. $500 \mathrm{MHz}{ }^{1} \mathrm{H}, \Delta=50 \mathrm{~ms}, \delta=4 \mathrm{~ms}$, linear ramp of 12 gradients from $g=0-53.45 \mathrm{~g} \mathrm{~cm}^{-1}$.
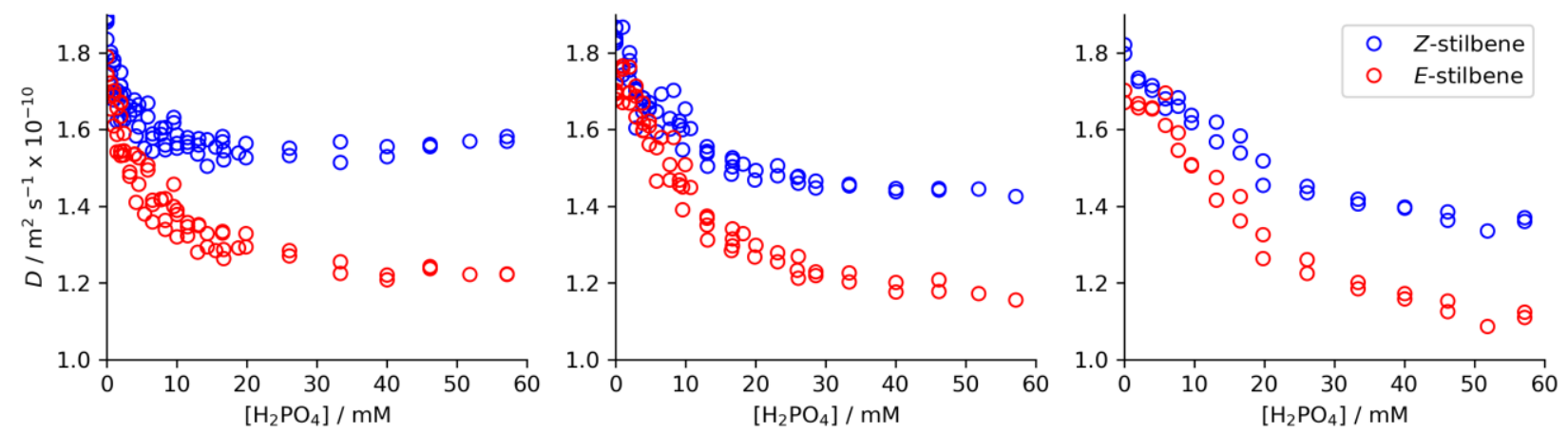

Figure S40. Comparison of measured diffusion coefficients of hosts 1 in $1: 1 E: Z$ mixtures of $1 \mathrm{mM}, 5 \mathrm{mM}$, and $10 \mathrm{mM}$ total concentration (as above). All data corrected for changes in viscosity due to the addition of $\left[\mathrm{NBu}_{4}\right]\left[\mathrm{H}_{2} \mathrm{PO}_{4}\right]$ (SI S4). Each point represents one diffusion experiment. $500 \mathrm{MHz}{ }^{1} \mathrm{H}, \Delta=50 \mathrm{~ms}, \delta=4 \mathrm{~ms}$, linear ramp of 12 gradients from $\mathrm{g}=0-53.45 \mathrm{~g} \mathrm{~cm}^{-1}$. 


\section{S8.4 Viscosity measurements for host-guest systems}

Viscosities and densities for $5 \mathrm{mM}$ solutions of host 1 in combination with $50 \mathrm{mM}$ of $\left[\mathrm{NBu}_{4}\right]\left[\mathrm{H}_{2} \mathrm{PO}_{4}\right]$ were measured at $25{ }^{\circ} \mathrm{C}$ using a Lovis $2000 \mathrm{M}$ rolling ball viscometer $(\varnothing 1.59 \mathrm{~mm}$ capillary; $1 \mathrm{~mm}$ stainless steel ball), with results shown in Table S9. The presence of $50 \mathrm{mM}\left[\mathrm{NBu}_{4}\right]\left[\mathrm{H}_{2} \mathrm{PO}_{4}\right]$ caused a $9.6 \%$ increase in dynamic viscosity $(\eta)$ relative to DMSO- $d_{6}$ with $0.5 \%$ water. Subsequent addition of $5 \mathrm{mM}$ of host 1 to the 50 $\mathrm{mM}\left[\mathrm{NBu}_{4}\right]\left[\mathrm{H}_{2} \mathrm{PO}_{4}\right]$ solution as either pure $E-1$, pure $Z-1$, or 1:1 E-1:Z-1 caused minor increases in $\eta$ of $1.44 \%$, $0.51 \%$, or $0.81 \%$ respectively with reference to $50 \mathrm{mM}\left[\mathrm{NBu}_{4}\right]\left[\mathrm{H}_{2} \mathrm{PO}_{4}\right]$, indicating that the addition of host 1 has only a minor effect on viscosity.

Table S9. Viscosity measurements of solutions of host and $\left[\mathrm{NBu}_{4}\right]\left[\mathrm{H}_{2} \mathrm{PO}_{4}\right]$ in DMSO- $d_{6}$ with $0.5 \% \mathrm{v} / \mathrm{v}$ added water.

\begin{tabular}{cccccccc}
\hline $\begin{array}{c}{\left[\mathrm{NBu}_{4}\right]\left[\mathrm{H}_{2} \mathrm{PO}_{4}\right]} \\
/ \mathrm{mM}\end{array}$ & $\begin{array}{c}{[E-1]} \\
/ \mathrm{mM}\end{array}$ & $\begin{array}{c}{[\mathrm{Z}-1]} \\
/ \mathrm{mM}\end{array}$ & $\begin{array}{c}\text { Density } \\
/ \mathrm{g} / \mathrm{cm}^{3}\end{array}$ & $\begin{array}{c}\text { Temperature } \\
/{ }^{\circ} \mathrm{C}\end{array}$ & $\begin{array}{c}\text { Dyn. Viscosity }(\eta) \\
/ \mathrm{mPa} \cdot \mathrm{s}\end{array}$ & $\begin{array}{c}\text { Error } \\
/ \%\end{array}$ & $\eta / \eta_{0}$ \\
\hline- & - & - & 1.1833 & 25.04 & 2.149 & 0.02 & 1.000 \\
$\mathbf{5 0}$ & - & - & 1.1819 & 25.06 & 2.356 & 0.04 & 1.096 \\
$\mathbf{5 0}$ & 5 & - & 1.1820 & 25.05 & 2.390 & 0.08 & 1.112 \\
$\mathbf{5 0}$ & - & 5 & 1.1818 & 25.06 & 2.368 & 0.03 & 1.102 \\
$\mathbf{5 0}$ & 2.5 & 2.5 & 1.1820 & 25.06 & 2.375 & 0.02 & 1.105 \\
\hline
\end{tabular}

While viscosities were not measured directly for 1:1 E:Z host mixtures at concentrations other than $5 \mathrm{mM}$, a linear interpolation between $\eta=2.356$ in the absence of host and $\eta=2.375$ for the $5 \mathrm{mM}$ mixture was used to estimate $\eta=2.360$ for $50 \mathrm{mM}\left[\mathrm{H}_{2} \mathrm{PO}_{4}\right]$ plus $1 \mathrm{mM} \mathrm{1:1} \mathrm{host} \mathrm{and} \eta=2.394$ for $50 \mathrm{mM}\left[\mathrm{H}_{2} \mathrm{PO}_{4}\right]$ plus $10 \mathrm{mM} \mathrm{1:1}$ host. This interpolated and extrapolated viscosity data was only used for the viscosity-corrected data shown in Table S12. 


\section{S8.5 Tabulated diffusion data at $50 \mathrm{mM}\left[\mathrm{NBu}_{4}\right]\left[\mathrm{H}_{2} \mathrm{PO}_{4}\right]$}

Table S10. Changes in diffusion coefficients of pure or 1:1 mixed solutions of $E-1$ and $Z-1$ in the presence of $50 \mathrm{mM}^{2}\left[\mathrm{NBu}_{4}\right]\left[\mathrm{H}_{2} \mathrm{PO}_{4}\right]$. DMSO- $d_{6}$ with $0.5 \%$ added water, $500 \mathrm{MHz}$. No correction applied for viscosity changes.

\begin{tabular}{|c|c|c|c|c|c|c|}
\hline [E-1] & [Z-1] & $D\left(\mathrm{H}_{2} \mathrm{PO}_{4}\right)^{[\mathrm{a}]}$ & $\begin{array}{c}D_{\mathrm{E}}^{[b]} \\
0^{-10} m^{2 \alpha^{-1}}\end{array}$ & $\begin{array}{c}D_{z^{[b]}}^{[b} \\
0^{-10} m^{2 c^{-1}}\end{array}$ & $D\left(\mathrm{NBu}_{4}\right)^{[\mathrm{b}]}$ & $D_{\text {DMSO }}{ }^{[\mathrm{b}]}$ \\
\hline /mM & $/ \mathrm{mM}$ & $/ 10^{-10} \mathrm{~m}^{2} \mathrm{~s}^{-1}$ & $/ 10^{-10} \mathrm{~m}^{2} \mathrm{~s}^{-1}$ & $/ 10^{-10} \mathrm{~m}^{2} \mathrm{~s}^{-1}$ & $/ 10^{-10} \mathrm{~m}^{2} \mathrm{~s}^{-1}$ & \\
\hline- & - & $1.99 \pm 0.02$ & - & - & $2.32 \pm 0.01$ & $6.32 \pm 0.04$ \\
\hline 0.5 & 0.5 & $1.90 \pm 0.02$ & $1.15 \pm 0.02$ & $1.45 \pm 0.01$ & $2.33 \pm 0.01$ & $6.35 \pm 0.02$ \\
\hline 2.5 & 2.5 & $1.82 \pm 0.06$ & $1.10 \pm 0.01$ & $1.34 \pm 0.01$ & $2.26 \pm 0.01$ & $6.28 \pm 0.03$ \\
\hline 5 & 5 & $1.69 \pm 0.08$ & $1.04 \pm 0.01$ & $1.26 \pm 0.01$ & $2.14 \pm 0.01$ & $6.11 \pm 0.03$ \\
\hline 5 & - & $1.79 \pm 0.04$ & $1.08 \pm 0.02$ & - & $2.21 \pm 0.01$ & $6.06 \pm 0.02$ \\
\hline- & 5 & $1.86 \pm 0.03$ & - & $1.29 \pm 0.01$ & $2.19 \pm 0.01$ & $6.02 \pm 0.02$ \\
\hline
\end{tabular}

[a] ${ }^{31} \mathrm{P}$ PGSTE experiment, $\delta=7 \mathrm{~ms}, \Delta=100 \mathrm{~ms}, g=0-53.45 \mathrm{G} \mathrm{cm}^{-1}$. [b] ${ }^{1} \mathrm{H}$ PGSTE experiment, $\delta=4 \mathrm{~ms}, \Delta=50 \mathrm{~ms}, g=0-53.45 \mathrm{G}$ $\mathrm{cm}^{-1}$.

Table S11. Diffusion data from Table S10, corrected for changes in viscosity using $\eta$ for $50 \mathrm{mM}\left[\mathrm{NBu}_{4}\right]\left[\mathrm{H}_{2} \mathrm{PO}_{4}\right]$ addition only, ignoring changes in $\eta$ caused by host.

\begin{tabular}{|c|c|c|c|c|c|c|c|}
\hline $\begin{array}{l}{[E-1]} \\
/ \mathrm{mM}\end{array}$ & $\begin{array}{l}{[Z-1]} \\
/ \mathrm{mM}\end{array}$ & $\eta / \eta_{0}$ & $\begin{array}{l}D^{\prime}\left(\mathrm{H}_{2} \mathrm{PO}_{4}\right)^{[\mathrm{a}]} \\
\left(10^{-10} \mathrm{~m}^{2} \mathrm{~s}^{-1}\right.\end{array}$ & $\begin{array}{c}D_{\mathrm{E}}^{\prime[\mathrm{b}]} \\
/ 10^{-10} \mathrm{~m}^{2} \mathrm{~s}^{-1}\end{array}$ & $\begin{array}{c}D_{z^{[b]}}^{[b]} \\
/ 10^{-10} \mathrm{~m}^{2} \mathrm{~s}^{-1}\end{array}$ & $\begin{array}{l}D^{\prime}\left(\mathrm{H}_{2} \mathrm{PO}_{4}\right)^{[\mathrm{b}]} \\
/ 10^{-10} \mathrm{~m}^{2} \mathrm{~s}^{-1}\end{array}$ & $\begin{array}{c}D_{\text {DMSO }^{[b]}} \\
/ 10^{-10} \mathrm{~m}^{2} \mathrm{~s}^{-1}\end{array}$ \\
\hline- & - & 1.096 & $2.18 \pm 0.02$ & - & - & $2.54 \pm 0.01$ & $6.93 \pm 0.04$ \\
\hline 0.5 & 0.5 & 1.096 & $2.08 \pm 0.02$ & $1.26 \pm 0.02$ & $1.59 \pm 0.01$ & $2.55 \pm 0.01$ & $6.96 \pm 0.02$ \\
\hline 2.5 & 2.5 & 1.096 & $2.00 \pm 0.07$ & $1.21 \pm 0.01$ & $1.47 \pm 0.01$ & $2.48 \pm 0.01$ & $6.88 \pm 0.03$ \\
\hline 5 & 5 & 1.096 & $1.85 \pm 0.09$ & $1.14 \pm 0.01$ & $1.38 \pm 0.01$ & $2.35 \pm 0.01$ & $6.70 \pm 0.03$ \\
\hline 5 & - & 1.096 & $1.96 \pm 0.04$ & $1.18 \pm 0.02$ & - & $2.42 \pm 0.01$ & $6.64 \pm 0.02$ \\
\hline- & 5 & 1.096 & $2.04 \pm 0.03$ & - & $1.41 \pm 0.01$ & $2.4 \pm 0.01$ & $6.60 \pm 0.02$ \\
\hline
\end{tabular}

[a] ${ }^{31} \mathrm{P}$ PGSTE experiment, $\delta=7 \mathrm{~ms}, \Delta=100 \mathrm{~ms}, g=0-53.45 \mathrm{G} \mathrm{cm}^{-1}$. [b] ${ }^{1} \mathrm{H}$ PGSTE experiment, $\delta=4 \mathrm{~ms}, \Delta=50 \mathrm{~ms}, g=0-53.45 \mathrm{G}$ $\mathrm{cm}^{-1}$.

Table S12. Diffusion data from Table S10, corrected for changes in viscosity caused by host and guest

\begin{tabular}{|c|c|c|c|c|c|c|c|}
\hline$[E-1]$ & {$[Z-1]$} & $\eta / \eta_{0}$ & $D^{\prime}\left(\mathrm{H}_{2} \mathrm{PO}_{4}\right)^{[\mathrm{a}]}$ & $D_{E}^{\prime[b]}$ & & $D^{\prime}\left(\mathrm{H}_{2} \mathrm{PO}_{4}\right)^{[\mathrm{b}]}$ & $D_{\text {DMSO }}^{\prime[b]}$ \\
\hline$/ \mathrm{mM}$ & $/ \mathrm{mM}$ & & $/ 10^{-10} \mathrm{~m}^{2} \mathrm{~s}^{-1}$ & $/ 10^{-10} \mathrm{~m}^{2} \mathrm{~s}^{-1}$ & $/ 10^{-10} \mathrm{~m}^{2} \mathrm{~s}^{-1}$ & $/ 10^{-10} \mathrm{~m}^{2} \mathrm{~s}^{-1}$ & $/ 10^{-10} \mathrm{~m}^{2} \mathrm{~s}^{-1}$ \\
\hline- & - & 1.096 & $2.18 \pm 0.02$ & - & - & $2.54 \pm 0.01$ & $6.93 \pm 0.04$ \\
\hline 0.5 & 0.5 & $1.098^{[\mathrm{c}]}$ & $2.09 \pm 0.02$ & $1.26 \pm 0.02$ & $1.59 \pm 0.01$ & $2.56 \pm 0.01$ & $6.97 \pm 0.02$ \\
\hline 2.5 & 2.5 & 1.105 & $2.01 \pm 0.07$ & $1.22 \pm 0.01$ & $1.48 \pm 0.01$ & $2.50 \pm 0.01$ & $6.94 \pm 0.03$ \\
\hline 5 & 5 & $1.114^{[\mathrm{c}]}$ & $1.88 \pm 0.09$ & $1.16 \pm 0.01$ & $1.40 \pm 0.01$ & $2.38 \pm 0.01$ & $6.81 \pm 0.03$ \\
\hline 5 & - & 1.112 & $1.99 \pm 0.04$ & $1.20 \pm 0.02$ & - & $2.46 \pm 0.01$ & $6.74 \pm 0.02$ \\
\hline- & 5 & 1.102 & $2.05 \pm 0.03$ & - & $1.42 \pm 0.01$ & $2.41 \pm 0.01$ & $6.63 \pm 0.02$ \\
\hline
\end{tabular}

[a] ${ }^{31} \mathrm{P}$ PGSTE experiment, $\delta=7 \mathrm{~ms}, \Delta=100 \mathrm{~ms}, g=0-53.45 \mathrm{G} \mathrm{cm}^{-1}$. [b] ${ }^{1} \mathrm{H}$ PGSTE experiment, $\delta=4 \mathrm{~ms}, \Delta=50 \mathrm{~ms}, g=0-53.45 \mathrm{G}$ $\mathrm{cm}^{-1}$. [c] Not measured directly but estimated by linear interpolation from other points: see S8.4. 


\section{Comparison of modelled and measured guest-dependent diffusion coefficients for pure $E$ and $Z$ systems}

Table S13. Parameters used for modelling concentration-dependent diffusion coefficients of $E-1$ and $Z-1$.

\begin{tabular}{ccccc}
\hline & $D_{0} / \mathrm{m}^{2} \mathbf{s}^{-1} \times 10^{-10}$ & $K_{\mathrm{i}} / \mathbf{M}^{-1}$ & $K_{1} / \mathbf{M}^{-1}$ & $K_{2} / \mathbf{M}^{-1}$ \\
\hline $\begin{array}{c}\text { Monomeric } \mathrm{H}_{2} \mathrm{PO}_{4}^{-} \\
\text {(see S6) }\end{array}$ & 3.39 & 120 & - & - \\
$\mathbf{5} \mathrm{mM} \mathrm{E-1}$ & 1.74 & - & 360 & 90 \\
$\mathbf{5} \mathrm{mM} \mathrm{Z-1}$ & 1.87 & - & 2100 & 70 \\
\hline
\end{tabular}

Host-guest speciation and diffusion coefficients for pure $E$ or $Z$ hosts binding up to two $\mathrm{H}_{2} \mathrm{PO}_{4}$-oligomers using the parameters given in Table S13 were modelled using Equation 13 (S5.3), and plotted in Figure S41. The modelled dependence of $D_{E}$ and $D z$ on $\mathrm{H}_{2} \mathrm{PO}_{4}^{-}$concentration significantly overestimates $D$ at all concentrations studied, particularly for the $E-1$ isomer, indicating that this model does not accurately reflect the structures formed in solution.
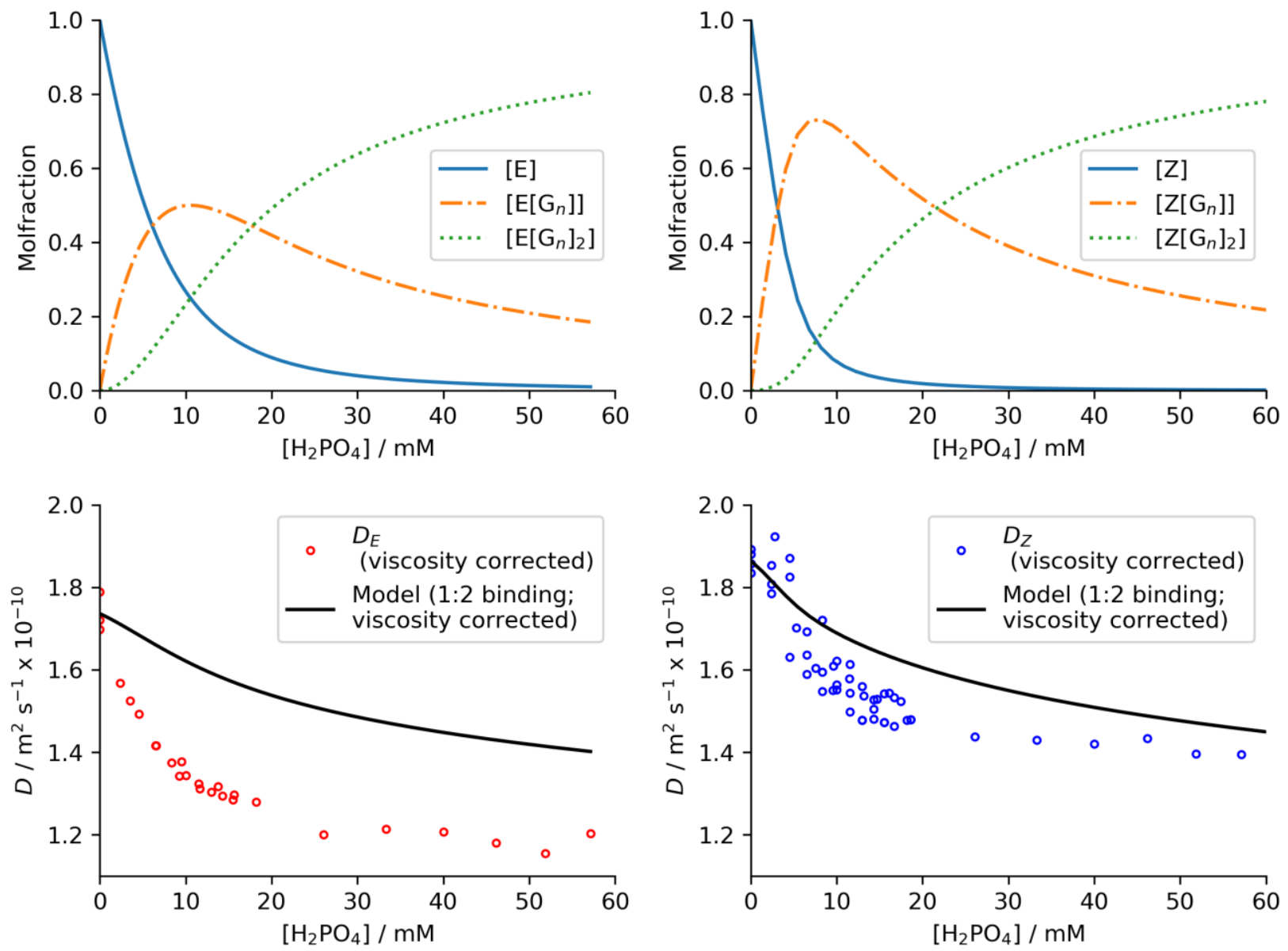

Figure S41. Comparison of experimental and modelled $\left[\mathrm{H}_{2} \mathrm{PO}_{4}\right]$-dependent diffusion coefficients of hosts, using Equation 13 and the parameters shown in Table S13. Top: speciation of $E$ (left) and $Z$ (right) hosts using a 1:2 host:guest binding model and the association parameters shown in Table S13. Bottom: modelled average diffusion coefficients of hosts binding up to $2 \mathrm{H}_{2} \mathrm{PO}_{4}{ }^{-}$oligomers (see S5.3 for details). This model is clearly insufficient to explain the large decrease in $D$ observed on addition of $\mathrm{H}_{2} \mathrm{PO}_{4}^{-}$, particularly for the $E-1$ isomer. 


\section{S9.1 Estimated diffusion coefficients of potential supramolecular host-guest complexes}

To aid in comparing the sizes of proposed complexes, approximate molecular weights are shown in Table S14. As $\mathrm{H}_{2} \mathrm{PO}_{4}$ - oligomers have been modelled as forming with a continuous distribution of sizes, no single definitive molecular weight can be given for complexes involving oligomeric $\mathrm{H}_{2} \mathrm{PO}_{4}$. Instead, we provide molecular weights for the calculated median and mean oligomer sizes.

Table S14. Estimated diffusion coefficients for representative supramolecular structures of the form $\left[H_{m} G_{n}\right]$. Estimated diffusion coefficients for complexes (calculated using Eq (11)) are shown in normal text. While a wide distribution of host-guest systems are expected to form in solution, the measured host diffusion coefficients at $5 \mathrm{mM}$ host and $50 \mathrm{mM}\left[\mathrm{NBu}_{4}\right]\left[\mathrm{H}_{2} \mathrm{PO}_{4}\right]$ suggest complexes of approximately $1.5-2.5 \mathrm{kDa}$ in size under these conditions.

\begin{tabular}{|c|c|c|c|c|c|}
\hline Complex & $\begin{array}{c}\text { Median MW } \\
\text { / kDa }\end{array}$ & $\begin{array}{c}\text { Mean MW } \\
\text { / kDa }\end{array}$ & $\begin{array}{l}D\left(\mathrm{H}_{2} \mathrm{PO}_{4}\right)^{[\mathrm{a}]} \\
/ 10^{-10} \mathrm{~m}^{2} \mathrm{~s}^{-1}\end{array}$ & $\begin{array}{c}D_{\mathrm{E}}^{[\mathrm{b}]} \\
/ 10^{-10} \mathrm{~m}^{2} \mathrm{~s}^{-1}\end{array}$ & $\begin{array}{c}D_{z^{[b]}}^{[b} \\
/ 10^{-10} \mathrm{~m}^{2} \mathrm{~s}^{-1}\end{array}$ \\
\hline Free host $\left[\mathrm{H}_{1} \mathrm{G}_{0}\right]$ & \multicolumn{2}{|c|}{0.5} & - & $1.74^{[\mathrm{a}]}$ & $1.87^{[a]}$ \\
\hline Oligomeric $\mathrm{H}_{2} \mathrm{PO}_{4}^{-}\left[\mathrm{G}_{n}\right]$ & 0.4 & 0.5 & $2.16^{[\mathrm{b}]}$ & & \\
\hline$\left(50 \mathrm{mM}\left[\mathrm{NBu}_{4}\right]\left[\mathrm{H}_{2} \mathrm{PO}_{4}\right], K_{\mathrm{i}}=120\right)$ & (4 $\mathrm{H}_{2} \mathrm{PO}_{4}$-units) & (5 $\mathrm{H}_{2} \mathrm{PO}_{4}$ units) & & & \\
\hline Monomeric G & 0 & & 3.39 & & \\
\hline \multicolumn{6}{|l|}{$\left(\mathrm{H}_{2} \mathrm{PO}_{4}^{-}\right.$, infinite dilution $)$} \\
\hline \multicolumn{6}{|c|}{ Host with monomeric phosphate $\left(D\left(\mathrm{H}_{2} \mathrm{PO}_{4}\right)=3.39\right)$} \\
\hline$\left[\mathrm{H}_{1} \mathrm{G}_{1}\right]$ & \multicolumn{2}{|c|}{0.6} & & 1.67 & 1.78 \\
\hline$\left[\mathrm{H}_{1} \mathrm{G}_{2}\right]$ & \multicolumn{2}{|c|}{0.7} & & 1.61 & 1.70 \\
\hline \multicolumn{6}{|c|}{ Host with phosphate oligomers $\left(50 \mathrm{mM}, \boldsymbol{D}\left(\mathrm{H}_{2} \mathrm{PO}_{4}\right)=2.16\right)$} \\
\hline$\left[\mathrm{H}_{1} \mathrm{G}_{1}^{\prime}\right]$ & 0.9 & 1.0 & & 1.51 & 1.58 \\
\hline$\left[\mathrm{H}_{1} \mathrm{G}_{2}^{\prime}\right]$ & 1.3 & 1.5 & & 1.37 & 1.42 \\
\hline$\left[\mathrm{H}_{2} \mathrm{G}_{1}^{\prime}\right]$ & 1.4 & 1.5 & & 1.22 & 1.35 \\
\hline$\left[\mathrm{H}_{2} \mathrm{G}_{2}^{\prime}\right]$ & 1.8 & 2.0 & & 1.20 & 1.26 \\
\hline$\left[\mathrm{H}_{2} \mathrm{G}_{3}^{\prime}\right]$ & 2.2 & 2.5 & & 1.14 & 1.18 \\
\hline$\left[\mathrm{H}_{3} \mathrm{G}_{2}^{\prime}\right]$ & 2.4 & 2.6 & & 1.09 & 1.15 \\
\hline$\left[\mathrm{H}_{3} \mathrm{G}_{3}^{\prime}\right]$ & 2.8 & 3.0 & & 1.05 & 1.10 \\
\hline$\left[\mathrm{H}_{3} \mathrm{G}_{4}^{\prime}\right]$ & 3.1 & 3.5 & & 1.01 & 1.05 \\
\hline 5 mM host, & & & $1.93^{[b]}(E), 2.01^{[b]}(Z)$ & $1.17^{[a]}$ & $1.39^{[a]}$ \\
\hline $50 \mathrm{mM}$ guest & & & & & \\
\hline
\end{tabular}

Experimentally obtained values: [a] ${ }^{31} \mathrm{P}$ PGSTE, $\delta=7 \mathrm{~ms}, \Delta=100 \mathrm{~ms}, g=0-53.45 \mathrm{G} \mathrm{cm}^{-1}$; [b] ${ }^{1} \mathrm{H}$ PGSTE experiment, $\delta=4 \mathrm{~ms}, \Delta=50$ $\mathrm{ms}, g=0-53.45 \mathrm{G} \mathrm{cm}^{-1}$. 


\section{S10. Photoswitching studies}

\section{S10.1 Time-dependent diffusion with in situ irradiation}

Photo-diffusion studies were conducted by combining in situ light irradiation with time-dependent diffusion experiments previously reported by our group. ${ }^{[8]}$ It is well known that NMR diffusion measurements are often disrupted by convection, generally caused by the presence of temperature gradients within the sample.[9] Convection can be challenging at the best of times, but here the use of in situ irradiation (and subsequent heating) deliver by fiber to the center of the sample can be almost guaranteed to generate temperature gradients during irradiation. This can be seen in the time-dependent diffusion data presented in Figure S42.
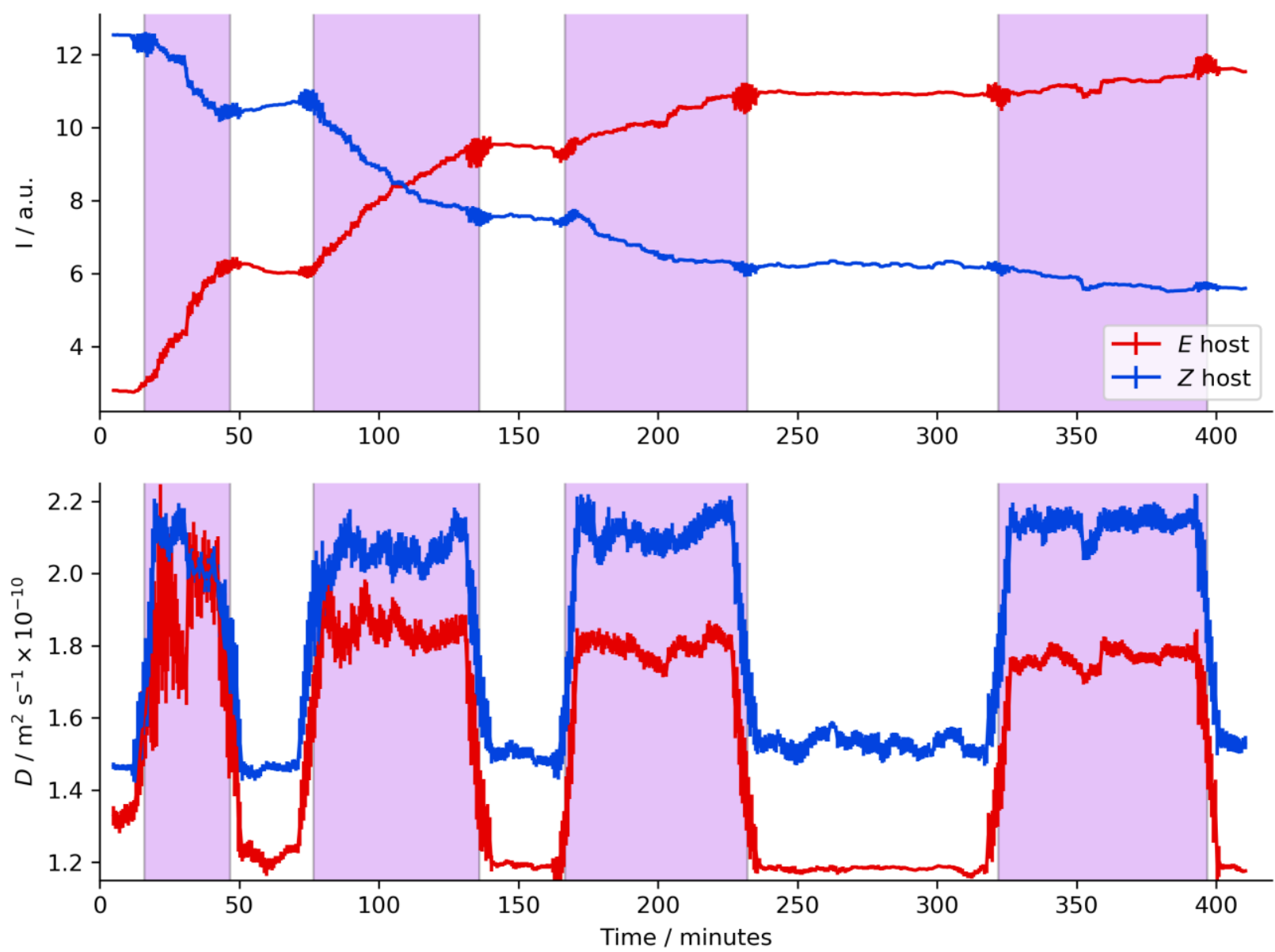

Figure S42. Time-resolved diffusion study while photoswitching under in situ irradiation ( $405 \mathrm{~nm}$ LED source). $5 \mathrm{mM}$ host (initially $\sim 90 \%$ Z-1) in solution with $50 \mathrm{mM}\left[\mathrm{NBu}_{4}\right]\left[\mathrm{H}_{2} \mathrm{PO}_{4}\right]$ was irradiated with $405 \mathrm{~nm}$ light during the shaded periods of time, while diffusion information was continuously acquired using a long list of random gradients as previously reported. ${ }^{[8]}$ Measured diffusion coefficients can be seen to increase sharply under irradiation, but this is convection driven resulting from temperature gradients caused by uneven sample heating by light irradiation. 


\section{S10.2 Monitoring temperatures and suppressing convection}

There are many approaches to suppressing convection in diffusion NMR experiments. We chose the crude but effective method of introducing physical obstructions to the sample to disrupt connective flow. We use glass TLC spotting pipettes broken up into $30-40 \mathrm{~mm}$ irregular lengths to pack the sample and restrict flow. These open-ended capillaries were added to the sample around the $1.5 \mathrm{~mm}$ quartz optic fibre and flame-sealed methanol capillary used for thermometry (Figure S43).

To our pleasant surprise, NMR lineshapes were retained and few difficulties were encountered in shimming after packing our samples with glass and quartz (signal intensity was reduced somewhat by the displacement of liquid from the active volume). Representative time-resolved diffusion data are shown in Figure S44.

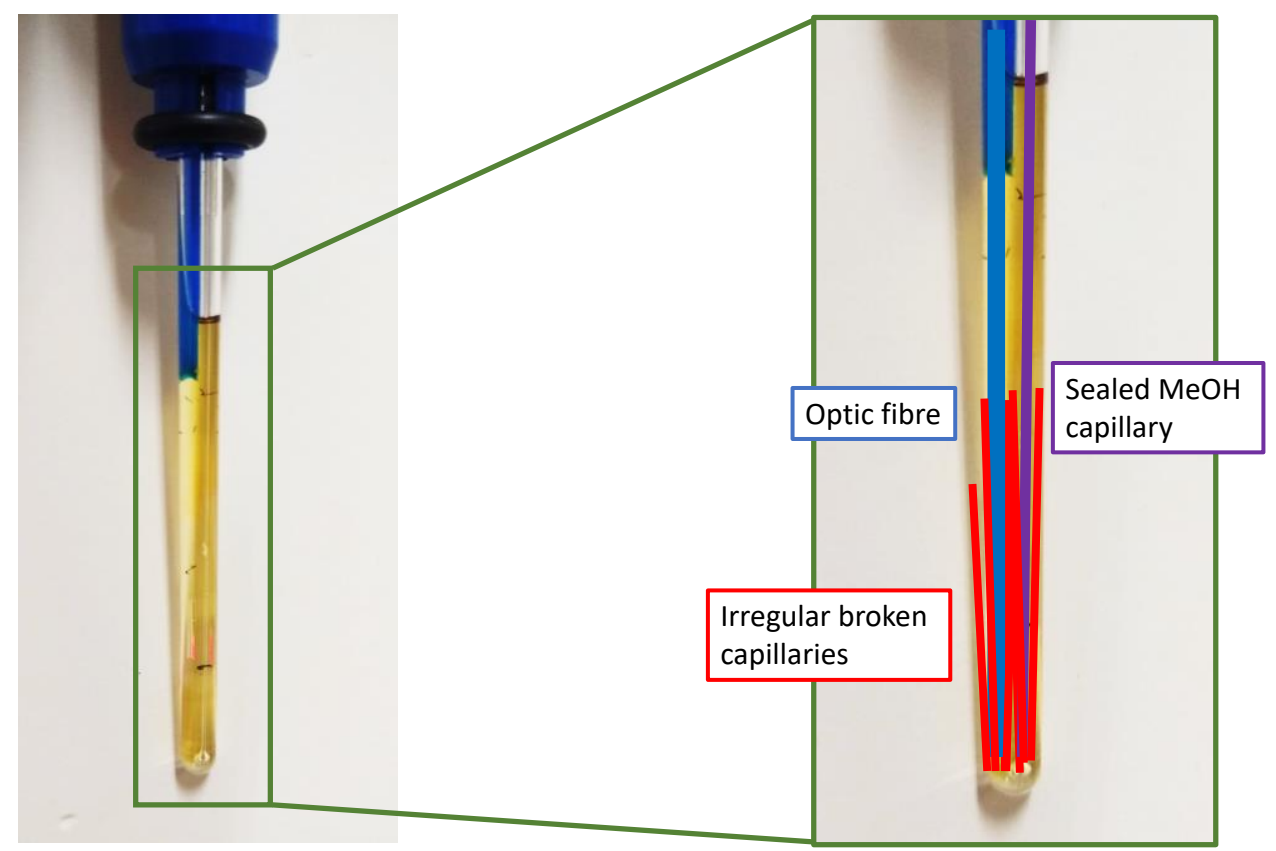

Figure S43. NMR sample used for photo-diffusion studies with in situ irradiation and temperature measurements. In the expansion the optic fiber (quartz, $1.5 \mathrm{~mm}$ diameter), flame-sealed methanol capillary (Sigma-Aldrich, $5 \mu \mathrm{L}$ capacity glass micropipette), and broken lengths of glass TLC capillaries are highlighted by colored lines. 

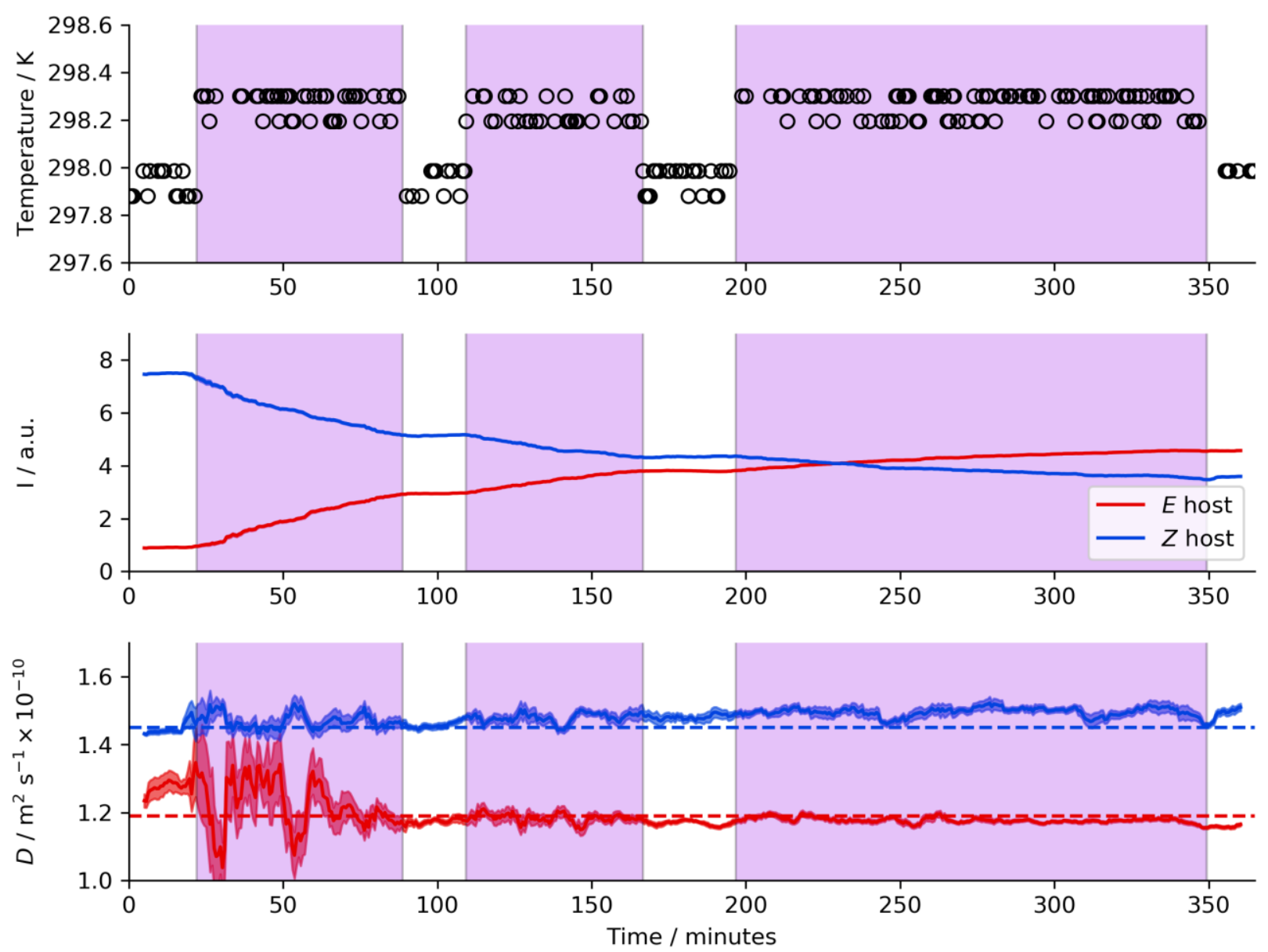

Figure S44. Time-resolved diffusion study ${ }^{[8]}$ while photoswitching under in situ irradiation (400 nm LED source), with flame-sealed methanol capillary added for in situ thermometry and short $(30-40 \mathrm{~mm})$ sections of broken glass capillaries added to suppress convection. $5 \mathrm{mM}$ host (initially $\sim 90 \% \mathrm{Z}-1$ ) in solution with $50 \mathrm{mM}\left[\mathrm{NBu}_{4}\right]\left[\mathrm{H}_{2} \mathrm{PO}_{4}\right]$ was irradiated with $405 \mathrm{~nm}$ light during the shaded periods of time, while diffusion information was continuously acquired using a long list of random gradients. Top: temperature measurements taken from the separation of the methanol $\mathrm{CH}_{3}$ and $\mathrm{OH}$ peaks (top) show an increase in sample temperature of approximately $0.35 \mathrm{~K}$ while under irradiation. ${ }^{[10]}$ The apparent quantization of temperature measurements results from the $\sim 0.5 \mathrm{~Hz}$ resolution of the NMR spectra. Middle: signal intensity changes of the tolyl peaks of $E-1$ and Z-1 during irradiation. Bottom: time-dependent diffusion measurements of the same peaks over time. Measured $D$ for each species taken from measurements of the 1:1 mixture of photoisomers (SI-S8.5) are shown as dashed horizontal lines for comparison. 


\section{S10.3 Demonstration of reversible photoswitching by UV-vis}

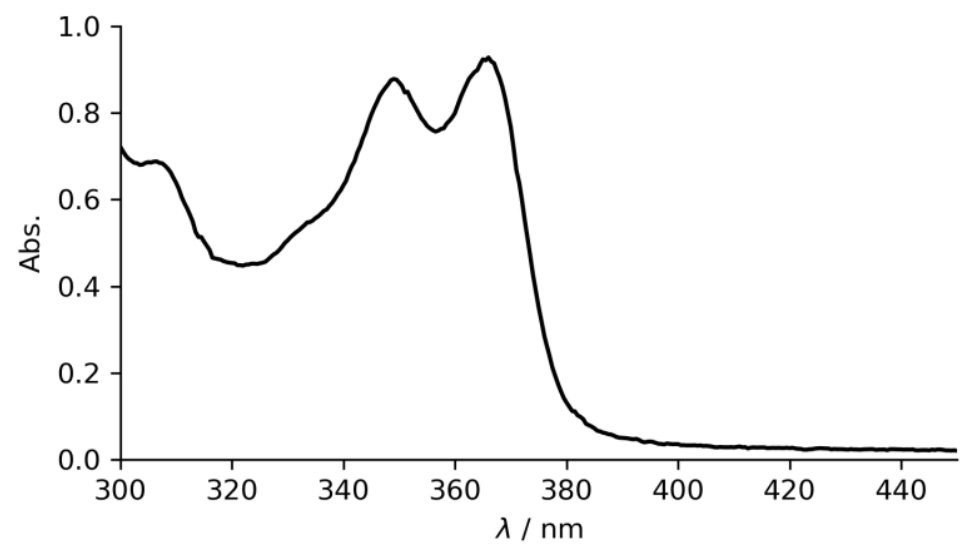

Figure S45. UV-vis absorption spectrum of $E-1$ (approx. $25 \mu \mathrm{M}$ ) in DMSO $+0.5 \%$ water. The absorption maximum $\lambda_{\max }$ Occurs at $365 \mathrm{~nm}$, identical to that previously reported for analogous host $E-S 2 \cdot{ }^{[3]}$

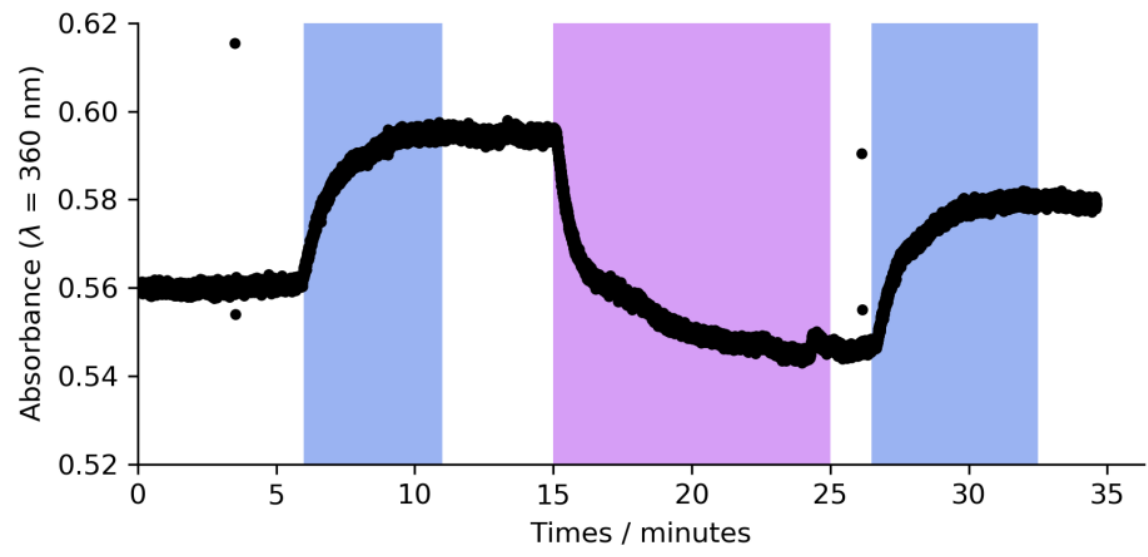

Figure S46. Demonstration of reversible photoswitching of compound 1 by UV-vis spectroscopy under irradiation from $385 \mathrm{~nm}$ (blue) and $375 \mathrm{~nm}$ (violet) LEDs. Solution of pure 1 (approx. $25 \mu \mathrm{M}$ ) in DMSO + 0.5\% water.

The reversibility of photoswitching in DMSO was studied by UV-vis spectroscopy with in situ irradiation delivered by $385 \mathrm{~nm}$ and $375 \mathrm{~nm}$ LEDs. These wavelengths are not ideal for selectively photoswitching this class of compound, but are sufficient to demonstrate the reversibility of photoswitching as shown in Figure S46. 


\section{S11. Geometry optimizations by DFT}

Input geometries were generated using Avogadro[11] (UFF optimization). The Gaussian 03 program ${ }^{[12]}$ was used for further geometry optimization at the DFT B3LYP/6-31G(d,p) level of theory using tight convergence criteria. The DFT optimized geometries were found to have zero imaginary frequencies.

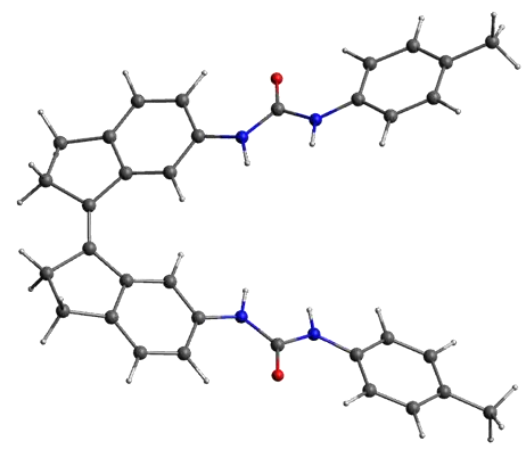

Table S15. Cartesian coordinates of Z-1 (approximate width $\times$ height $\times$ depth $=15.5 \times 10.1 \times 13.2 \AA$ )

\begin{tabular}{|c|c|c|c|}
\hline atom & $x$ & Y & Z \\
\hline C & -4.4187180000 & -2.6292070000 & 1.3266160000 \\
\hline C & -3.9527390000 & -1.5791220000 & 0.5111400000 \\
\hline C & -5.8729570000 & -2.4232700000 & 1.6806280000 \\
\hline C & -6.3342430000 & -1.3578480000 & 0.6529360000 \\
\hline $\mathrm{H}$ & -5.9755270000 & -2.0360570000 & 2.7036870000 \\
\hline $\mathrm{H}$ & -6.4586460000 & -3.3468050000 & 1.6303780000 \\
\hline C & -5.0527180000 & -0.6315450000 & 0.2447640000 \\
\hline $\mathrm{H}$ & -7.0910580000 & -0.6809600000 & 1.0584210000 \\
\hline $\mathrm{H}$ & -6.7811660000 & -1.8572210000 & -0.2186010000 \\
\hline C & -3.5683980000 & -3.6730620000 & 1.6727960000 \\
\hline C & -2.2574410000 & -3.7131230000 & 1.1939130000 \\
\hline C & -1.8023360000 & -2.6928510000 & 0.3403620000 \\
\hline C & -2.6518610000 & -1.6288650000 & 0.0019210000 \\
\hline $\mathrm{H}$ & -3.9213350000 & -4.4811900000 & 2.3083480000 \\
\hline $\mathrm{H}$ & -1.5913490000 & -4.5217820000 & 1.4561660000 \\
\hline $\mathrm{H}$ & -2.3033540000 & -0.8637980000 & -0.6848360000 \\
\hline C & -3.5684300000 & 3.6730450000 & -1.6727910000 \\
\hline C & -2.2574770000 & 3.7131210000 & -1.1938980000 \\
\hline $\mathrm{H}$ & -1.5913930000 & 4.5217880000 & -1.4561450000 \\
\hline C & -1.8023660000 & 2.6928510000 & -0.3403460000 \\
\hline C & -2.6518800000 & 1.6288550000 & -0.0019140000 \\
\hline $\mathrm{N}$ & -0.5165810000 & -2.6862610000 & -0.2443320000 \\
\hline C & 0.5623550000 & -3.5111720000 & 0.0458160000 \\
\hline $\mathrm{N}$ & 1.6615730000 & -3.2297750000 & -0.7522750000 \\
\hline $\mathrm{C}$ & 2.9335330000 & -3.8420110000 & -0.7334530000 \\
\hline $\mathrm{O}$ & 0.5451870000 & -4.3803600000 & 0.9072120000 \\
\hline C & 3.8773100000 & -3.3837580000 & -1.6653740000 \\
\hline C & 3.3017570000 & -4.8591470000 & 0.1588180000 \\
\hline C & 4.5892410000 & -5.3906590000 & 0.0976570000 \\
\hline C & 5.1558110000 & -3.9296050000 & -1.7080860000 \\
\hline
\end{tabular}




\begin{tabular}{|c|c|c|c|}
\hline C & 5.5408340000 & -4.9487480000 & -0.8284620000 \\
\hline C & 6.9185680000 & -5.5637080000 & -0.8958930000 \\
\hline $\mathrm{H}$ & 6.9497470000 & -6.4025140000 & -1.6029560000 \\
\hline $\mathrm{H}$ & 7.2313860000 & -5.9506340000 & 0.0785830000 \\
\hline $\mathrm{H}$ & 7.6670300000 & -4.8361060000 & -1.2250050000 \\
\hline $\mathrm{H}$ & 2.5852350000 & -5.2186980000 & 0.8826370000 \\
\hline $\mathrm{H}$ & 4.8566950000 & -6.1770440000 & 0.7994330000 \\
\hline $\mathrm{H}$ & 3.6100390000 & -2.5891770000 & -2.3594030000 \\
\hline $\mathrm{H}$ & 5.8663780000 & -3.5520500000 & -2.4391240000 \\
\hline $\mathrm{H}$ & -0.3719810000 & -1.9445230000 & -0.9136010000 \\
\hline $\mathrm{H}$ & 1.5454680000 & -2.5424810000 & -1.4824010000 \\
\hline C & 0.5623220000 & 3.5111820000 & -0.0458070000 \\
\hline$N$ & 1.6615350000 & 3.2298050000 & 0.7522970000 \\
\hline C & 2.9334970000 & 3.8420380000 & 0.7334640000 \\
\hline $\mathrm{O}$ & 0.5451590000 & 4.3803460000 & -0.9072270000 \\
\hline C & 3.3017300000 & 4.8591420000 & -0.1588410000 \\
\hline C & 3.8772670000 & 3.3838140000 & 1.6654070000 \\
\hline C & 5.1557690000 & 3.9296600000 & 1.7081080000 \\
\hline C & 4.5892150000 & 5.3906520000 & -0.0976900000 \\
\hline C & 5.5408010000 & 4.9487710000 & 0.8284510000 \\
\hline C & 6.9185360000 & 5.5637280000 & 0.8958700000 \\
\hline $\mathrm{H}$ & 7.6670010000 & 4.8361240000 & 1.2249700000 \\
\hline $\mathrm{H}$ & 6.9497240000 & 6.4025310000 & 1.6029380000 \\
\hline $\mathrm{H}$ & 7.2313440000 & 5.9506590000 & -0.0786070000 \\
\hline $\mathrm{H}$ & 2.5852140000 & 5.2186700000 & -0.8826770000 \\
\hline $\mathrm{H}$ & 3.6099890000 & 2.5892580000 & 2.3594610000 \\
\hline $\mathrm{H}$ & 5.8663300000 & 3.5521280000 & 2.4391640000 \\
\hline $\mathrm{H}$ & 4.8566760000 & 6.1770120000 & -0.7994920000 \\
\hline $\mathrm{H}$ & 1.5454180000 & 2.5425490000 & 1.4824570000 \\
\hline$N$ & -0.5166160000 & 2.6862790000 & 0.2443590000 \\
\hline $\mathrm{H}$ & -0.3720100000 & 1.9445390000 & 0.9136240000 \\
\hline C & -3.9527540000 & 1.5790980000 & -0.5111430000 \\
\hline $\mathrm{H}$ & -2.3033680000 & 0.8637900000 & 0.6848440000 \\
\hline C & -4.4187400000 & 2.6291790000 & -1.3266200000 \\
\hline $\mathrm{H}$ & -3.9213720000 & 4.4811700000 & -2.3083440000 \\
\hline C & -5.8729740000 & 2.4232240000 & -1.6806430000 \\
\hline C & -5.0527240000 & 0.6315070000 & -0.2447770000 \\
\hline C & -6.3342550000 & 1.3577940000 & -0.6529580000 \\
\hline $\mathrm{H}$ & -6.7811920000 & 1.8571600000 & 0.2185760000 \\
\hline $\mathrm{H}$ & -7.0910570000 & 0.6808970000 & -1.0584510000 \\
\hline $\mathrm{H}$ & -5.9755300000 & 2.0360130000 & -2.7037050000 \\
\hline $\mathrm{H}$ & -6.4586740000 & 3.3467520000 & -1.6303960000 \\
\hline
\end{tabular}

Sum of electronic and zero-point Energies $=-1683.883953$ 


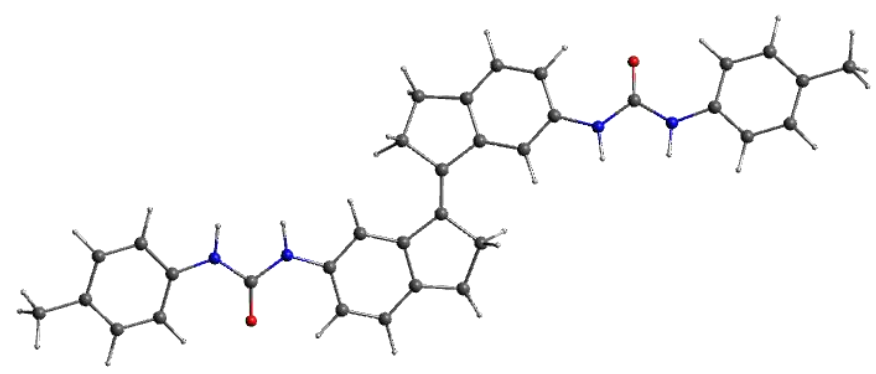

Table S16. Cartesian coordinates of $E-1$ (approximate width $\times$ height $\times$ depth $=26.9 \times 10.2 \times 2.8 \AA$ ).

\begin{tabular}{|c|c|c|c|}
\hline atom & $x$ & Y & Z \\
\hline C & 1.7307360000 & 2.4455110000 & -0.8581430000 \\
\hline C & 1.6501510000 & 1.0686670000 & -0.5668060000 \\
\hline C & 0.3615640000 & 3.0232440000 & -1.1207740000 \\
\hline C & -0.6039440000 & 1.9032300000 & -0.6565820000 \\
\hline $\mathrm{H}$ & 0.2273660000 & 3.2315030000 & -2.1906950000 \\
\hline $\mathrm{H}$ & 0.1930620000 & 3.9688890000 & -0.5944620000 \\
\hline C & 0.2418030000 & 0.6338950000 & -0.5797530000 \\
\hline $\mathrm{H}$ & -1.4559230000 & 1.7864390000 & -1.3321670000 \\
\hline $\mathrm{H}$ & -1.0104210000 & 2.1500260000 & 0.3341140000 \\
\hline C & 2.9642930000 & 3.0830780000 & -0.8889100000 \\
\hline C & 4.1393680000 & 2.3780140000 & -0.6207050000 \\
\hline C & 4.0668470000 & 1.0096400000 & -0.3109790000 \\
\hline C & 2.8229460000 & 0.3590410000 & -0.2835020000 \\
\hline $\mathrm{H}$ & 3.0281880000 & 4.1438660000 & -1.1176240000 \\
\hline $\mathrm{H}$ & 5.1016020000 & 2.8678410000 & -0.6376280000 \\
\hline $\mathrm{H}$ & 2.7850880000 & -0.6897100000 & -0.0104510000 \\
\hline C & -2.9642860000 & -3.0830350000 & -0.8890290000 \\
\hline C & -4.1393650000 & -2.3779770000 & -0.6208240000 \\
\hline $\mathrm{H}$ & -5.1015980000 & -2.8678060000 & -0.6377670000 \\
\hline C & -4.0668490000 & -1.0096120000 & -0.3110630000 \\
\hline C & -2.8229490000 & -0.3590120000 & -0.2835520000 \\
\hline$N$ & 5.1973210000 & 0.2210930000 & -0.0055450000 \\
\hline C & 6.5296460000 & 0.6070880000 & 0.0516980000 \\
\hline$N$ & 7.3613870000 & -0.4460710000 & 0.4046280000 \\
\hline C & 8.7647880000 & -0.4394010000 & 0.5522650000 \\
\hline O & 6.9250110000 & 1.7412930000 & -0.1826970000 \\
\hline C & 9.3723340000 & -1.6428400000 & 0.9415430000 \\
\hline C & 9.5719080000 & 0.6871470000 & 0.3363880000 \\
\hline C & 10.9512800000 & 0.5845210000 & 0.5096270000 \\
\hline C & 10.7510330000 & -1.7214050000 & 1.1083700000 \\
\hline C & 11.5736270000 & -0.6093010000 & 0.8925950000 \\
\hline C & 13.0737000000 & -0.7017300000 & 1.0410440000 \\
\hline $\mathrm{H}$ & 13.5028480000 & 0.2517150000 & 1.3638680000 \\
\hline $\mathrm{H}$ & 13.5553750000 & -0.9684740000 & 0.0916330000 \\
\hline $\mathrm{H}$ & 13.3580790000 & -1.4636510000 & 1.7733150000 \\
\hline $\mathrm{H}$ & 9.1156970000 & 1.6215230000 & 0.0441740000 \\
\hline $\mathrm{H}$ & 11.5597710000 & 1.4698500000 & 0.3409770000 \\
\hline $\mathrm{H}$ & 8.7595420000 & -2.5245240000 & 1.1197800000 \\
\hline
\end{tabular}




$\begin{array}{lrrr}\text { H } & 11.1925570000 & -2.6667620000 & 1.4137680000 \\ \mathrm{H} & 4.9830960000 & -0.7459300000 & 0.1878470000 \\ \mathrm{H} & 6.9311790000 & -1.3379360000 & 0.5996190000 \\ \mathrm{C} & -6.5296460000 & -0.6070850000 & 0.0516520000 \\ \mathrm{~N} & -7.3614020000 & 0.4460800000 & 0.4045310000 \\ \mathrm{C} & -8.7647970000 & 0.4393820000 & 0.5522210000 \\ \mathrm{O} & -6.9249950000 & -1.7413120000 & -0.1826660000 \\ \mathrm{C} & -9.5718880000 & -0.6872200000 & 0.3365310000 \\ \mathrm{C} & -9.3723670000 & 1.6428540000 & 0.9413660000 \\ \mathrm{C} & -10.7510600000 & 1.7213950000 & 1.1082450000 \\ \mathrm{C} & -10.9512570000 & -0.5846180000 & 0.5098200000 \\ \mathrm{C} & -11.5736260000 & 0.6092320000 & 0.8926570000 \\ \mathrm{C} & -13.0736950000 & 0.7016400000 & 1.0411630000 \\ \mathrm{H} & -13.3580500000 & 1.4633410000 & 1.7736740000 \\ \mathrm{H} & -13.5028490000 & -0.2518970000 & 1.3637020000 \\ \mathrm{H} & -13.5553850000 & 0.9686890000 & 0.0918450000 \\ \mathrm{H} & -9.1156580000 & -1.6216180000 & 0.0444170000 \\ \mathrm{H} & -8.7595970000 & 2.5245820000 & 1.1194580000 \\ \mathrm{H} & -11.1926020000 & 2.6667780000 & 1.4135370000 \\ \mathrm{H} & -11.5597260000 & -1.4699900000 & 0.3413160000 \\ \mathrm{H} & -6.9312170000 & 1.3379880000 & 0.5993750000 \\ \mathrm{~N} & -5.1973290000 & -0.2210700000 & -0.0056360000 \\ \mathrm{H} & -4.9831070000 & 0.7459480000 & 0.1877850000 \\ \mathrm{C} & -1.6501490000 & -1.0686310000 & -0.5668570000 \\ \mathrm{H} & -2.7850950000 & 0.6897320000 & -0.0104750000 \\ \mathrm{C} & -1.7307300000 & -2.4454680000 & -0.8582290000 \\ \mathrm{H} & -3.0281770000 & -4.1438170000 & -1.1177700000 \\ \mathrm{C} & -0.3615540000 & -3.0231940000 & -1.1208550000 \\ \mathrm{C} & -0.2418010000 & -0.6338580000 & -0.5797730000 \\ \mathrm{C} & 0.6039470000 & -1.9031910000 & -0.6566220000 \\ \mathrm{H} & 1.0104100000 & -2.1500110000 & 0.3340740000 \\ \mathrm{H} & 1.4559360000 & -1.7863830000 & -1.3321920000 \\ \mathrm{H} & -0.2273410000 & -3.2314270000 & -2.1907790000 \\ \mathrm{H} & -0.1930590000 & -3.9688520000 & -0.5945640000 \\ & & & \end{array}$

Sum of electronic and zero-point Energies $=-1683.887605$ 


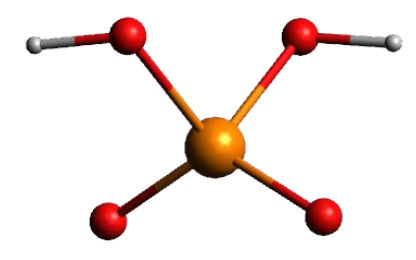

Table S17. Cartesian coordinates of $\mathrm{H}_{2} \mathrm{PO}_{4}^{-}$(approximate radius $=2.5 \AA$ ).

\begin{tabular}{lccc}
\hline atom & X & Y & Z \\
\hline P & 0.0000000000 & 0.0000180000 & -0.1653310000 \\
O & -1.0101600000 & -0.8033300000 & 0.9083060000 \\
H & -1.8339000000 & -0.3034530000 & 0.8348330000 \\
O & 1.0101720000 & 0.8031570000 & 0.9084420000 \\
O & -0.8685690000 & 1.0143440000 & -0.8576320000 \\
H & 1.8339010000 & 0.3032610000 & 0.8349340000 \\
O & 0.8685580000 & -1.0141790000 & -0.8578410000
\end{tabular}

Sum of electronic and zero-point Energies $=-643.562195$ 


\section{S12. Scripts used for data processing}

\section{S12.1 Analysis of association data from chemical shifts}

Script S1. Python code used for fitting association constants to chemical shift data.

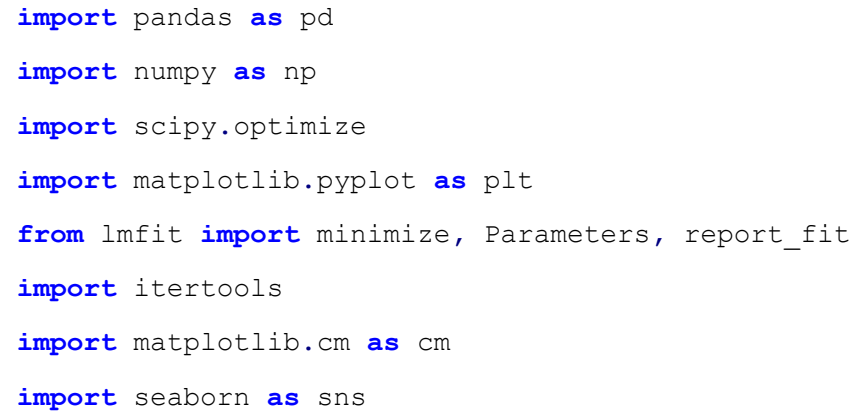


except TypeError:

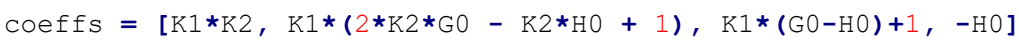

$R=n p \cdot r o o t s(\operatorname{coeffs})$

return $\min (\mathrm{R}[\mathrm{R}>=0])$

def nmr21 (X, K1, K2, delHG, delH2G) :

' ' 'nmr21: calculates chemical shift difference delDel for a given peak from the free host chemical

shift as a function of $\mathrm{X}=\mathrm{HO}, \mathrm{GO}, \mathrm{K} 1, \mathrm{~K} 2$, delHG = chemical shift difference on first association, delH2G = chemical shift difference on second association.' ''

$\mathrm{HO}, \mathrm{GO}=\mathrm{X}$

$\mathrm{H}=\mathrm{H} 21(\mathrm{GO}, \mathrm{HO}, \mathrm{K} 1, \mathrm{~K} 2)$

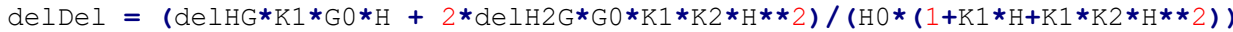

return delDel

def nmr21_dataset(X,params, i) :

' ' 'Given $\mathrm{X}=\mathrm{HO}$, GO and params = lmfit parameters element for multiple peaks, calculates chemical shifts for each peak, for each [GO, HO] pairing'''

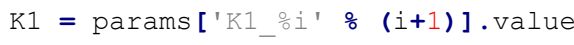

$\mathrm{K} 2=$ params ['K2_-i' $\%(i+1)] \cdot v a l u e$

delHG = params ['delDHG1 \%i' \% (i+1)].value

delHG2 = params['delDHG2 i. 응 (i+1)].value

return nmr21 (X, K1, K2, delHG, delHG2)

def objective(params, $x$, data):

"" Calculate total residual for fits to several data sets""

$\operatorname{dataT}=\mathrm{np} \cdot \operatorname{array}(\operatorname{data} \cdot \mathrm{T}[2: \mathbf{]})$

ndata, $\mathrm{nx}=$ dataT. shape

resid $=0.0 * \operatorname{dataT}[:]$

\# make residual per data set

for $i$ in range(ndata):

$\operatorname{dataT}[i]=\operatorname{dataT}[i]-\operatorname{dataT}[i][0]$

$\operatorname{resid}[i,:]=\operatorname{dataT}[i,:]-\operatorname{nmr} 21$ dataset$(x, \operatorname{params}, i)$

\# now flatten this to a 1D array, as minimize() needs

return resid.flatten()

$\mathrm{X}=$ data.iloc $[:, 0]$, data.iloc $[:, 1]$

$\operatorname{dataT}=n p \cdot \operatorname{array}(\operatorname{data} \cdot \mathrm{T}[2:])$

fit_params = Parameters()

for iy, $y$ in enumerate(dataT):

fit_params.add ('K1_\%i' $\%(i y+1)$, value=1000, $\min =0.0, \max =1 e 6$ )

fit_params.add('K2_\%i' $\%(i y+1), \operatorname{value}=100, \min =0.0, \max =1 e 4)$

fit_params.add('deldHG1_oi' $\frac{\circ}{(i y+1),}$ value=1.0, $\min =-4.0, \max =4.0$ )

fit_params.add('delDHG2 $\%$ ' $\%(i y+1)$, value=-1.0, $\min =-4.0, \max =4.0$ )

for iy in range $(2$, len $(\operatorname{dataT})+1)$ : 


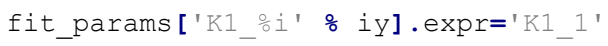

fit_params ['K2_oi' $\left.\frac{\circ}{i} y\right] \cdot \operatorname{expr}=$ ' $K 2{ }_{-}{ }^{1}$ '

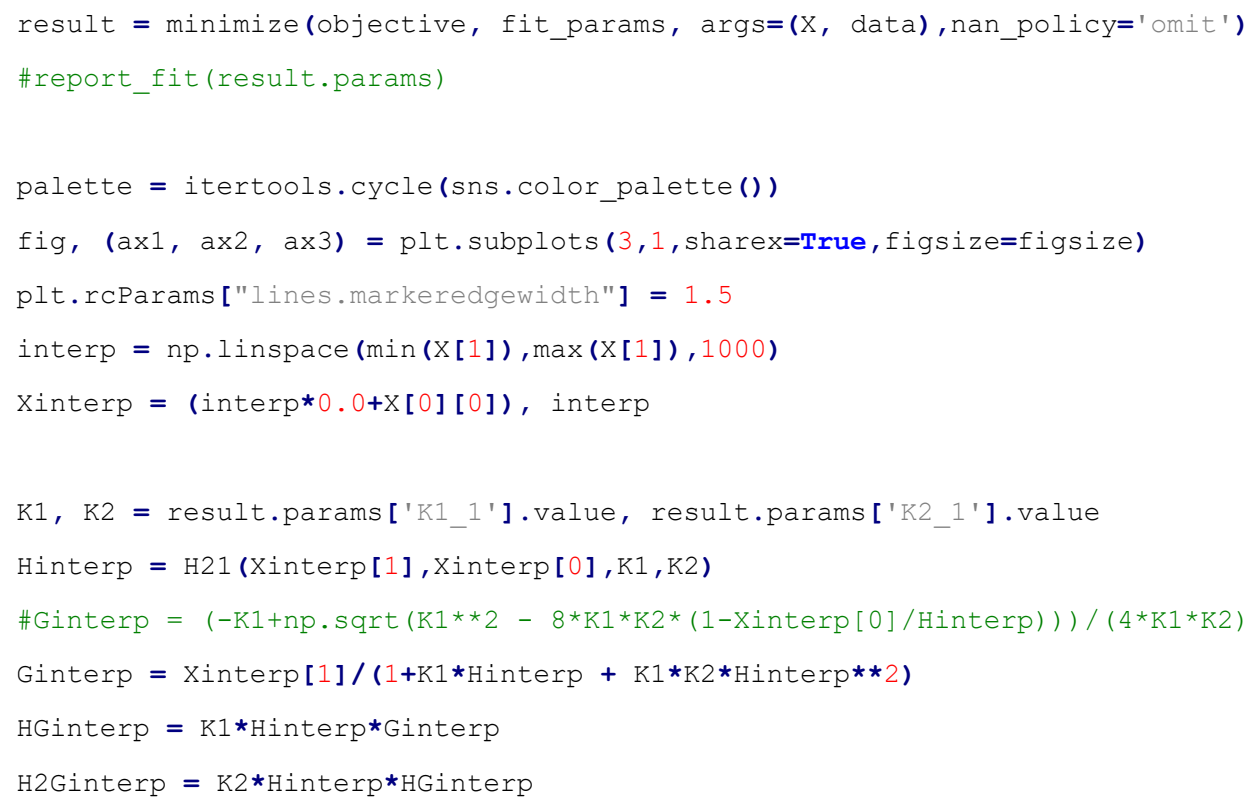


plt.tight_layout()

fig.align_labels()

plt.show()

return result, fig

\#Global fit for $1: 2 \mathrm{H}: \mathrm{G}$ complex data

def Global12(data,figsize= $(8,6)$, alpha=None, fmt=' $0^{--^{\prime}}$ ) :

' ' 'data: A pandas dataframe (with header) containining host concentrations in the first column, guest concentrations in the second column, and chemical shifts in subsequent columns.

figsize: Optional. a tuple passed to matplotlib for plotting of association data.

alpha: Optional. Cooperativity used for fitting 1:2 model. Allowed to float if set to None (default). For a non-cooperative $1: 2$ fit, set alpha=1.

fmt: $\quad$ Formatting string used for residuals of plot.' ''

def $\mathrm{G} 12(\mathrm{GO}, \mathrm{HO}, \mathrm{K} 1, \mathrm{~K} 2)$ :

$\mathrm{GO}, \mathrm{H} 0, \mathrm{~K} 1, \mathrm{~K} 2=\mathrm{np} \cdot \operatorname{asarray}(\mathrm{GO}), \mathrm{np} \cdot \operatorname{asarray}(\mathrm{H} 0), \mathrm{np} \cdot \operatorname{asarray}(\mathrm{K} 1), \mathrm{np} \cdot \operatorname{asarray}(\mathrm{K} 2)$

try:

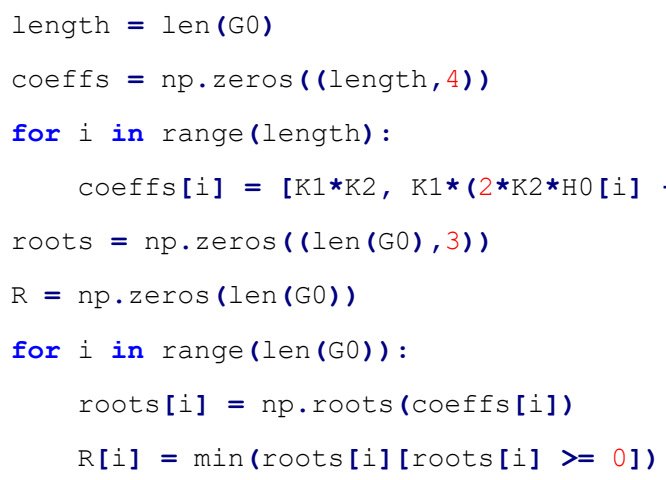


return $\mathrm{nmr} 12(\mathrm{X}, \mathrm{K} 1, \mathrm{~K} 2$, delHG, delHG2)

objective(params, $\mathrm{x}$, data):

"" calculate total residual for fits to several data sets""

$\operatorname{dataT}=\mathrm{np} \cdot \operatorname{array}(\operatorname{data} \cdot \mathrm{T}[2:])$

ndata, $\mathrm{nx}=$ dataT. shape

resid $=0.0 *$ dataT $[:]$

\# make residual per data set

for $i$ in range (ndata):

$\operatorname{dataT}[i]=\operatorname{dataT}[i]-\operatorname{dataT}[i][0]$

$\operatorname{resid}[i,:]=\operatorname{dataT}[i,:]-\operatorname{nmr} 12 \_\operatorname{dataset}(\mathrm{X}, \operatorname{params}, i)$

\# now flatten this to a 1D array, as minimize() needs

return resid.flatten()

$\mathrm{X}=$ data.iloc $[:, 0]$, data.iloc $[:, 1]$

$\operatorname{dataT}=\mathrm{np} \cdot \operatorname{array}(\operatorname{data} \cdot \mathrm{T}[2:])$

fit_params = Parameters()

for iy, $y$ in enumerate(dataT):

fit_params.add('K1_\%i' $\%(i y+1)$, value=1000, $\min =0.0, \max =1 e 5$ )

if alpha $==$ None:

fit_params.add('alpha_oi' $\%(i y+1)$, value=1, min=0.0, $\max =10$ )

else:

fit_params.add('alpha_oi' $\%(i y+1)$, value=alpha, vary=False)

fit_params.add('delDHG1_oi' $\frac{\circ}{0}(i y+1)$, value=1.0, $\min =-4.0, \max =4.0$ )

fit_params.add('delDHG2_i' $\frac{\circ}{0}(i y+1)$, value=-1.0, $\min =-4.0, \max =4.0$ )

for iy in range $(2$, len $(\operatorname{dataT})+1)$ :

fit_params['K1_oi' \% iy].expr='K1_1'

fit_params ['alpha_oi' \% iy].expr='alpha_1'

result $=$ minimize(objective, fit_params, args=(x, data), nan_policy='omit')

\#report_fit(result.params)

palette $=$ itertools.cycle(sns.color_palette())

fig, (ax1, ax2, $a x 3)=$ plt. $\operatorname{subplots}(3,1$, sharex=True,figsize=figsize)

plt.rcParams ["lines.markeredgewidth"] $=1.5$

interp $=n p \cdot \operatorname{linspace}(\min (\mathrm{X}[1]), \max (\mathrm{X}[1]), 1000)$

Xinterp $=($ interp*0.0+X[0][0]), interp

$\mathrm{K} 1$ = result.params [ $\mathrm{K}{ }_{1}{ }^{1}$ '] $\cdot$ value

$\mathrm{K} 2=\mathrm{K} 1$ *result.params['alpha_1'].value/4

Ginterp $=\mathrm{G} 12$ (Xinterp[1],Xinterp[0],K1,K2)

Hinterp $=$ Xinterp $[0] /(1+K 1 *$ Ginterp $+\mathrm{K} 1$ *K2 * Ginterp * Ginterp $)$ 


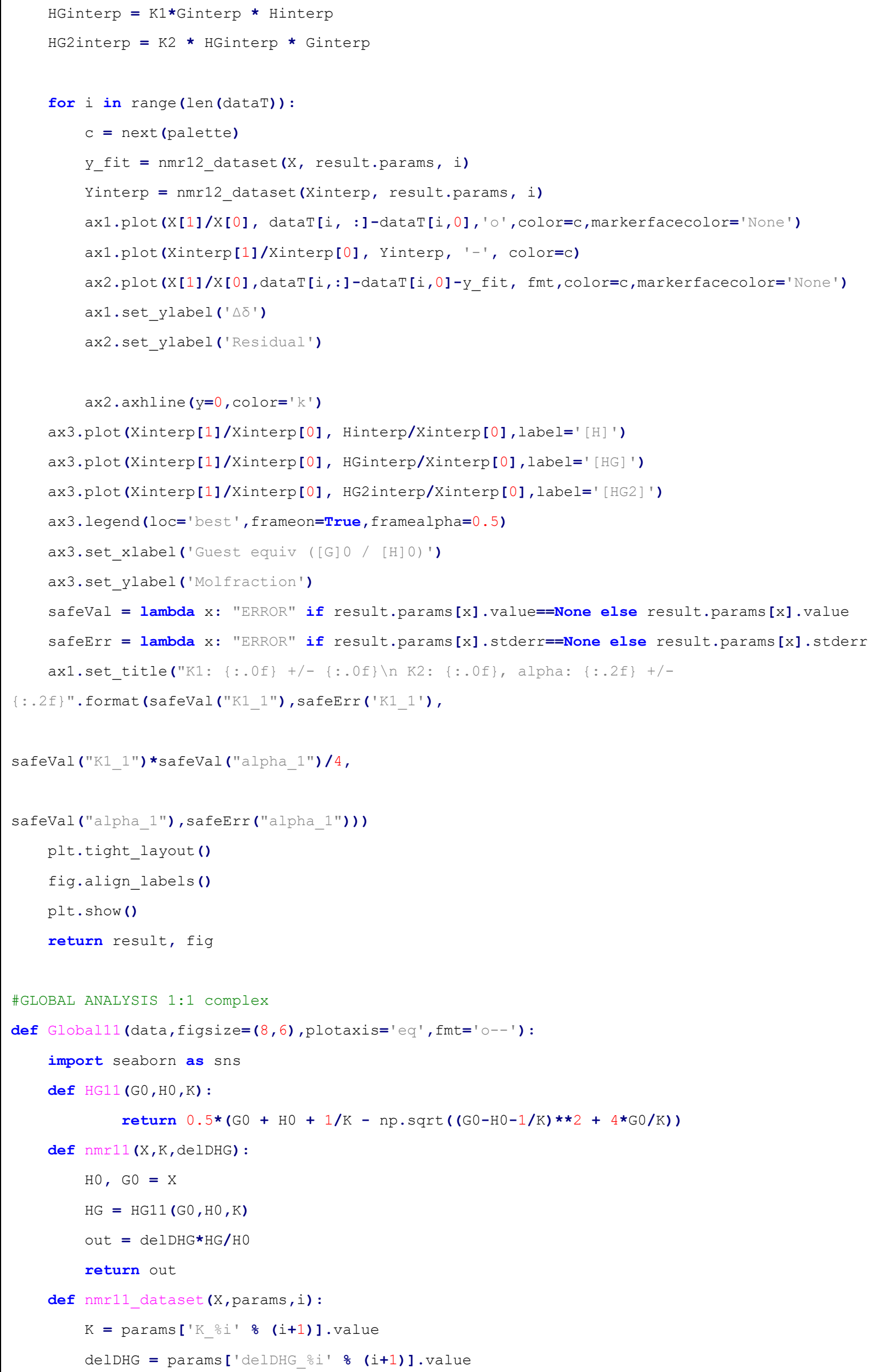


return $\mathrm{nmrl1}(\mathrm{X}, \mathrm{K}$, del $\mathrm{DHG})$

def objective(params, $x$, data):

""Calculate total residual for fits to several data sets""

$\operatorname{dataT}=\mathrm{np} \cdot \operatorname{array}(\operatorname{data} \cdot \mathrm{T}[2:])$

ndata, $\mathrm{nx}=$ dataT. shape

resid $=0.0 *$ dataT $[:]$

\# make residual per data set

for $i$ in range(ndata):

$\operatorname{dataT}[i]=\operatorname{dataT}[i]-\operatorname{dataT}[i][0]$

$\operatorname{resid}[i,:]=\operatorname{dataT}[i,:]-\operatorname{nmr} 11$ dataset$(\mathrm{X}, \operatorname{params}, i)$

\# now flatten this to a 1D array, as minimize() needs

return resid.flatten()

$\mathrm{X}=$ data.iloc $[:, 0]$, data.iloc $[:, 1]$

$\operatorname{dataT}=\mathrm{np} \cdot \operatorname{array}(\operatorname{data} \cdot \mathrm{T}[2:])$

fit_params = Parameters()

for iy, $y$ in enumerate(dataT):

fit_params.add('K_oi' $\frac{\circ}{(i y+1),}$ value=200, $\min =0.0, \max =1 e 6$ )

fit_params.add('delDHG_oi' $\frac{\circ}{\circ}(i y+1), \operatorname{value}=0.4, \min =-4.0, \max =4.0$ )

for iy in range $(2$, len $(\operatorname{dataT})+1)$ :

fit_params ['K_oi' $\%$ iy].expr=' $K_{-} 1$ '

result = minimize(objective, fit_params, args=(x, data), nan_policy='omit')

import matplotlib. $\mathrm{cm}$ as $\mathrm{cm}$

import seaborn as sns

palette $=$ itertools. cycle(sns.color_palette())

plt.rcParams ["lines.markeredgewidth"] $=1.5$

fig, $(\mathrm{ax} 1, \mathrm{ax} 2, \mathrm{ax} 3)=$ plt.subplots $(3,1$, sharex=True,figsize=figsize)

interp $=n p \cdot \operatorname{linspace}(\min (x[1]), \max (x[1]), 1000)$

Xinterp $=($ interp*0.0+X[0][0]), interp

HGinterp = HG11 (Xinterp[1],Xinterp[0], result.params['K_1'].value)

Hinterp = Xinterp[0] - HGinterp

for $i$ in range(len(dataT)):

$c=$ next (palette)

y_fit $=$ nmr11_dataset $(x$, result.params, i)

Yinterp = nmr11_dataset(Xinterp, result.params, i)

if plotaxis $==$ ' $^{\prime} \mathrm{q}^{\prime}$ :

ax1.plot (x[1]/x[0], dataT[i, :]-dataT[i,0], 'o', color=c,markerfacecolor='None') 


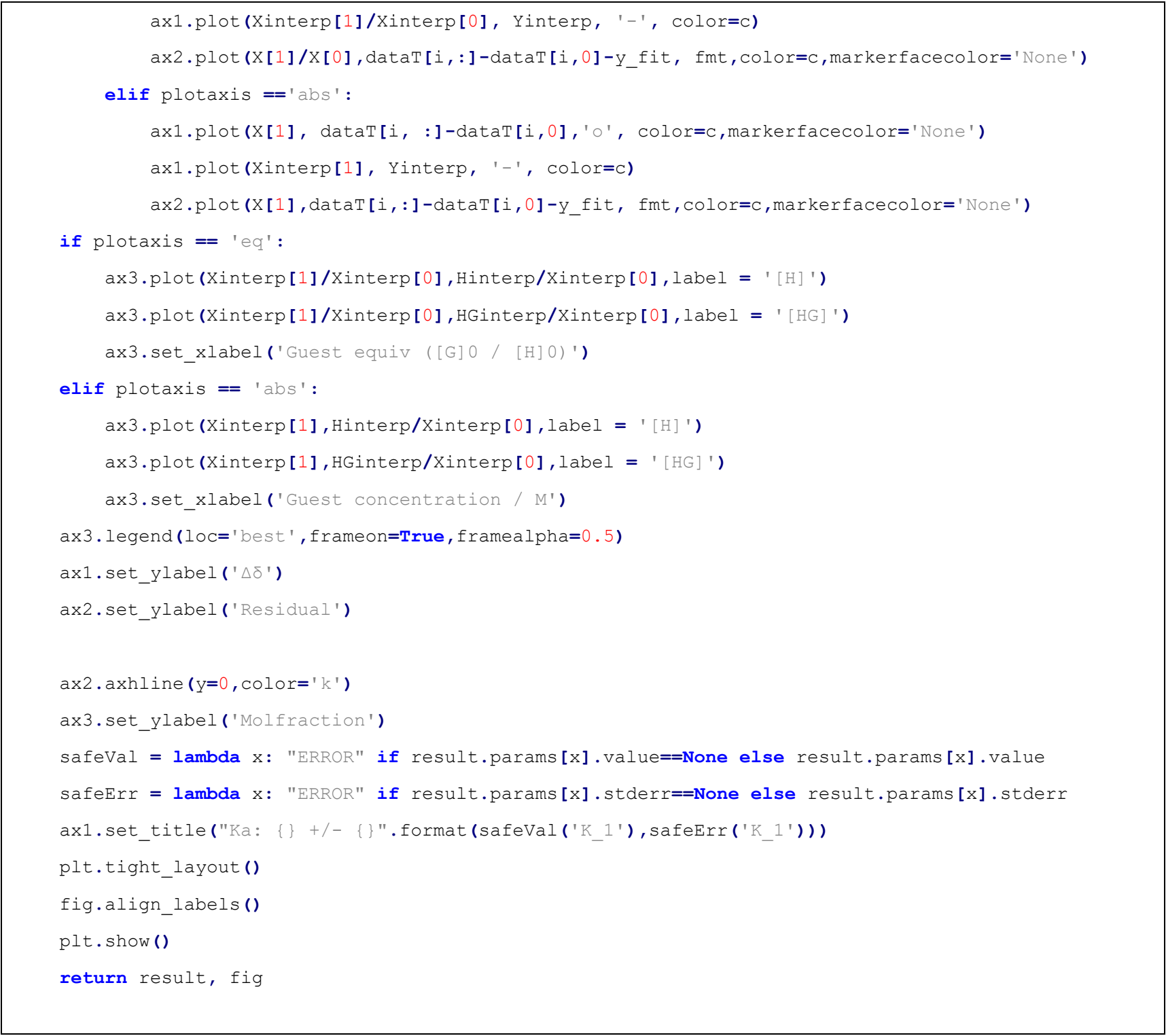

\section{S12.2 Processing and analysis of diffusion data}

Script S 2. Functions used for analysis and processing of diffusion NMR data. MestReNova was used to obtain integrals of peaks of interest, and

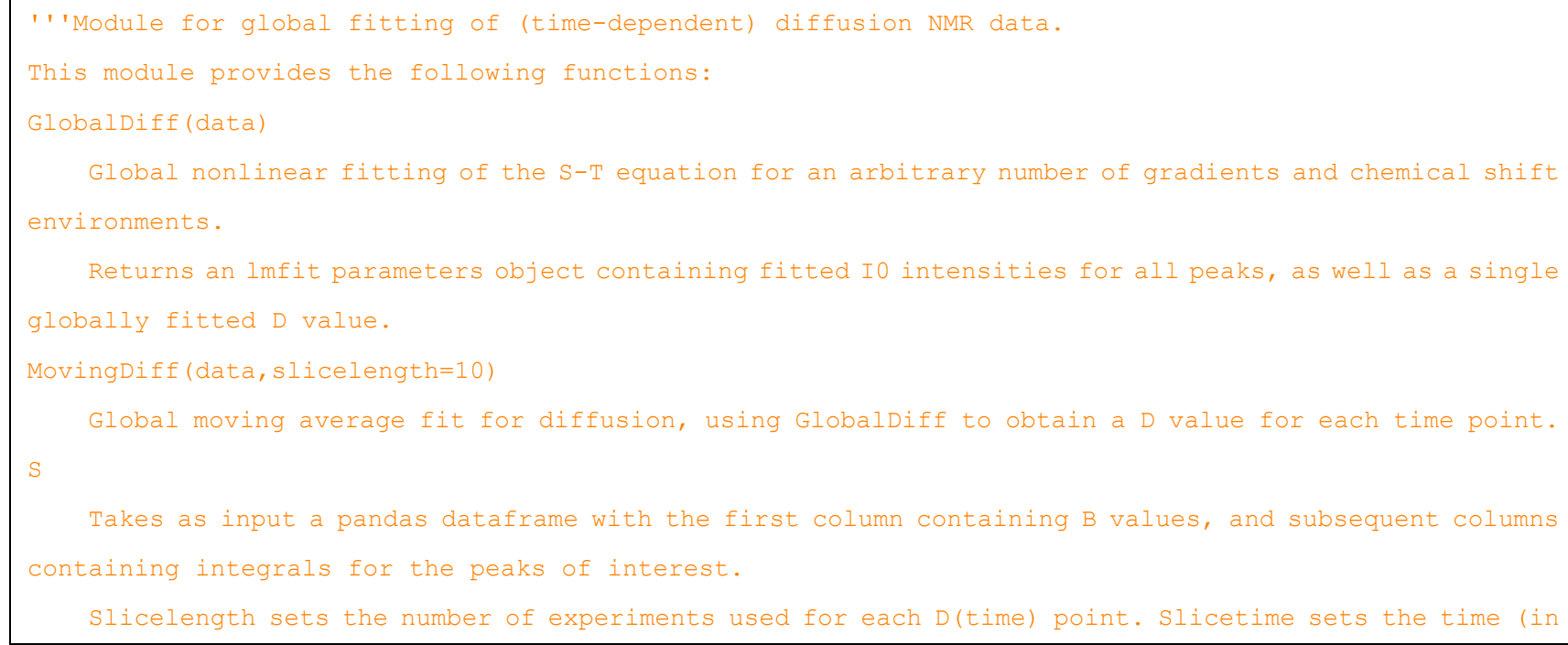

Returns an lmfit parameters object containing fitted I0 intensities for all peaks, as well as a single globally fitted D value.

MovingDiff(data, slicelength=10)

Global moving average fit for diffusion, using Globaldiff to obtain a D value for each time point. S

Takes as input a pandas dataframe with the first column containing B values, and subsequent columns containing integrals for the peaks of interest.

Slicelength sets the number of experiments used for each D(time) point. Slicetime sets the time (in 
minutes) taken to acquire each gradient slice.

Returns (Dpoints, Iopoints, Derr, Ierr): four pandas dataframes, each with indices corresponding to time. Iopoints and Ierr contain a column for each fitted NMR peak, while Dpoint and Der contain a single column with globally fitted diffusion data.

For systems involving multiple chemical species, use separateMovingDiffusion to obtain individual (non-globally fitted) diffusion coefficients.

Dpoints, Iopoints, Derr, and Ierr contain diffusion points, extrapolated intensities, and respective errors for each from fitting.

MovingDiff CSv(fname, slicelength=10, slicetime=2/3)

A wrapper for MogvingDiff to act on a similarly formatted . Csv file.

SeparateMovingDiffusion (data, slicelength=10, slicetime=2/3)

Returns (Dpoints, IOpoints, Derr, Ierr): four pandas dataframes, each with indexes corresponding to time and a column for each peak.

Dpoints, IOpoints, Derr, and Ierr contain diffusion points, extrapolated intensities, and respective errors for each from fitting.

SeparateMovingDiffusion_csv(fname, slicelength=10, slicetime=2/3)

Generates a pair of pandas dataframes [D, I] containing calculation time-dependent diffusion coefficients and unattenuated integrals.

Acts on a .csv file with the first column containing B-values, and each subsequent column containing the corresponding integrals for a particular chemical shift.

MeoHTemp (dDelta)

Calculates temperature from methanol OH-CH3 chemical shift separation (in ppm)

MeOHDiff(dDelta)

Calculates expected diffusion coefficient from methanol OH-CH3 chemical shift separation (in ppm) ' ' '

def Globaldiff(data):

'' 'Function to globally fit a single diffusion coefficient to data from a list of peaks

Input: a pandas dataframe consisting of:

B_O IO_O II_O ... In In $_{-}$

B_1 IO_1 I1_1 ... In 1

$\cdots$

B_m I0_m II_m ... In_m

where $\mathrm{B}$ is the list of B-parameters for all experiments, and each column In contains the integrals measured for a single peak.

The function returns a single lmfit Parameters object.

1, '

\section{import numpy as $\mathrm{np}$}

import pandas as pd

from lmfit import minimize, Parameters, report fit

def $\operatorname{STExp}(B, I 0, D)$ :

$I 0, B, D=n p \cdot \operatorname{asarray}(I 0), n p \cdot \operatorname{asarray}(B), n p \cdot \operatorname{asarray}(D)$

return $I 0 *_{n p} \cdot \exp (-B * D)$

def STExp_dataset(B,params, i) : 


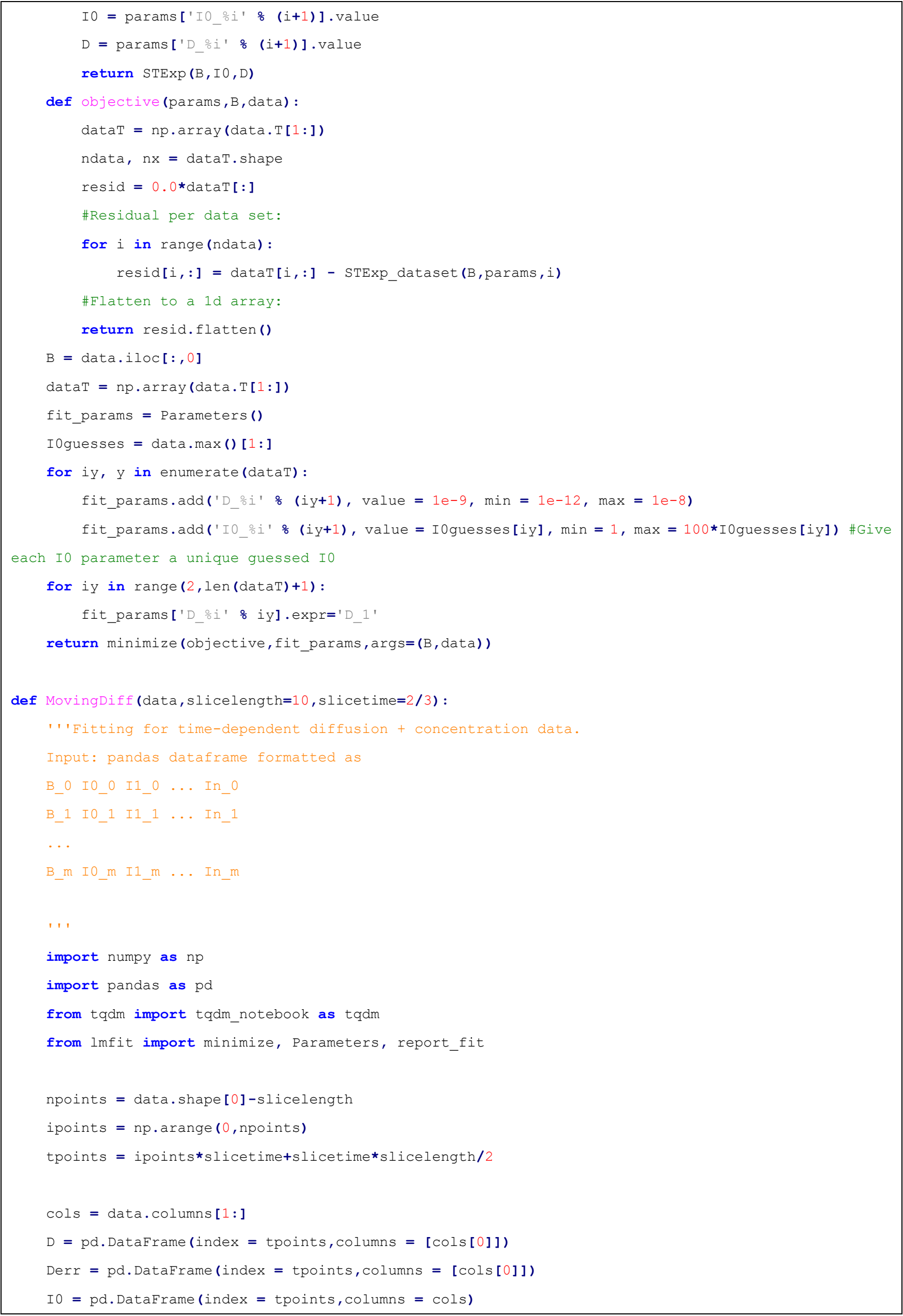


IOerr $=$ pd. DataFrame $($ index $=$ tpoints, columns $=$ cols $)$

for $i$ in tqdm(range (npoints), desc='Progress: ' , position=1, leave=False):

params = GlobalDiff(data.iloc[i:itslicelength])

IOslice, I0errslice $=[],[]$

for Ival in range $(0, \operatorname{len}(\operatorname{cols}))$ :

ParamName $=$ 'IO_ \{\} '. format $(\operatorname{Ival}+1)$

\#I0.insert (params.params [ParamName]. value, index=i, col)

I0slice.append (params.params [ParamName].value)

I0errslice.append (params.params [ParamName].stderr)

D.loc[tpoints[i], cols[0]] = params.params['D_1'].value

Derr.loc[tpoints[i], cols[0]] = params.params['D_1'].stderr

I0.loc[tpoints[i], cols] = I0slice

I0err.loc[tpoints[i],cols] = I0errslice

return D, IO, Derr, IOerr

def MovingDiff_csv(fname, slicelength=10, slicetime=2/3):

' 'A simple wrapper of MovingDiff() to act on .CSv files''

import pandas as pd

return MovingDiff(pd.read_csv(fname), slicelength,slicetime)

def SeparateMovingDiffusion(data, slicelength=10, slicetime=2/3):

''Moving average diffusion processing for multiple separate chemical species.

Acts on a pandas dataframe containing a list of B-values in teh first column, and corresponding peak integrals in subsequent columns.

Returns a pair of pandas dataframes [D,I] containing the calculated diffusion coefficients and concentrations for each peak present in the input array. ' '

import pandas as pd

import numpy as np

from tqdm import tqdm_notebook as tqdm

npoints = data.shape[0]-slicelength

ipoints $=$ np.arange $(0$, npoints $)$

tpoints = ipoints*slicetime+slicetime*slicelength/2

$\mathrm{D}=$ pd. DataFrame (index = tpoints, columns=data. columns $[1:])$

$I=$ pd. DataFrame (index = tpoints, columns=data. columns [1:])

Derr $=$ pd. DataFrame (index = tpoints, columns=data. columns [1:])

Ierr $=$ pd. DataFrame $($ index $=$ tpoints, columns=data. columns $[1:])$

for peak in tqdm(data.columns[1:], desc='Peak-by-peak progress',position=2):

td, ti,tderr,tierr $=$

MovingDiff(pd. concat ([data.iloc [:,0], data[peak] ], axis=1), slicelength=slicelength,slicetime=slicetime )

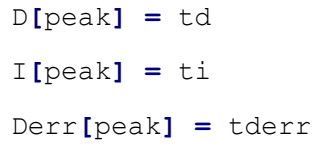




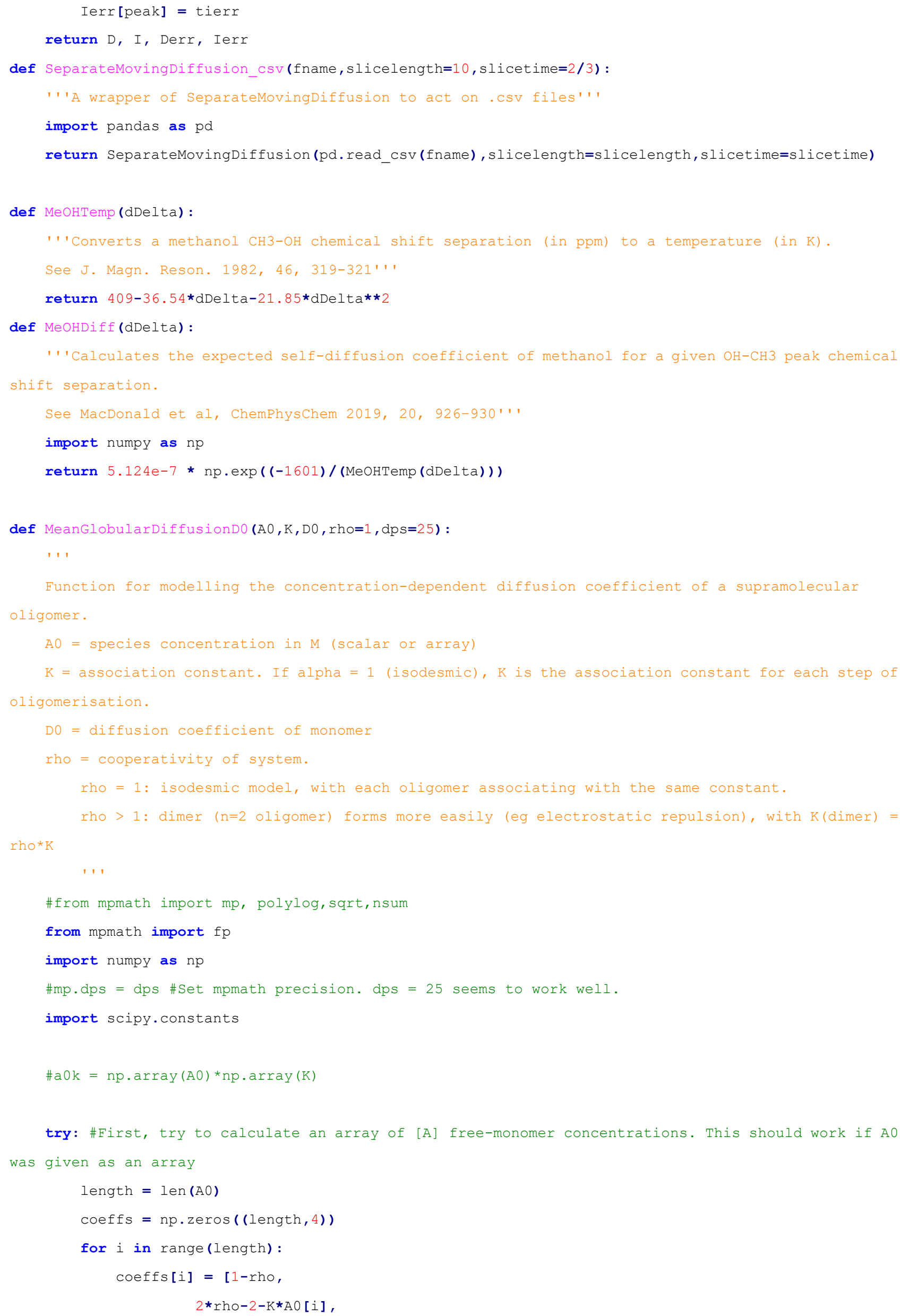




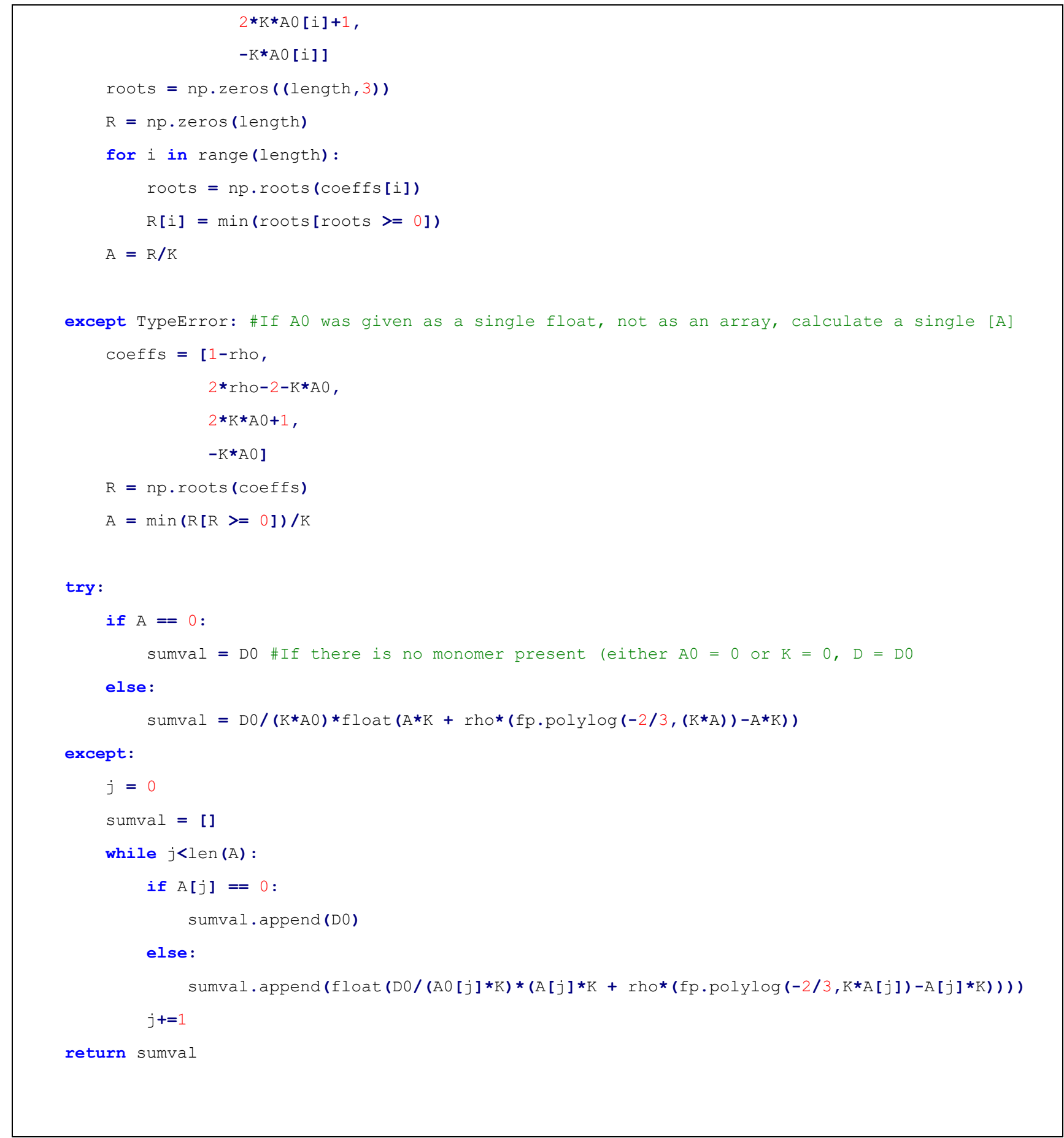




\section{S13. Additional References}

[1] D. Barišić, V. Tomišić, N. Bregović, Anal. Chim. Acta 2019, 1046, 77-92.

[2] K. Izutsu, T. Adachi, T. Fujinaga, Electrochim. Acta 1970, 15, 135-145.

[3] S. J. Wezenberg, B. L. Feringa, Org. Lett. 2017, 19, 324-327.

[4] R. B. Martin, Chem. Rev. 1996, 96, 3043-3064.

[5] W. Sutherland, The London, Edinburgh, and Dublin Philosophical Magazine and Journal of Science 1905, 9 , 781-785.

[6] W. S. Price, F. Tsuchiya, Y. Arata, J. Am. Chem. Soc. 1999, 121, 11503-11512.

[7] P. Thordarson, Chem. Soc. Rev. 2011, 40, 1305-1323.

[8] T. S. C. MacDonald, W. S. Price, J. E. Beves, ChemPhysChem 2019, 20, 926-930.

[9] a) T. M. Barbosa, R. Rittner, C. F. Tormena, G. A. Morris, M. Nilsson, RSC Adv. 2016, 6, 95173-95176; b) I. Swan, M. Reid, P. W. A. Howe, M. A. Connell, M. Nilsson, M. A. Moore, G. A. Morris, J. Magn. Reson. 2015, 252, 120-129.

[10] C. Ammann, P. Meier, A. Merbach, J. Magn. Reson. 1982, 46, 319-321.

[11] M. D. Hanwell, D. E. Curtis, D. C. Lonie, T. Vandermeersch, E. Zurek, G. R. Hutchison, Journal of Cheminformatics 2012, 4, 17.

[12] Gaussian 03, Revision D.01, G. W. T. M. J. Frisch, H. B. Schlegel, G. E. Scuseria, M. A. Robb, J. R. Cheeseman, J. A. Montgomery, Jr., T. Vreven, K. N. Kudin, J. C. Burant, J. M. Millam, S. S. Iyengar, J. Tomasi, V. Barone, B. Mennucci, M. Cossi, G. Scalmani, N. Rega, G. A. Petersson, H. Nakatsuji, M. Hada, M. Ehara, K. Toyota, R. Fukuda, J. Hasegawa, M. Ishida, T. Nakajima, Y. Honda, O. Kitao, H. Nakai, M. Klene, X. Li, J. E. Knox, H. P. Hratchian, J. B. Cross, V. Bakken, C. Adamo, J. Jaramillo, R. Gomperts, R. E. Stratmann, O. Yazyev, A. J. Austin, R. Cammi, C. Pomelli, J. W. Ochterski, P. Y. Ayala, K. Morokuma, G. A. Voth, P. Salvador, J. J. Dannenberg, V. G. Zakrzewski, S. Dapprich, A. D. Daniels, M. C. Strain, O. Farkas, D. K. Malick, A. D. Rabuck, K. Raghavachari, J. B. Foresman, J. V. Ortiz, Q. Cui, A. G. Baboul, S. Clifford, J. Cioslowski, B. B. Stefanov, G. Liu, A. Liashenko, P. Piskorz, I. Komaromi, R. L. Martin, D. J. Fox, T. Keith, M. A. Al-Laham, C. Y. Peng, A. Nanayakkara, M. Challacombe, P. M. W. Gill, B. Johnson, W. Chen, M. W. Wong, C. Gonzalez, and J. A. Pople, Gaussian Inc., Wallingford CT, 2004. 


\title{
Controlled diffusion of photoswitchable receptors by binding antielectrostatic phosphate oligomers
}

\author{
Thomas S. C. MacDonald, ${ }^{[a]}$ Ben L. Feringa ${ }^{[b]}$ William S. Price, ${ }^{[c]}$ Sander J. Wezenberg, ${ }^{*[b, d]}$ and \\ Jonathon E. Beves ${ }^{*[a]}$
}

\begin{abstract}
Dihydrogen phosphate anions are found to spontaneously associate into anti-electrostatic oligomers via hydrogen bonding interactions at millimolar concentrations in DMSO. Diffusion NMR measurements supported formation of these oligomers, which can be bound by photoswitchable anion receptors to form large bridged assemblies of approximately three times the volume of the unbound receptor. Photoisomerization of the oligomer-bound receptor causes a decrease in diffusion coefficient of up to $16 \%$, corresponding to a $70 \%$ increase in effective volume. This new approach to external control of diffusion opens prospects in controlling molecular transport.
\end{abstract}

Active control over molecular transport by synthetic systems is a topic of major contemporary interest. ${ }^{[1]}$ Recent progress has shown that motors, ${ }^{[2]}$ enzymes, or other energy consuming nanostructures can effectively drive molecular transport in solution. ${ }^{[2 b, 3]}$ Despite these advances, controlling transport of molecules in solution remains a challenging goal. One way to control transport is by modulating the diffusion rate of species in solution. Various theoretical proposals and experimental data have shown that increasing or decreasing the rate of diffusion can lead to directional transport when coupled with, for example, concentration gradients. ${ }^{[4]}$ Diffusion rates have been influenced using molecular photoswitches ${ }^{[5]}$ by altering self-assembled discrete structures ${ }^{[5 c, 5 e, 6]}$ or polymers. ${ }^{[5 a, 5 e, 6-7]}$ While diffusion $\mathrm{NMR}^{[8]}$ measurements are a known approach for characterizing supramolecular assembly, ${ }^{[9]}$ the use of switchable assembly to control diffusive transport is relatively unexplored.

In contrast to the chemical intuition that like charges repel, some anions are known to associate through hydrogen-bonds and form polyanionic species. ${ }^{[10]}$ This antielectrostatic hydrogen bonding $(\mathrm{AEHB})$ is common in the solid state for oxoanions such as $\mathrm{HCO}_{3}^{-}, \mathrm{HSO}_{4}^{-}$, and $\mathrm{H}_{2} \mathrm{PO}_{4}^{-}$(Figure 1). While AEHB interactions have been identified in solid-state crystal structures, detection of unchaperoned anion dimers or oligomers in solution is challenging due to limited spectroscopic signatures, weak anion-anion bonds, labile protons and rapidly exchanging bound species. These difficulties can be attenuated by the use of an anion-binding host to template AEHB interactions, ${ }^{[11]}$ leading to

[a] T. S. C. MacDonald, Dr. Jonathon E. Beves

School of Chemistry, UNSW Sydney

Sydney, NSW 2052 (Australia)

Email: j.beves@unsw.edu.au

[b] Dr. S. J. Wezenberg, Prof. B. L. Feringa

Stratingh Institute for Chemistry, University of Groningen

Nijenborgh 4, 9747 AG Groningen (The Netherlands)

[c] Prof. W. S. Price

School of Science, Western Sydney University

Penrith, NSW 2751 (Australia)

[d] Dr. S. J. Wezenberg

Leiden Institute of Chemistry, Leiden University

Einsteinweg 55, 2333 CC Leiden (The Netherlands)

Email: s.j.wezenberg@lic.leidenuniv.nl

Supporting information for this article is given via a link at the end of the document. reports of $\mathrm{HSO}_{4}^{-}$dimers ${ }^{[12]}$ and $\mathrm{H}_{2} \mathrm{PO}_{4}^{-}$dimers ${ }^{[13]}$ and oligomers $^{[14]}$ in solution. Conductimetric and spectroscopic techniques have been used to establish the formation of $\mathrm{AEHB}$ $\mathrm{HCO}_{3}{ }^{-}$and $\mathrm{H}_{2} \mathrm{PO}_{4}{ }^{-}$dimers in water ${ }^{[15]}$ as well as in $\mathrm{DMSO}^{[16]}$ and suggested the possibility of higher-order oligomers. ${ }^{[15 c]}$ However, to the best of our knowledge, the unassisted formation of AEHB oxoanion oligomers in solution has yet to be conclusively established.
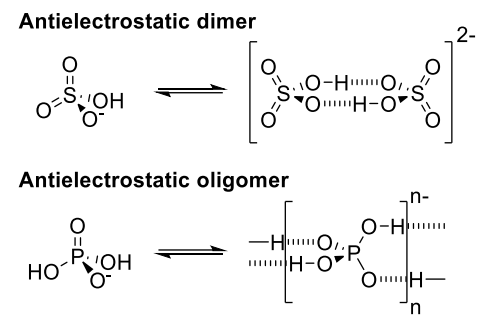

Figure 1. Antielectrostatic hydrogen-bonding of anions. Anions with a single hydrogen bond donor/acceptor pair $\left(e . g . \mathrm{HSO}_{4}^{-}\right)$may form dimers ${ }^{[12 a]}$ while anions with multiple donor/acceptors (e.g. $\mathrm{H}_{2} \mathrm{PO}_{4}^{-}$) can form oligomers in the solid state. ${ }^{[14 b]}$

Many small molecular receptors have been developed to selectively bind anions. ${ }^{[17]}$ Such binding may result in changes in the rate of diffusion of the receptor. If the binding properties could be modified by external stimuli, for example light, ${ }^{[18]}$ this could represent a means to control the rate of diffusion. Recently, some of us developed the first photoswitchable receptors exhibiting strong dihydrogen phosphate binding. ${ }^{[19]}$ These receptors were based on molecular motor and stiff-stilbene scaffolds ${ }^{[20]}$ containing urea anion binding motifs. These hosts could be converted from a weakly guest-binding $E$ to a strongly binding $Z$ form using near-UV light (Figure 2). We anticipated that the use of this type of photoswitchable anion receptors with AEHB dihydrogen phosphate oligomers would allow changes in diffusion to be controlled by light.
$E-1$

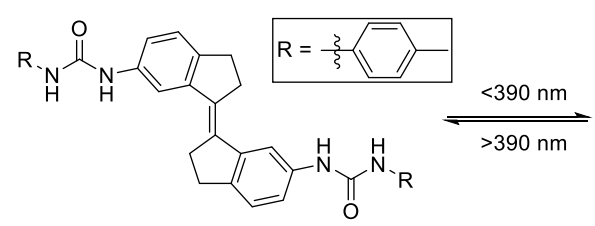

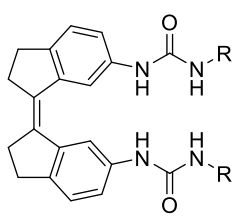

Z-1
Figure 2. Bis-urea anion binding photoswitch 1. Isomers $E-1$ and $Z-1$ exhibit different binding properties: the binding of $Z-1$ to anions is approximately an order of magnitude stronger than that of $E-\mathbf{1}$. The photoisomers can be interconverted by irradiation with near-UV light.

Herein we report quantitative self-association data for the antielectrostatic oligomerization of dihydrogen phosphate in DMSO at millimolar concentrations, and the use of a 
photoswitchable anion receptor to allow reversible binding to control rates of diffusive transport.

Our initial studies of tetrabutylammonium dihydrogen phosphate $\left(\left[\mathrm{NBu}_{4}\right]\left[\mathrm{H}_{2} \mathrm{PO}_{4}\right]\right)$ solutions in DMSO- $d_{6}$ with $0.5 \%$ added water ${ }^{[21]}$ revealed a surprising decrease in the diffusion coefficient of the $\mathrm{H}_{2} \mathrm{PO}_{4}^{-}$anion $D\left(\mathrm{H}_{2} \mathrm{PO}_{4}\right)$ at higher concentrations, while the diffusion coefficient of the $\mathrm{NBu}_{4}{ }^{+}$ counterion $D\left(\mathrm{NBu}_{4}\right)$ remained relatively constant (Figure 3; see SI-6). This behavior cannot be explained by changes in ion pairing or viscosity which must affect the diffusion coefficients of both species equally.

Control experiments conducted with tetrabutylammonium acetate did not show comparable continuing decreases in diffusion coefficients of either $\mathrm{NBu}_{4}{ }^{+}$or acetate over the same concentration range as used for $\left[\mathrm{NBu}_{4}\right]\left[\mathrm{H}_{2} \mathrm{PO}_{4}\right]$ (SI-S6.1), indicating that the formation of oligomers was unique to $\mathrm{H}_{2} \mathrm{PO}_{4}$.

Diffusion coefficients vary approximately proportionally to the inverse cube root of molecular volume, $\mathrm{V}^{-1 / 3}{ }^{-22]}$ The $50 \%$ decrease in $D\left(\mathrm{H}_{2} \mathrm{PO}_{4}\right)$ as the $\mathrm{H}_{2} \mathrm{PO}_{4}{ }^{-}$concentration is increased from 2 to $300 \mathrm{mM}$ suggests an eight-fold increase in effective volume over this concentration range. We propose this decrease in $D\left(\mathrm{H}_{2} \mathrm{PO}_{4}\right)$ is a result of the formation of $\mathrm{AEHB}$ oligomers of $\mathrm{H}_{2} \mathrm{PO}_{4}^{-}$in solution.

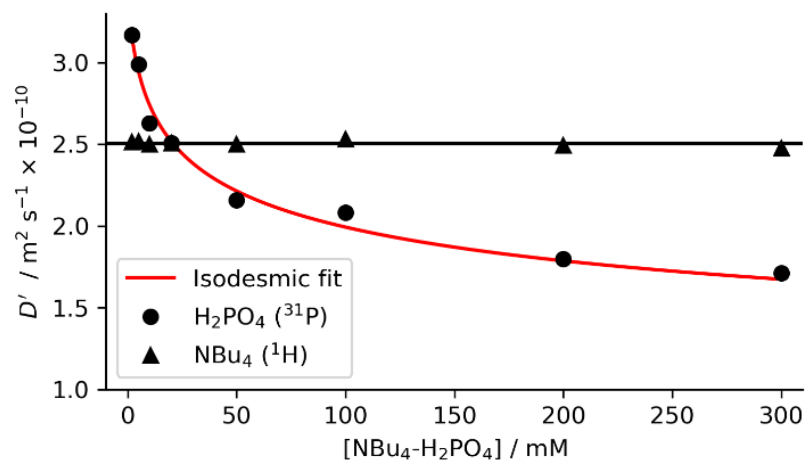

Figure 3. Diffusion coefficients of tetrabutylammonium dihydrogen phosphate $\left(\left[\mathrm{NBu}_{4}\right]\left[\mathrm{H}_{2} \mathrm{PO}_{4}\right]\right)$ measured by ${ }^{1} \mathrm{H}(500 \mathrm{MHz})$ or ${ }^{31} \mathrm{P}(202 \mathrm{MHz}) \mathrm{NMR}$ over the 2-300 mM concentration range and corrected for changes in viscosity using independent viscosity measurements (see SI-S4). An isodesmic oligomerisation model (red line) was fitted to the measured diffusion coefficients of dihydrogen phosphate giving parameters $K_{\mathrm{i}}=120 \pm 32 \mathrm{M}^{-1}$ and $D_{0}=3.39 \pm 0.11 \times 10^{-10} \mathrm{~m}^{2} \mathrm{~s}^{-1}$. All measurements in DMSO- $d_{6}$ with $0.5 \%$ added water. Data was processed using scripts given in SI-12.

A simple model for supramolecular oligomerization is the isodesmic model, in which the addition of each monomer to an oligomer occurs with the same association constant $K_{\mathrm{i}}$ (SIS5.1). ${ }^{[23]}$ Combining this model with an inverse-cube relationship between $D$ and oligomer size (see SI-S5.2 for derivation and details) gives a model for the concentration dependence of the measured $D$ of a molecular species undergoing reversible oligomerization:

$$
\bar{D}=\frac{D_{0}}{K_{i}[\mathrm{~A}]_{0}} \mathrm{Li}_{-\frac{2}{3}}\left(K_{i}[\mathrm{~A}]\right)
$$

where $\mathrm{Li}_{\mathrm{s}}(\mathrm{z})$ is the polylogarithm function, ${ }^{[24]} D_{0}$ is the diffusion coefficient of the monomer, $K_{\mathrm{i}}$ is the isodesmic association constant, $[A]_{0}$ is the total concentration, and $[A]$ is the concentration of the free (monomeric) species which can be obtained from $K_{\mathrm{i}}$ and $[\mathrm{A}]_{0}$. Nonlinear regression of $\mathrm{Eq}(1)$ onto the measured diffusion coefficients of $\mathrm{H}_{2} \mathrm{PO}_{4}{ }^{-}$gave $K_{\mathrm{i}}=120 \pm 32$ $\mathrm{M}^{-1}$, surprisingly close to the reported dimerization constant of $\mathrm{H}_{2} \mathrm{PO}_{4}^{-}$in DMSO $\left(180 \mathrm{M}^{-1}\right)^{[16]}$. Our measured $K_{\mathrm{i}}$ corresponds to median complexes comprised of 4 or $10 \mathrm{H}_{2} \mathrm{PO}_{4}{ }^{-}$subunits at 50 or $300 \mathrm{mM}$ concentrations, respectively (Figure $4 \mathrm{a}$, Figure S11), and as far as we know this surprisingly strong process in a polar solvent is the first measurement of indefinite AEHB selfassociation.

To modify the diffusion rate of a switchable receptor, we turned to the previously developed stiff stilbene ${ }^{[5 c, 5 e]}$ bis-urea. ${ }^{[19 c}$, 19e] The bis-tolyl derivative 1 (Figure 2) was synthesized to take advantage of the convenient methyl ${ }^{1} \mathrm{H}$ NMR signal for diffusion NMR experiments (see SI-3). The association constants for $\mathrm{H}_{2} \mathrm{PO}_{4}^{-}$and $\mathrm{OAc}^{-}$were measured by NMR titrations and fitted to $1: 2\left[\mathrm{HG}_{2}\right]$ binding models, with results ${ }^{[25]}$ comparable to those previously reported for the non-substituted phenyl derivative ${ }^{[19 c]}$ when studied over the same guest concentration range. Binding studies at higher concentrations of $\mathrm{H}_{2} \mathrm{PO}_{4}^{-}$, however, resulted in slightly different association constants when fitted to the same binding model (SI-S7.8-7.10) illustrating that competition due to self-association of $\mathrm{H}_{2} \mathrm{PO}_{4}^{-}$complicates binding models for association constants. ${ }^{[26]}$ For example, a recent report of $\mathrm{H}_{2} \mathrm{PO}_{4}$ binding ${ }^{[27]}$ found different binding constants and stoichiometries when measured at different concentrations by UV-vis absorption or NMR spectroscopy, likely due to $\mathrm{H}_{2} \mathrm{PO}_{4}^{-}$aggregation.

The photoswitching properties of $\mathbf{1}$ were studied in DMSO- $d_{6}$ with $0.5 \%$ added water ${ }^{[19 c]}$ and absorption spectra (Figure S45) are in line with the parent compound. ${ }^{[19 c]}$ The thermal half-life is sufficiently long that no thermal isomerization was observable over the timescales used in the experiments reported here. In the presence of $50 \mathrm{mM}\left[\mathrm{NBu}_{4}\right]\left[\mathrm{H}_{2} \mathrm{PO}_{4}\right]$ the photostationary state under non-optimal irradiation with a $405 \mathrm{~nm}$ LED comprised a $E / Z$ ratio of $58: 42$ measured by NMR integration.

The measured diffusion coefficients of $E-1$ and $Z-1 \quad(D(E-1)$ and $D(Z-1))$ in DMSO- $d_{6}$ with $0.5 \%$ added water are shown in Table 1. In the absence of $\mathrm{H}_{2} \mathrm{PO}_{4}^{-}$, the extended $E-1$ isomer diffuses slightly more slowly $(7 \%)$ than the more compact $Z-1$ (Table 1; entry 1 vs 2). Given the large difference in size between host $1(\mathrm{MW}=529)$ and the $\mathrm{H}_{2} \mathrm{PO}_{4}{ }^{-}$anion $(\mathrm{MW}=97),{ }^{[28]}$ we might have anticipated a modest decrease in average host diffusion coefficients at guest concentrations where nearcomplete complexation occurs based on measured binding constants. ${ }^{[29]}$ Instead we observe a large decrease in measured $D$ that continues to decrease at concentrations above those predicted for near-complete complexation (e.g. $\left[\mathrm{H}_{2} \mathrm{PO}_{4}{ }^{-}\right]=50$ $\mathrm{mM},[1]=5 \mathrm{mM}$ : Table 1, entries 4-8; SI-8). After correcting for $\mathrm{H}_{2} \mathrm{PO}_{4}$-induced viscosity changes (see SI-4), ${ }^{\left[{ }^{[0]}\right]}$ the measured $D$ of pure $E-1$ or $Z-1$ in the presence of $50 \mathrm{mM}\left[\mathrm{NBu}_{4}\right]\left[\mathrm{H}_{2} \mathrm{PO}_{4}\right]$ was found to decrease by, respectively, 33\% $(D(E-1))$ and $26 \%(D(Z-$ 1)) relative to $D$ without $\left[\mathrm{NBu}_{4}\right]\left[\mathrm{H}_{2} \mathrm{PO}_{4}\right]$ (Table 1; entries 1 vs $4 ; 2$ vs 5; Figure 5 for full $\left[\mathrm{H}_{2} \mathrm{PO}_{4}^{-}\right]$-dependent diffusion data). This suggests greater than 2 or 3 -fold increases in effective volumes of the $Z-1$ or $E-1$ hosts, respectively. 

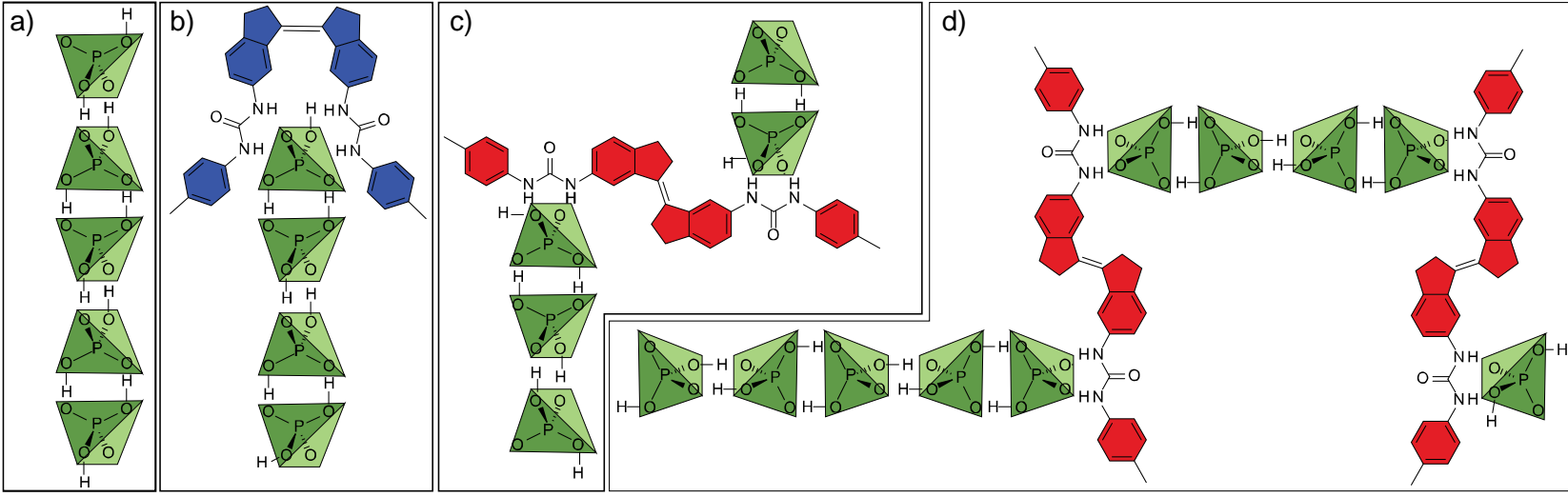

Figure 4. Proposed supramolecular assemblies present in solution. (a) Anti-electrostatic dihydrogenphosphate $\left(\mathrm{H}_{2} \mathrm{PO}_{4}{ }^{-}\right)$oligomers, $\mathrm{G}_{\mathrm{n}}$, form from monomeric phosphates. These oligomers are bound by anion-binding Z-1 (b) and $E-1$ (c) bis-urea hosts to form ditopic $\left[H\left(G_{n}\right)\right]$ or $\left[H\left(G_{n}\right)_{2}\right]$ complexes. d) As $E-1$ possesses divergent urea binding sites, larger supramolecular structures can form from $\mathrm{H}_{2} \mathrm{PO}_{4}{ }^{-}$chains linked by $E$-1 hosts.

Table 1. Changes in diffusion coefficients of pure isomers and $1: 1$ mixed solutions of $E-1$ and $Z-1$ in the presence of $50 \mathrm{mM} \mathrm{NBu}_{4}-\mathrm{H}_{2} \mathrm{PO}{ }_{4}{ }^{[a]}$

\begin{tabular}{|c|c|c|c|c|c|c|c|}
\hline Entry & $\begin{array}{c}{\left[\mathrm{H}_{2} \mathrm{PO}_{4}^{-}\right]} \\
/ \mathrm{mM}\end{array}$ & $\begin{array}{l}{[E-1]} \\
/ \mathrm{mM}\end{array}$ & $\begin{array}{l}{[Z-1]} \\
/ \mathrm{mM}\end{array}$ & $\begin{array}{l}\boldsymbol{D}\left(\mathbf{H}_{2} \mathbf{P O}_{4}\right)^{[\mathrm{b}]} \\
/ 10^{-10} \mathrm{~m}^{2} \mathrm{~s}^{-1}\end{array}$ & $\begin{array}{c}D(E-1)^{[c]} \\
/ 10^{-10} \mathrm{~m}^{2} \mathrm{~s}^{-1}\end{array}$ & $\begin{array}{c}D(Z-1)^{[\mathrm{c}]} \\
/ 10^{-10} \mathrm{~m}^{2} \mathrm{~s}^{-1}\end{array}$ & $\begin{array}{c}D\left(\mathrm{NBu}_{4}\right)^{[\mathrm{c}]} \\
/ 10^{-10} \mathrm{~m}^{2} \mathrm{~s}^{-1}\end{array}$ \\
\hline 1 & - & 5 & - & - & $1.74 \pm 0.03$ & - & - \\
\hline 2 & - & - & 5 & - & - & $1.87 \pm 0.01$ & - \\
\hline 3 & 50 & - & - & $2.16 \pm 0.03$ & - & - & $2.50 \pm 0.02$ \\
\hline 4 & 50 & 5 & - & $1.93 \pm 0.04$ & $1.17 \pm 0.03$ & - & $2.39 \pm 0.01$ \\
\hline 5 & 50 & - & 5 & $2.01 \pm 0.03$ & - & $1.39 \pm 0.01$ & $2.37 \pm 0.02$ \\
\hline 6 & 50 & 5 & 5 & $1.83 \pm 0.08$ & $1.12 \pm 0.02$ & $1.36 \pm 0.01$ & $2.31 \pm 0.01$ \\
\hline 7 & 50 & 2.5 & 2.5 & $1.97 \pm 0.07$ & $1.19 \pm 0.01$ & $1.45 \pm 0.03$ & $2.44 \pm 0.01$ \\
\hline 8 & 50 & 0.5 & 0.5 & $2.05 \pm 0.02$ & $1.27 \pm 0.03$ & $1.57 \pm 0.03$ & $2.52 \pm 0.02$ \\
\hline
\end{tabular}

[a] DMSO- $d_{6}$ with $0.5 \%$ added water. [b] $202 \mathrm{MHz}{ }^{31} \mathrm{P}$ PGSTE, $\delta=7 \mathrm{~ms}, \Delta=100 \mathrm{~ms}, g=0-53.45 \mathrm{G} \mathrm{cm}{ }^{-1}$. [c] $500 \mathrm{MHz}{ }^{1} \mathrm{H}$ PGSTE, $\delta=4 \mathrm{~ms}, \Delta=50 \mathrm{~ms}, g=$ $0-53.45 \mathrm{G} \mathrm{cm}^{-1}$

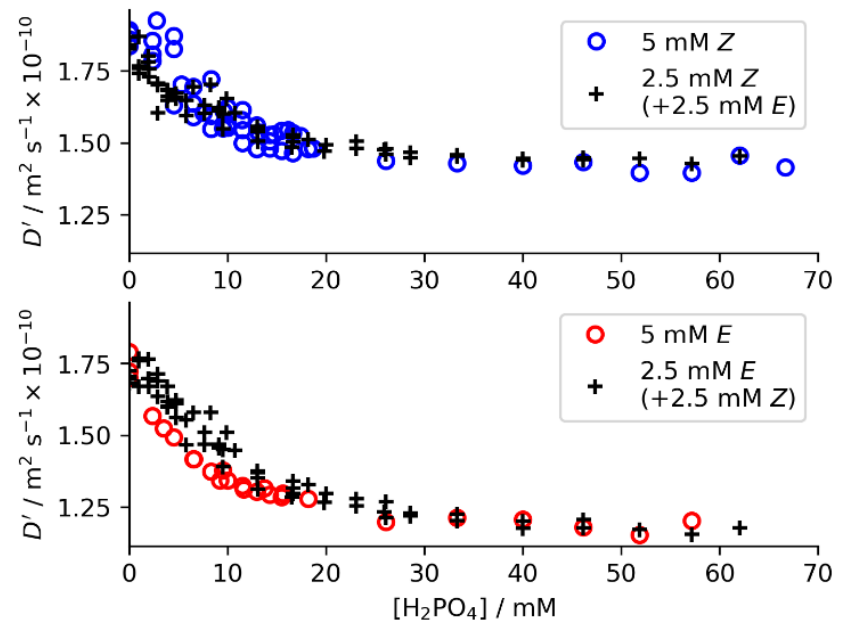

Figure 5. Diffusion measurements of hosts $Z-1$ and $E-1$ under titration with $\left[\mathrm{NBu}_{4}\right]\left[\mathrm{H}_{2} \mathrm{PO}_{4}\right]$. Measured $D$ for $5 \mathrm{mM}$ solutions of pure $Z-1$ or $E-1$ (0), compared with mixed $2.5 \mathrm{mM}: 2.5 \mathrm{mM} \mathrm{E-1:Z-1} \mathrm{(+).}$

These substantial decreases in measured $D$ are too large to be explained by the formation of simple ditopic $\left[\mathrm{HG}_{2}\right]$ complexes ${ }^{[19 c]}$ or even $\left[H\left(G_{n}\right)_{2}\right]$ complexes, where $G_{n}$ is an oligomeric chain of $n$ hydrogen-bonded $\mathrm{H}_{2} \mathrm{PO}_{4}^{-}$subunits that forms as in the absence of host ${ }^{[31]}$ (Figure 4b,c see Figure S11 for modelling). ${ }^{[19 c]}$

Host $E-1$ forms larger structures than host $Z-1$ (note that despite $E-1$ having a lower measured $K_{1}$ for $\mathrm{H}_{2} \mathrm{PO}_{4}^{-}$than $Z-1$, there is no free host left in both cases at $50 \mathrm{mM}$, see Supporting Information S9). This observation is also supported by changes in the measured diffusion of $\mathrm{H}_{2} \mathrm{PO}_{4}^{-}, D\left(\mathrm{H}_{2} \mathrm{PO}_{4}\right)$, (measured by ${ }^{31} \mathrm{P}$ NMR), which decreases by $11 \%$ or $7 \%$ in the presence of 5 $\mathrm{mM}$ of $E-1$ or Z-1, respectively (Table 1; entries 3 vs 4, 5). This indicates that $\mathrm{H}_{2} \mathrm{PO}_{4}^{-}$is also assembled into larger average structures in the presence of $E-1$ than by $Z-1$.

Compared to $5 \mathrm{mM}$ solutions of a single-isomer, $D(E-1)$ and $D(Z-1)$ decrease by just $4 \%$ and $2 \%$, respectively, when an additional $5 \mathrm{mM}$ of the other host is present (Table 1; entries 4 vs $6 ; 5$ vs 6 ), suggesting minimal interactions between the $E$ and $Z$-isomers.

Relative to that of a solution of pure $\left[\mathrm{NBu}_{4}\right]\left[\mathrm{H}_{2} \mathrm{PO}_{4}\right], D\left(\mathrm{H}_{2} \mathrm{PO}_{4}\right)$ decreases on going from $5 \mathrm{mM}$ of $Z-1(-7 \%$, Table 1 , entry 5 ,) to $5 \mathrm{mM}$ of $E-1(-11 \%$, entry 4$)$ to $5 \mathrm{mM}$ of each of $Z-1$ and $5 \mathrm{mM}$ of E-1 (-15\%, entry 6). $D\left(\mathrm{H}_{2} \mathrm{PO}_{4}\right)$ for a solution of $2.5 \mathrm{mM} \mathrm{E-1}$ and $2.5 \mathrm{mM} \mathrm{Z-1}(-9 \%$, entry 7$)$ is also the average of that $5 \mathrm{mM}$ solutions of each isomer (entries 4,5 ). This also suggests the $\mathrm{H}_{2} \mathrm{PO}_{4}^{-}$does not experience anything other than a statistical binding by the hosts, with no evidence of cross-linking between different host isomers. 
However, there is evidence suggesting complexes are formed involving multiple host molecules of the same isomer. To test this, titration experiments with $\left[\mathrm{NBu}_{4}\right]\left[\mathrm{H}_{2} \mathrm{PO}_{4}\right]$ were conducted with solutions of $1: 1$ mixtures of $E-1: Z-1$ at 1,5 , and $10 \mathrm{mM}$ total concentrations (SI-8.3). A small but observable decrease in $D$ for both $E-1$ and $Z-1$ was found as the total concentration of the host increases from 1 to 5 to $10 \mathrm{mM}$ (e.g. at $50 \mathrm{mM}$ $\left[\mathrm{NBu}_{4}\right]\left[\mathrm{H}_{2} \mathrm{PO}_{4}\right]$ : Table 1, entries 6-8; also SI-S8.3). This data supports the formation of structures involving multiple hosts, e.g. structures such as shown in Figure 4d.

Host 1 could also increase the effective size of polyanionic complexes by increasing ion-pairing to the $\mathrm{NBu}_{4}{ }^{+}$cations. This would result in a decrease in $D\left(\mathrm{NBu}_{4}\right)$ with increasing host concentration, but only a $5 \%$ decrease in $D\left(\mathrm{NBu}_{4}\right)$ is observed (Table 1 , entry 3 vs $4 ; 3$ vs 5 ). There is also no difference between $D\left(\mathrm{NBu}_{4}\right)$ in the presence of $E-1$ or $Z-1$, despite $E-1$ forming much larger complexes (Table 1; entries 4 vs 5). These observations suggest the hosts do not significantly change ion pairing between the $\mathrm{NBu}_{4}{ }^{+}$and oligomers of $\mathrm{H}_{2} \mathrm{PO}_{4}{ }^{-}$.

From measured diffusion coefficients of free host $(5 \mathrm{mM})$ and oligomeric $\mathrm{H}_{2} \mathrm{PO}_{4}^{-}(50 \mathrm{mM})$, we estimate the assemblies formed involve 1-2 molecules of 1 with 2-3 chains of oligomeric guest $\mathrm{G}_{n}$, (where $n$ is the same as that formed at $50 \mathrm{mM}\left[\mathrm{NBu}_{4}\right]\left[\mathrm{H}_{2} \mathrm{PO}_{4}\right]$ in the absence of host, see SI-S9 for discussion of methodology). ${ }^{[32]}$ From the modelled size distribution of $\mathrm{H}_{2} \mathrm{PO}_{4}$ oligomers at $50 \mathrm{mM}$ (Figure S11), this corresponds to complexes incorporating approximately $10 \mathrm{H}_{2} \mathrm{PO}_{4}^{-}$subunits with average molecular weights of $1.5-2.0 \mathrm{kDa}$. Together, these results indicate that $\mathrm{H}_{2} \mathrm{PO}_{4}{ }^{-}$anions not only form aggregates in polar and hydrogen-bond accepting solvents, but that these structures can associate to form larger assemblies with multiple hosts in solution.

As host 1 is a photoswitch, the E-1:Z-1 distribution of isomers can be controlled using light (SI-10). By combining in situ irradiation within the NMR spectrometer ${ }^{[33]}$ with recently developed time-resolved diffusion NMR techniques ${ }^{[34]}$ we simultaneously measured changes in concentration and diffusion coefficients of E-1 and Z-1 under $400 \mathrm{~nm}$ irradiation (Figure 6).

Photoswitching of organic molecules is expected to result in differences in $D$, but such changes would typically be minor (e.g. the $7 \%$ difference between $D(E-1)$ and $D(Z-1)$ in the absence of anion guest (Table 1, entries 1 and 2). Switchable anion binding might give more control over the effective host $D$, but complexes with small anions (e.g. $\mathrm{Cl}^{-}, \mathrm{OAc}^{-}, \mathrm{NO}_{3}^{-}, \mathrm{HSO}_{4}^{-}$) might only cause modest changes in host $D$, as found for control experiments with acetate $(8 \%$ and $4 \%$ decrease, respectively, in $D(E-1)$ and $D(Z$

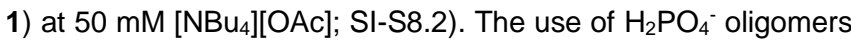
allows greater control over $D$ : switching host 1 from $Z-1$ to $E-1$ causes a "molecular gear change" and a 16\% decrease in measured $D$ (Table 1 , entries 4 and 5), suggestive of an approximately $70 \%$ increase in average molecular volume. This demonstrates the possibility of achieving substantial control over the diffusion rate of small molecules in bulk solution by coupling photocontrol of guest-binding to the ability of $\mathrm{H}_{2} \mathrm{PO}_{4}^{-}$to form extended supramolecular structures. ${ }^{\left[{ }^{[3]}\right]}$ As $\mathbf{1}$ is a thermally stable ("P-type") photoswitch, these changes in $D$ will persist in the dark. ${ }^{[5 e]}$
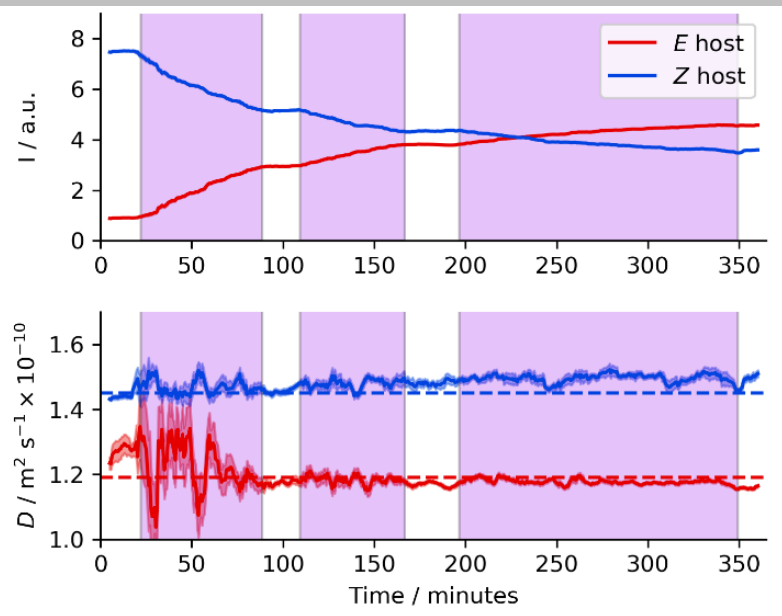

Figure 6. Photoswitching of $Z-1$ host in the presence of $50 \mathrm{mM} \mathrm{H}_{2} \mathrm{PO}_{4}^{-}$under in situ irradiation with $400 \mathrm{~nm}$ light (shaded purple areas). Concentrations (top) and diffusion coefficients (bottom) were monitored simultaneously using timeresolved diffusion NMR. ${ }^{[34 a, 34 b]}$ Lines and shaded areas on diffusion subplot are respectively values and errors from the Stejskal-Tanner fit. Dashed horizontal lines show measured $D(E-1)$ and $D(Z-1)$ for a $5 \mathrm{mM} \mathrm{1:1} \mathrm{mixture} \mathrm{of}$ isomers (Table 1, entry 7). $500 \mathrm{MHz}{ }^{1} \mathrm{H}, \delta=4 \mathrm{~ms}, \Delta=50 \mathrm{~ms}, g=0-53.45 \mathrm{G}$ $\mathrm{cm}^{-1}$, DMSO- $d_{6}$ with $0.5 \%$ added water and glass capillaries used to suppress convection. ${ }^{[36]}$ See Figure S44 for data with in situ temperature measurements, and Figure S46 for demonstration of reversibility of switching. ${ }^{[34 b, 37]}$

In conclusion, we sought to use the switchable anion-binding properties of host 1 to achieve photocontrol of translational diffusion rates. Diffusion NMR allowed characterization of the thermodynamics of the antielectrostatic self-assembly of the bare dihydrogen phosphate anion in solution, a longsuspected ${ }^{[15 a, 15 b]}$ but previously uncharacterized phenomenon. We obtained a surprisingly high isodesmic association constant of $K_{\mathrm{i}}=120 \pm 32 \mathrm{M}^{-1}$ for $\mathrm{H}_{2} \mathrm{PO}_{4}^{-}$self-association, which corresponds to complexes of a median size of 4 (or 10) $\mathrm{H}_{2} \mathrm{PO}_{4}$ subunits at concentrations of $50 \mathrm{mM}$ (or $300 \mathrm{mM}$ ). Binding studies with $\mathrm{H}_{2} \mathrm{PO}_{4}^{-}$in DMSO therefore involve competition between host- $\mathrm{H}_{2} \mathrm{PO}_{4}^{-}$and $\mathrm{H}_{2} \mathrm{PO}_{4}^{-}-\mathrm{H}_{2} \mathrm{PO}_{4}^{-}$interactions, which poses problems for fitting titration data (SI-7.11 for further discussion). Because of the limited solubility of our bis-urea receptor, this study was conducted exclusively in wet DMSO. It would be reasonable to assume that in less polar solvents such as DMF, acetonitrile, or dichloromethane self-association of $\mathrm{H}_{2} \mathrm{PO}_{4}^{-}$may be more significant.

Combining the unusual anti-electrostatic oligomerization of $\mathrm{H}_{2} \mathrm{PO}_{4}^{-}$with a photoswitchable anion-binding receptor allowed light to induce a "gear change" and sharply change the rate of receptor diffusion, equivalent to a $70 \%$ change in effective volume. Can control of diffusion via a spatially selective stimulus (such as light, as demonstrated here) drive directional transport of small molecular species and create concentration gradients? This remains an interesting open question.

\section{Acknowledgements}

We thank Prof. Tim Schmidt, Prof. Palli Thordarson and Prof. Amar Flood for fruitful discussions. The Australian Research Council (JEB, FT170100094), the Australian Government (TSCM, Australian Postgraduate Award), the Ministry of Education, Culture and Science (Gravitation Program 024.001.035) and the European Research Council (Advanced 
Grant no. 694345 to B.L.F. and Starting Grant no. 802830 to S.J.W.) are acknowledged for funding.

\section{Conflict of interest}

The authors declare no conflict of interest.

Keywords: diffusion - photoswitches - antielectrostatic hydrogen bonds $\bullet$ self-assembly $\bullet$ anion-binding

[1] a) E. R. Kay, D. A. Leigh, F. Zerbetto, Angew. Chem. Int. Ed. 2007, 46, 72-191; b) P. Hänggi, F. Marchesoni, Rev. Mod. Phys. 2009, 81, 387442; c) E. Lauga, T. R. Powers, Rep. Prog. Phys. 2009, 72, 096601; d) S. Sengupta, M. E. Ibele, A. Sen, Angew. Chem., Int. Ed. 2012, 51 8434-8445; e) R. Kapral, J. Chem. Phys. 2013, 138, 020901; f) X. Ma K. Hahn, S. Sanchez, J. Am. Chem. Soc. 2015, 137, 4976-4979; g) S. Sanchez, L. Soler, J. Katuri, Angew. Chem., Int. Ed. 2015, 54, 14141444.

[2] a) W. R. Browne, B. L. Feringa, Nat. Nanotechnol. 2006, 1, 25-35; b) T. Kudernac, N. Ruangsupapichat, M. Parschau, B. Maciá, N. Katsonis, S R. Harutyunyan, K.-H. Ernst, B. L. Feringa, Nature 2011, 479, 208-211; c) B. L. Feringa, Angew. Chem. Int. Ed. 2017, 56, 11060-11078.

[3] a) C. Stock, N. Heureux, W. R. Browne, B. L. Feringa, Chem.- Eur. J. 2008, 14, 3146-3153; b) N. Heureux, F. Lusitani, W. R. Browne, M. S. Pshenichnikov, P. H. M. van Loosdrecht, B. L. Feringa, Small 2008, 4 476-480; c) D. Pantarotto, W. R. Browne, B. L. Feringa, Chem. Commun. 2008, 1533-1535; d) D. A. Wilson, R. J. M. Nolte, J. C. M. van Hest, Nature Chem. 2012, 4, 268-274; e) V. García-López, P.-T. Chiang, F. Chen, G. Ruan, A. A. Martí, A. B. Kolomeisky, G. Wang, J. M. Tour, Nano Lett. 2015, 15, 8229-8239; f) C. Lozano, B. ten Hagen, H Löwen, C. Bechinger, Nat. Commun. 2016, 7, 12828; g) X. Yao, T. Li, J. Wang, X. Ma, H. Tian, Adv. Optical Mater. 2016, 4, 1322-1349; h) J. Katuri, X. Ma, M. M. Stanton, S. Sánchez, Acc. Chem. Res. 2017, 50, $2-11$; i) X. Zhao, K. Gentile, F. Mohajerani, A. Sen, Acc. Chem. Res. 2018, 51, 2373-2381; j) Y. Tu, F. Peng, J. M. Heuvelmans, S. Liu, R. J. M. Nolte, D. A. Wilson, Angew. Chem. Int. Ed. 2019, 58, 8687-8691; k) M. Fernández-Medina, M. A. Ramos-Docampo, O. Hovorka, V. Salgueiriño, B. Städler, Adv. Funct. Mater. 2020, 30.

[4] a) J. L. Anderson, D. C. Prieve, Langmuir 1991, 7, 403-406; b) R. D. Astumian, ACS Nano 2014, 8, 11917-11924; c) J. Agudo-Canalejo, T. Adeleke-Larodo, P. Illien, R. Golestanian, Acc. Chem. Res. 2018, 51 , 2365-2372; d) C. Weistuch, S. Pressé, J. Phys. Chem. B 2018, 122, 5286-5290; e) R. P. Sear, Phys. Rev. Lett. 2019, 122, 128101.

[5] a) F. Rakotondradany, M. A. Whitehead, A.-M. Lebuis, H. F. Sleiman, Chem.- Eur. J. 2003, 9, 4771-4780; b) S. Lee, S. Oh, J. Lee, Y. Malpani, Y.-S. Jung, B. Kang, J. Y. Lee, K. Ozasa, T. Isoshima, S. Y. Lee, M. Hara, D. Hashizume, J.-M. Kim, Langmuir 2013, 29, 5869-5877; c) J.-F. Xu, Y.-Z. Chen, D. Wu, L.-Z. Wu, C.-H. Tung, Q.-Z. Yang, Angew. Chem. Int. Ed. 2013, 52, 9738-9742; d) J. T. van Herpt, J. Areephong, M. C. A. Stuart, W. R. Browne, B. L. Feringa, Chem.- Eur. J. 2014, 20 1737-1742; e) X. Yan, J.-F. Xu, T. R. Cook, F. Huang, Q.-Z. Yang, C.-H Tung, P. J. Stang, Proc. Natl Acad. Sci. U. S. A. 2014, 111, 8717-8722; f) A. J. McConnell, C. S. Wood, P. P. Neelakandan, J. R. Nitschke, Chem. Rev. 2015, 115, 7729-7793; g) L. Yang, X. Tan, Z. Wang, X Zhang, Chem. Rev. 2015, 115, 7196-7239.

[6] M. Han, Y. Luo, B. Damaschke, L. Gómez, X. Ribas, A. Jose, P. Peretzki, M. Seibt, G. H. Clever, Angew. Chem. Int. Ed. 2016, 55, 445449.

[7] a) S.-S. Sun, J. A. Anspach, A. J. Lees, Inorg. Chem. 2002, 41, 1862 1869; b) S. Chen, L.-J. Chen, H.-B. Yang, H. Tian, W. Zhu, J. Am. Chem. Soc. 2012, 134, 13596-13599.

[8] a) P. Stilbs, Prog. Nucl. Magn. Reson. Spectrosc. 1987, 19, 1-45; b) W. S. Price, Concepts Magn. Reson. 1997, 9, 299-336; c) W. S. Price, Concepts Magn. Reson. 1998, 10, 197-237; d) C. S. Johnson, Prog Nucl. Magn. Reson. Spectrosc. 1999, 34, 203-256; e) P. T. Callaghan, Translational Dynamics and Magnetic Resonance: Principles of Pulsed Gradient Spin Echo NMR, Oxford University Press, 2011

[9] a) Y. Cohen, L. Avram, L. Frish, Angew. Chem. Int. Ed. 2005, 44, 520 554 ; b) J. M. Zayed, F. Biedermann, U. Rauwald, O. A. Scherman, Polym. Chem. 2010, 1, 1434-1436; c) S.-L. Li, T. Xiao, B. Hu, Y. Zhang, F. Zhao, Y. Ji, Y. Yu, C. Lin, L. Wang, Chem. Commun. 2011, 47, 10755-10757; d) Y. Liu, Z. Wang, X. Zhang, Chem. Soc. Rev. 2012, 41 5922-5932; e) L. Avram, Y. Cohen, Chem. Soc. Rev. 2015, 44, 586$602 ;$ f) L. Sian, A. Guerriero, M. Peruzzini, C. Zuccaccia, L. Gonsalvi, A Macchioni, Organometallics 2019, 39, 941-948.

[10] a) F. Weinhold, R. A. Klein, Angew. Chem Int Ed. 2014, 53, 1121411217 ; b) I. Mata, E. Molins, I. Alkorta, E. Espinosa, J. Phys. Chem. A 2015, 119, 183-194; c) Y. Liu, A. Sengupta, K. Raghavachari, A. H. Flood, Chem 2017, 3, 411-427; d) Q. He, P. Tu, J. L. Sessler, Chem 2018, 4, 46-93; e) C. Wang, Y. Fu, L. Zhang, D. Danovich, S. Shaik, Y. Mo, J. Comput. Chem. 2018, 39, 481-487; f) F. Weinhold, Inorg. Chem. 2018, 57, 2035-2044.
[11] N. Bregović, N. Cindro, L. Frkanec, K. Užarević, V. Tomišić, Chem.- Eur. J. 2014, 20, 15863-15871.

[12] a) E. M. Fatila, E. B. Twum, A. Sengupta, M. Pink, J. A. Karty, K. Raghavachari, A. H. Flood, Angew. Chem. Int. Ed. 2016, 55, $14057-$ 14062; b) E. M. Fatila, E. B. Twum, J. A. Karty, A. H. Flood, Chem.- Eur. J. 2017, 23, 10652-10662; c) D. Barišić, N. Cindro, M. J. Kulcsár, M. Tireli, K. Užarević, N. Bregović, V. Tomišić, Chem.- Eur. J. 2019, 25, 4695-4706.

[13] a) Y. Kubo, S. Ishihara, M. Tsukahara, S. Tokita, J. Chem. Soc., Perkin Trans. 2 2002, 2, 1455-1460; b) V. Amendola, M. Boiocchi, D. Esteban Gómez, L. Fabbrizzi, E. Monzani, Org. Biomol. Chem. 2005, 3, 26322639; c) G. Baggi, M. Boiocchi, L. Fabbrizzi, L. Mosca, Chem.- Eur. J. 2011, 17, 9423-9439; d) D. Mungalpara, H. Kelm, A. Valkonen, K. Rissanen, S. Keller, S. Kubik, Org. Biomol. Chem. 2017, 15, 102-113; e) D. M. Gillen, C. S. Hawes, T. Gunnlaugsson, J. Org. Chem. 2018, 83, 10398-10408; f) W. Zhao, B. Qiao, J. Tropp, M. Pink, J. D. Azoulay, A. H. Flood, J. Am. Chem. Soc. 2019, 141, 4980-4989.

[14] a) D. Mungalpara, A. Valkonen, K. Rissanen, S. Kubik, Chem. Sci. 2017, 8, 6005-6013; b) E. M. Fatila, M. Pink, E. B. Twum, J. A. Karty, A H. Flood, Chem. Sci. 2018, 9, 2863-2872.

[15] a) R. H. Wood, R. F. Platford, J. Solution Chem. 1975, 4, 977-982; b) F. Rull, A. Del Valle, F. Sobron, S. Veintemillas, J. Raman Spectrosc. 1989, 20, 625-631; c) J. M. Shaver, K. A. Christensen, J. A. Pezzuti, M. D. Morris, Appl. Spectrosc. 1998, 52, 259-264; d) J. S. McNally, X. P. Wang, C. Hoffmann, A. D. Wilson, Chem. Commun. 2017, 53, 10934 10937.

[16] D. Barišić, V. Tomišić, N. Bregović, Anal. Chim. Acta 2019, 1046, 77-92.

[17] a) P. A. Gale, E. N. W. Howe, X. Wu, Chem 2016, 1, 351-422; b) L. Chen, S. N. Berry, X. Wu, E. N. W. Howe, P. A. Gale, Chem 2020, 6, 61-141.

[18] a) M.-M. Russew, S. Hecht, Adv. Mater. 2010, 22, 3348-3360; b) C. Brieke, F. Rohrbach, A. Gottschalk, G. Mayer, A. Heckel, Angew. Chem. Int. Ed. 2012, 51, 8446-8476; c) J. Zhang, Q. Zou, H. Tian, Adv. Mater. 2013, 25, 378-399; d) R. Göstl, A. Senf, S. Hecht, Chem. Soc. Rev. 2014, 43, 1982-1996; e) S. Erbas-Cakmak, D. A. Leigh, C. T. McTernan, A. L. Nussbaumer, Chem. Rev. 2015, 115, 10081-10206; f) M. P. O'Hagan, S. Haldar, M. Duchi, T. A. A. Oliver, A. J. Mulholland, J. C. Morales, M. C. Galan, Angew. Chem. Int. Ed. 2019, 58, 4334-4338.

[19] a) S. J. Wezenberg, M. Vlatković, J. C. M. Kistemaker, B. L. Feringa, J. Am. Chem. Soc. 2014, 136, 16784-16787; b) M. Vlatković, B. L. Feringa, S. J. Wezenberg, Angew. Chem. Int. Ed. 2016, 55, 1001-1004 c) S. J. Wezenberg, B. L. Feringa, Org. Lett. 2017, 19, 324-327; d) S. J. Wezenberg, B. L. Feringa, Nat. Commun. 2018, 9, 1984; e) J. de Jong, B. L. Feringa, S. J. Wezenberg, ChemPhysChem 2019, 20, 3306-3310.

20] D. Villarón, S. Wezenberg, Angew. Chem. Int. Ed.2020, 10.1002/anie.202001031.

[21] Consistent with previous studies (e.g. ref. 19), the addition of a known percentage of water reduces the variablity of trace water content. For a description of the speciation, see SI-2.

[22] W. S. Price, F. Tsuchiya, Y. Arata, J. Am. Chem. Soc. 1999, 121 11503-11512.

[23] R. B. Martin, Chem. Rev. 1996, 96, 3043-3064.

[24] L. Lewin, Polylogarithms and associated functions, North Holland, New York, 1981.

[25] See Supporting Information S7 for details of binding constants.

[26] P. Thordarson, Chem. Soc. Rev. 2011, 40, 1305-1323.

[27] J. Cho, P. Verwilst, M. Kang, J.-L. Pan, A. Sharma, C. S. Hong, J. S. Kim, S. Kim, Chem. Commun. 2020, 56, 1038-1041.

[28] Geometries calculated by DFT are given in the supporting information, SI-11

[29] At $5 \mathrm{mM}$ host concentrations used, and with $K_{1}$ of 360 and 2100 for $E-1$ and $Z-1$ respectively, the proportion of unbound host is less than $5 \%$ with respectively 5.5 equiv and 2.5 equiv of $\mathrm{H}_{2} \mathrm{PO}_{4}$. See Supporting Information S9 for details.

[30] Viscosities of $\left[\mathrm{NBu}_{4}\right]\left[\mathrm{H}_{2} \mathrm{PO}_{4}\right]$ solutions in DMSO- $d_{6}$ were measured directly and fitted to a viscosity calibration curve, which was used to compensate for changes in measured $D$ caused by viscosity. See Supporting Information S4 for details.

[31] Equivalent experiments using [NBu$][\mathrm{OAc}]$ in place of $\left[\mathrm{NBu}_{4}\right]\left[\mathrm{H}_{2} \mathrm{PO}_{4}\right]$ do not result in similar changes in the measured $D$ of the host, suggesting that the ability of $\mathrm{H}_{2} \mathrm{PO}_{4}{ }^{-}$to form extended hydrogen-bound chains is critical for the observed changes in measured $D$ (see Supporting Information SI-8.2).

[32] This analysis does not rely on the accuracy of the isodesmic binding model and fitted parameters: the proposed $\left[\mathrm{H}_{1-2}\left(\mathrm{G}_{n}\right)_{2-3}\right]$ average structure only requires the experimentally measured effective $D\left(\mathrm{H}_{2} \mathrm{PO}_{4}\right)$. See Supporting Information S9 for details.

[33] C. Feldmeier, H. Bartling, E. Riedle, R. M. Gschwind, J. Magn. Reson. 2013, 232, 39-44.

[34] a) M. Urbańczyk, D. Bernin, A. Czuroń, K. Kazimierczuk, Analyst 2016 141, 1745-1752; b) T. S. C. MacDonald, W. S. Price, J. E. Beves, ChemPhysChem 2019, 20, 926-930; c) T. S. C. MacDonald, W. S. Price, R. D. Astumian, J. E. Beves, Angew. Chem. Int. Ed. 2019, 58, 18864-18867.

[35] Some evidence also suggests that complexes involving two or more host molecules are selective for the same host isomer. Comparing $D(E$ 1) and $D(Z-1)$ for $5 \mathrm{mM}$ solutions of pure isomers to those for $5 \mathrm{mM}$ of a $1: 1$ mixture of the isomers, both isomers diffuse faster in the mixed 
solution (Table 1; entries 4, 5, 7). The increase is small (2\% for $D(E-1)$,

$4 \%$ for $D(Z-1))$, but a similar trend appears during time-resolved

diffusion monitoring of photoswitching hosts (Fig. 6), where switching $Z$ -

1 into $E-1$ also causes a slight increase in $\mathrm{D}(Z-1)$ and decrease in $D(E-$

1).

[36] a) I. Swan, M. Reid, P. W. A. Howe, M. A. Connell, M. Nilsson, M. A.

Moore, G. A. Morris, J. Magn. Reson. 2015, 252, 120-129; b) T. M.

Barbosa, R. Rittner, C. F. Tormena, G. A. Morris, M. Nilsson, RSC Adv.

2016, 6, 95173-95176.

[37] C. Ammann, P. Meier, A. Merbach, J. Magn. Reson. 1982, 46, 319-321. 


\section{COMMUNICATION}

Dihydrogen phosphate is complex! Self-assembled antielectrostatic hydrogen-bonded oligomers of dihydrogen phosphate control the diffusion properties of a photoswitchable anion-binding host in dilute polar solvent.

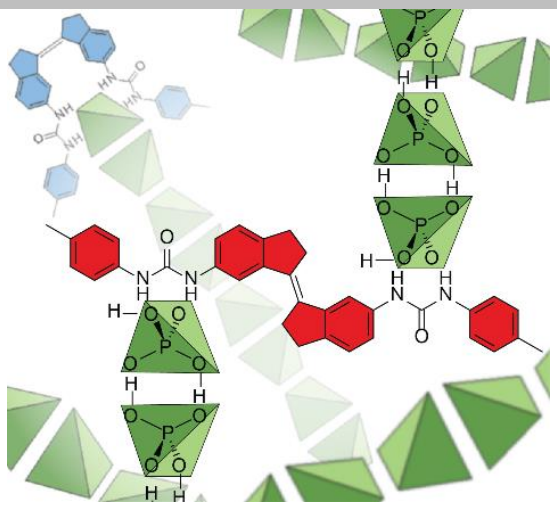

Thomas S. C. MacDonald, Ben L.

Feringa, William S. Price, Sander J. Wezenberg, and Jonathon E. Beves*

Page No. - Page No.

Controlled diffusion of photoswitchable receptors by binding antielectrostatic phosphate oligomers 


\section{Other files}

NMR_purehost-H2PO4_titrations.zip (630.22 MiB)

Viscometry.zip (6.10 KiB)

Diffusion data.zip (430.82 KiB)

NMR_aniondilutionstudies.zip (285.32 MiB)

NMR_photodiffusion.zip (1.15 GiB) view on ChemRxiv • download file view on ChemRxiv - download file view on ChemRxiv - download file view on ChemRxiv • download file view on ChemRxiv • download file 